\title{
IMPACT TESTS ON
}

\section{THE WROUGHT STEELS OF COMMERCE.}

By Mr. A, E. SFATON, Member, of LoNDon, and Mr. Alexander JUDE, of Birmingham.

\section{Part 1.}

The objects of this Paper are to show some of the characteristios and peculiarities of wrought steels as supplied by steel manufacturers for commercial purjoses; to assist in the development of a more rational method of testing the suitability of such steels for each particular purpose of the engineer; and to point out a few of the peculiarities that are observed in the fracture of test specimens and actual pieces of machinery. The Paper is in fact the outcome of the constant endeavour of engineers to avoid the use of material which raight be dangerous in the construction of machinery liable to severe alternating stresses, and more especially to attempt to find the very best steel for those parts liable to shock, owing to the inability to make those parts larger in the very fast moving engines so much in demand today.

Considerable movement has been made of late towards the establishment of a shock test for steel, conducted on a smaller scale than is the custom with axles, for instance, where the full-sized article is tested. The authors are strongly of opinion that progress in this direction is taking place still too slowly, and the 
principal object of this Paper therefore is to further the appreciation of this valuable test. All the experiments have been made on the ordinary steel supplied by various manufacturers as suitable for such parts. Some of the test-pieces are from forgings, such as crank-shafts, connecting-rods, \&c., and others from the bar-steel supplied for stud and bolt making. In no case have the authors dealt with what may be called a "fancy" material, the product of laboratory molting-pots. The tensile tests have been made in a

FiG. I.

"Impact" Testing-Maclize.

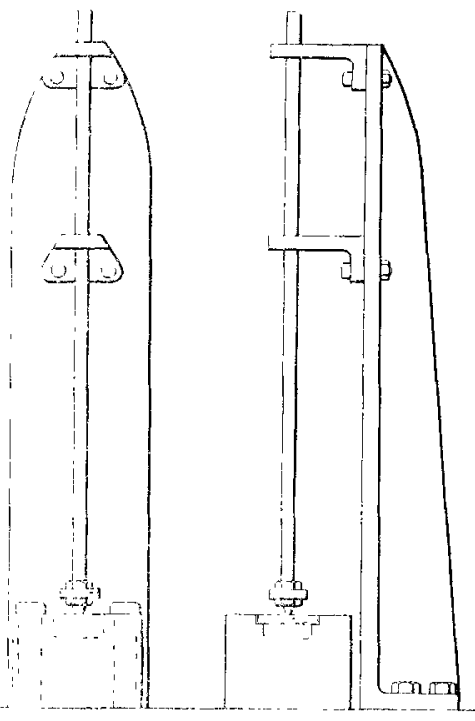

"Impact" Test-Bars.

FIG. 2.

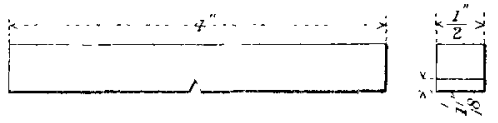

FIG. 3.

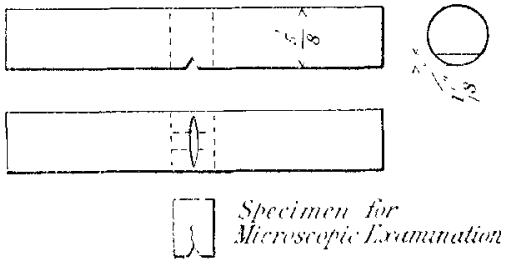

Buckton-testing machine, while the shock tests have been carried out in an apparatus, designed by the authors to require, as a rule, more than one blow to produce fracture. Such apparatus, as shown in Fig. 1, consists essentially of a weight of $6 \mathrm{Ibs}$., arranged to drop freely through 24 inches on to the test-bar, Figs. 2 and 3 , which rests on fixed supports 3 inches apart. The test-bar is 4 inches long, so that there is half-an-inch overlap at each end. After each blow the test-piece is reversed. In the authors' opinion the apparatus to test 
the endurance of a material under shock should not be one in which the sample is fractured at the first blow, especially for steels that are soft and are really very tough, although they admit that for some purposes such a test may be instructive and actually necessary for very high carbon steels. For constructional purposes the engineer is not greatly concerned with steels with more than about 0.4 per cent. carbon. Although a large number of experiments have proved to them that in every case, and with every description of structural steel, the power to resist shock has been materially enhanced by oiltempering, they have confined themselves mainly to the examination of the material as supplied by the makers rather than of that which has been subjected to any heat treatment of their own.

At present everybody makes tension tests, and trusts more or less to them alone. One takes up an advertising or scientific article on, say, "Special Nickel Alloys of Steel," which demonstrates their suitability for doing all sorts of wonderful things, and the first and the main thing one is expected to be impressed with is the superior tensile and elongation results which are arrived at. One has occasionally yielded to the temptation to use such steels for which a very big price has been paid, but they have usually proved no better servants than ordinary material. A large majority of engineers rest content with a tension test alone, no matter to what use they are putting the steel, for the reason, perhaps, that it is rather an expensive test, taking into consideration the cost of plant, ete. It is sometimes stated, consequently, that an ordinary mild steel (say "Admiralty" grade) is not good for certain purposes, but that a particular "special" steel is perfectly safe, etc., because the elastic limit and, tensile strength are someuhat better.

A similar assertion is made in the Sixth Report to the Alloys Research Committee,* in reference to heat-treated steel for guns. How much are the tensile strength and elastic limit thereby raised? The answer is: Anything from about 5 to 30 per cent. (For heattreated steels compare Tables 2 (page 26) and 17 (page 66) of that Report for the structural steels.)

* Proceelings 1904, Part 1, rage 78. 
This increased percentage must be a mere trifle for such articles as are subjected to stresses or shocks of an unknown effective magnitude, and it seems absurd to say that the difference between danger and security in a gun is ever met by a 30 per cent. increase in the quality of the steel.

But, nevertheless, it is certain that such treated steel is suitable for its purpose, and it is therefore evident that, in order to account for it, something far more important than the mere improvement in tensile properties has been contributed to the original qualities of the material. To anticipate a little, it is because the shock strength is improved several hundred per cent., as against the insignificant. increase of, say, 30 per cent. at most in the tensile strength and elastic limit.

The following are the tests that can be made on most pieces of metal, steel in particular :-

1. Tension and elongation.

2. Compression.

3. Cross-bending.

4. Hammering out to a point or thin edge.

5. Fatigue by gradual reversal of stress, either by bending in one plane or by rotation, as adopted by Wöhler, Professor Ewing, and others.

6. The same, but with the stress uniformly distributed over the section, as suggested by Professor Osborne Reynolds.

7. Impact on unnotched bars.

8. Impact on notched bars.

9. Chemical analysis.

10. Micro-analysis.

There may be variations of the above.

The general uses of steel may be divided into four main groups :-

(a) Structural work subject to steady loads only, such as boilers, buildings, tanks, etc.

(b) Structural work subject to recurrent loads of one kind, at intervals, in addition to the load due to its own weight, such as bridges, \&c. 
(c) Structures subject to rapidly repeated loads of one kind, all more or less suddenly applied, as with bolts and studs, rails, \&c.

(d) Structures subject to alternating loads, such as in the fixed and moving parts of machinery in general; and in many parts of a ship.

For the first two, there is no doubt that the tension test is a good and sufficient one, as the predominant stress is certainly pure static tension, but it is insufficient for the very heterogeneous groups ( $c$ and $d$ ). The question may then be asked: Which of the tests in the above long list is really a true universal gauge of the suitability of a piece of steel for any purpose it may be put to? As a help to answer this question, attention may be drawn to the following analysis of stresses in the steel parts of an up-to-date steam-engine of moderate size :-

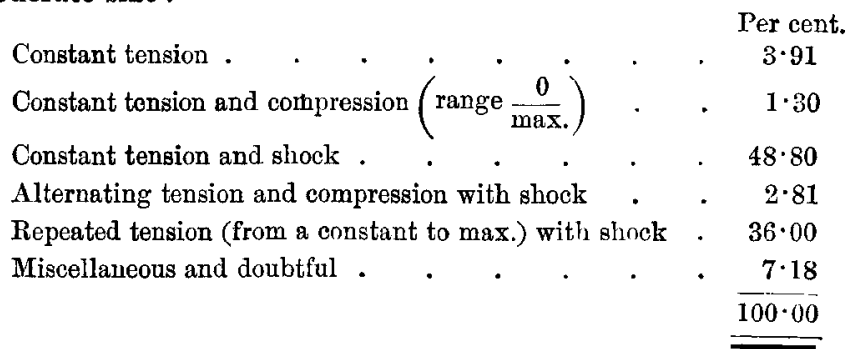

It will be seen that $87 \cdot 6$ per cent. of the whole engine is subject to more or less shock, while pure tension forms an insignificant percentage of the total stress; vibratory or alternating stress, where the transition from one kind to another is gradual (say, following a sine law), and unaccompanied by shock, does not occur at all in normal conditions, although it may ve conceded that under ideal conditions, in the crankshaft, for instance, it will occur. This is in only one machine. If however various other machines are examined, it will be found that nine out of ten are working unier similar conditions. Consider a printing machine or a textile machine, or even the bicycle. When a bicycle frame gives way under ordinary wear and tear, it gives way by the effect of accumulated shock as a rule. Moreover it invariably gives way 
in the vicinity of (but not necessarily through) the brazing, where the heat of brazing has not perhaps burnt the metal, but has taken the "work" out of it and rendered it more coarsely crystalline than in the unaffected parts of the tubes.

Referring again to the steam-engine, there are important parts, such as the piston-rmls and connecting-rods, which, under ideal conditions of working, are subject mainly to direct alternating stresses. When, in the majority of cases, a piston-rod gives way, it breaks at the end through the line A B, Fig. 4, and not through the smallest area $C D$, supposing that happens to be less than the area at the bottom of the thread. In fact, it is dislocated through a section where the effect of repeated blows can accumulate. There is undoubtedly, in addition to the suddenly applied steam loads, a

\section{Fig. 4.}

Fracture of Piston-rods.

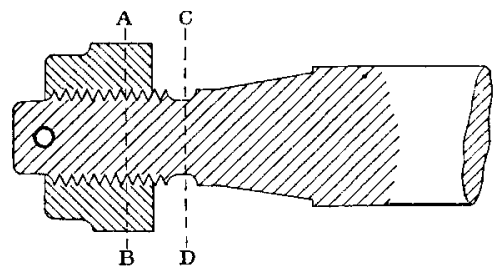

series of true thongh comparatively minute blows (with proper adjustment) arising from the necessary slackness in all the bearings.

The question may be asked: Why do not this rod and similar pieces of machinery break in the same place by the accumulated effect of stress reversals or variations, just as well as with a series of blows? It may be possible that they do so in some instances, but there are a fow considerations which incline the authors to the opinion that this is not the case as a general rule.

(a) In the first place, from Hooke's law $\left(f=\frac{d \mathrm{E}}{l}\right)$, it will be secn that no matter how small $l$ is, $d$ is correspondingly small, and the behaviour of the metal in the nick of the thread should be much. the same as it is in a shank of the same diameter, except that the position of the nick would necessarily determine the place where it would break, if weak enough to do so. 
Fig. 5 is taken from a Paper by Professor Osborne Reynolds and Mr. J. H. Smith, read before the Royal Society.* Some of the members may have already seen it. The authors are indebted to them and the Royal Society for its reproduction. The experiments on which this diagram was based were not made in the Wöhler fashion, and as adopted by Mr. Stead, Professor Ewing and others,

Fia. 5.-Mild Steel (Forged).

Diagram for Failure under Revereals of Direct Stress. (Mr. J. H. Smith.)

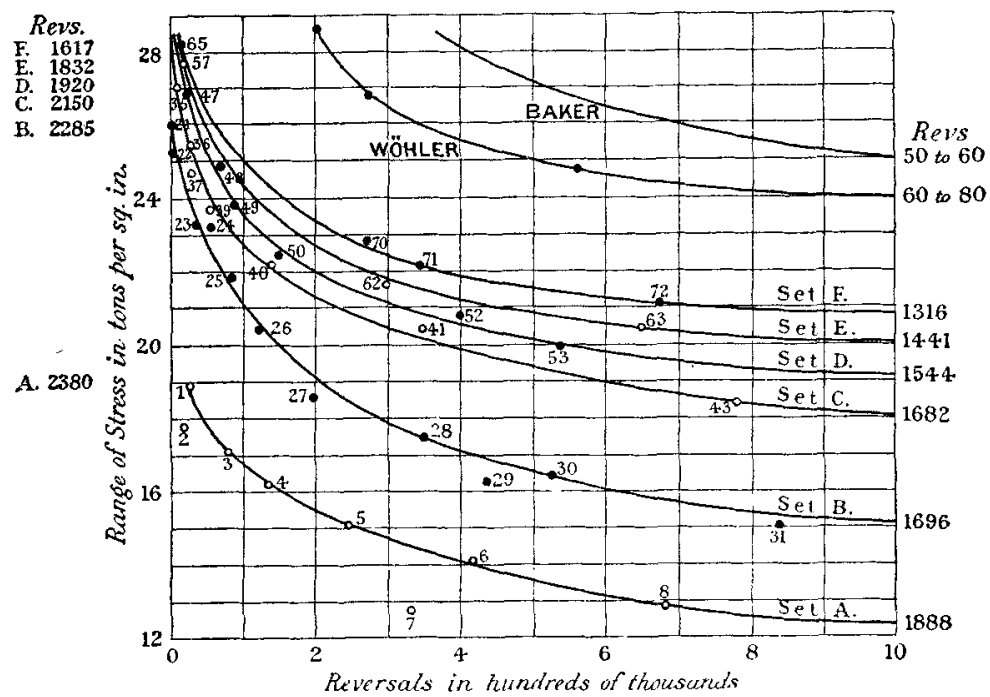

where reversal of stress is obtained by means of a rotation. Here the stresses were pure tension and compression distributed uniformly over the section, and not, as in their experiments, with the maximum stresses at the surface. The variation of stress practically followed the sine law.

(b) There are also exhibited portions of some broken studs, in which the working stress probably never exceeded 23 tons, and certainly could not, by the most extreme method of calculation, have

* Philosophical Transactions, Royal Society, 1902, Vol. 199, page 265. 
exceeded $4 \frac{3}{4}$ tons per square inch. Some examples are shown in Fig. 6, and to these the same remarks apply. The stress given above is the maximum, and the variation of stress is from the initial "nip-up" to this value. In no case did the rate of variation exceed 350 reversals per minute, and the stresses were in all cases variable (that is, of the same sign) and not alternating (from + to - ). The curves in Fig. 5 (page 1141) alone show that, with a range of stress anything below about $11 \frac{1}{2}$ tons per square inch and with 1,880 reversals per minute, it is impossible to break such a steel bar.

Frg. 6.

Fracture of Studs.
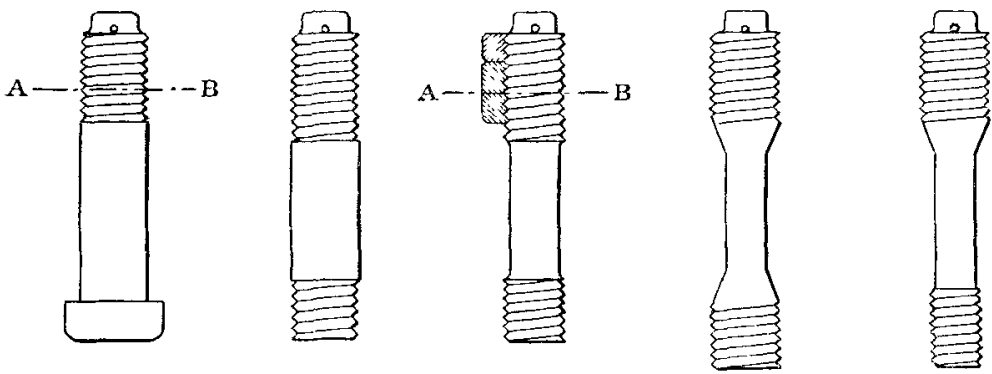

The total number of variations in six particular cases of the broken studs was as follows:-

$\begin{array}{lr}\text { A } & 3,240,000 \\ \text { B } & 7,000,000 \\ \text { C } & 1,240,000 \\ \text { D } & 2,800,000 \\ \text { E } & 5,700,000 \\ \text { F } & 15,400,000\end{array}$

which represents after all only a short life of a few days in the case of some modern engines. From consideration of the relative speeds at which the variations were made, and the limiting condition as determined by the diagram, it ought to be much more impossible to break these studs by the mild "varied stress" treatment actually meted out to them. From the above two considerations, it would appear reasonable to conclude that the effect of alternating or variable stresses of the magnitudes determined by the usual factors 
of safety is quite harmless - especially in those cases where the stress is nearly if not quite uniform over the whole area (as distinguished from those cases where it varies, as in a beam from 0 to a maximum at the surface). Something of a more searching nature must be looked for, and it seems as if it can only be shock, that is, a number of minute blows more or less persistently applied.

There have no doubt been many cases where mild steel forgings of this kind have to all appearances broken in an unaccountable way. In some cases under the authors' notice the shanks of studs have been reduced very considerably, so that the area was only about one-half that at the bottom of the thread. Yet, without a single exception, they all broke through the thread. In fact, some one or two of such studs have for unavoidable reasons had a larger thread at one end than at the other, but nevertheless they broke through the larger thread and not through the smaller one. More curious still, in at least three cases under their notice, a complete annular ring has broken between two adjoining threads; and further, these threads rarely break at the ends of the nuts, but in various places, often somewhere near the middle. In the case of those cut up for testing, the usual tensile tests were quite satisfactory, and in one or two where an analysis was taken of the metal close to the fractured surface, chey were also quite satisfactory. But, on being subjected to an impact test, they all gave exceedingly poor results. For instance:-

(A) broke after only 1 blow.

(B) "

"13 blows.

(C) "

(D) ,

, 9 "

$" 7 "$

From numerous tests it is found that the average impact strength with this particular machine, Fig. 1 (page 1136), for "Admiralty" mild steel, ordinary forging quality, is equal to about twenty blows. This would be for articles having scantlings of a few pounds. The maximum for the grade and for similar scantlings may be taken at about thirty blows. Thus, all these test specimens from broken articles gave results considerably below the expected average.

(c) There is yet a third point in favour of the contention that failure is by shock and not by true alternating or variable stresses. 
It is well known that the resistance to alternating stress (rotation method) increases with the carbon content and elastic limit of the steel, but the resistance to shock decreases with an increase in those factors (for " normal" steel) to an extent that will be explained in Part 2 (page 1148).

It has been found in a large number of instances that, where fracture has occurred after a few hours' work when using normal medium grade steel $(0.25$ to $0.3 \mathrm{C}$.), this occurrence has been either greatly delayed or indefinitely postponed by the substitution of lowcarbon steel, especially when in its best toughened (fine grained) condition. Therefore, apart from the question whether even thirty blows given by this particular machine is a good and sufficient insurance against fracture, the point is that it is not satisfactory to subject all steel to one particular test, just because that test may be a suitable one for large quantities of it for one particular purpose. Let. there be these particular tests for bridge steel and boiler steel by all means, but steel that would be used for the miscellaneous forgings of machinery in general should be tried by its own crucial tests. Caraxles, cranks, and similar articles perhaps should be subjected to an alternating stress by the rotation method instead of by the shock test, as in their case also the tension test is almost useless as a gauge of the suitability of the material. Professor Ewing and others have shown most conclusively, that the resistance to an alternating stress of the kind adopted in their researches bears no relation to the resistance to pure tension. There is plenty in each of the aforementioned groups of the uses of steel to warrant different testing methods when necessary.

Reverting to the question: Is there (for groups $(c)$ and $(d)$ in particular) one comprehensive test for steel forgings? The following appears to be the practical answer:-

Simple Tension is not sufficient;

Bending is not sufficient;

Impact on plain bars is doubtful-certainly too tedious, if without distortion;

Reversal of stress by either method (before described) is fairly good; but 
Impact on a notched-bar is best of all for the following reasons:-

Firstly, because it appears to be a gauge of the preponderant stress. (It is doubtful whether "stress" is the proper term to use; "disloceting agent" would be better, although even this is hardly correct, as is shown in Part 2, page 1148.)

Secondly, because experience shows that, with absolute certainty, there is always a good enough ductility when there is a good resistance to shock. But it is known equally well that there may be obtained an excellent tension and elongation result from steel which is quite incapable to resist shock.

Thirdly, because 99 per cent. of all forgings are notched in some way or other, though not necessarily with a $\checkmark$ nick. Moreover sharp edges, internal and external, cannot always be avoided in machine design, or even deep scratches in actual construction.

Two corollaries may be added to these reasons. The first is that, as ascertained from the supplementary evidence with many kinds of steels, there is every reason to believe that the desire for a high-tension steel一one combining a high tensile strength with the usual factors of safety-is to a great extent a mistaken one. Nor is this to be regretted, where it can be shown by suitable tests that a comparatively low-tension material is more reliable, because requirements can be more fully and safely met by a low-tension material, if a lower factor of safety be permitted. The second corollary is that if, as seems to be the case, one is sure by such means of a satisfactorily ductile material, then, knowing the approximate analysis for the class of steel being used, the impact test is sufficiently comprehensive for both groups $(a)$ and $(b)$.

It must not be concluded that the factors of elastic limit, etc., are despised, but, since the forces that cause breakage are in practice far below the elastic limit in magnitude, and, moreover, as the factor of safety is quite arbitrary and the same in no two pieces of machinery, it seems to the authors that the cart is put before the 
horse to a great "extent. In fact, under the usual conditions of design, enough is known about the elastic limit, which can only vary (in a given grade of steel) between comparatively small and insignificant limits, whereas the shock strength can vary almost between infinite limits.

Opinions differ as to the best means of making the impact test, but the consensus of opinion appears to be that it should be made with a machine that breaks at one blow, and at the same time measures the energy expended in breaking the specimen. M. Frémont considered that breaking by a series of blows gave results that were similar to those from a static bending test, that is, they are more a gange of ductility and tensile strength than of resistance to shock. The authors are not with him in this opinion, provided that the blows are not heavy enough to produce material bending; it is possible that he meant in this sense, much the same test as Professor Heyn undertook in a series of experiments on the "overheating of mild steel." Here he had a nicked bar with one end stuck in a vice. A blow was given by a hammer, bending the bar to a right angle. A reverse blow knocked it back again, and so on until fractire occurred. This is not the method the authors have adopted, for, with the weight and size of specimen used, the bending is very small indeed even for the softest steels.

From the very many bars that have been tested, they have found the number of blows to produce fracture is a fair gauge of the toughness or anti-brittleness. But there is no relation whatever between this result and the tensile result, except as has previously been mentioned, that if the impact result is good the elongation is sure to be good also; but, on the other hand, a steel showing high tensile strength and good elongation may be useless to resist shock. For example:- 


\begin{tabular}{|c|c|c|c|}
\hline & Tension. & Elongation. & Impact. \\
\hline $\left.\begin{array}{c}\text { Cold-drawn bar of very } \\
\text { low (less than } 0 \cdot 1) \\
\text { carbon steel }\end{array}\right\} \begin{array}{c}(a) \\
(b)\end{array}$ & $\begin{array}{c}\text { Tons per sq. in. } \\
31 \cdot 63 \\
31 \cdot 27\end{array}$ & $\begin{array}{c}\text { Per cent. on } \\
2 \text { ins. } \\
31 \\
20\end{array}$ & $\begin{array}{c}\text { Blows. } \\
1 \\
180\end{array}$ \\
\hline 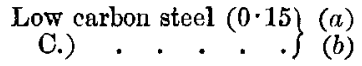 & $\begin{array}{l}28 \cdot 3 \\
27\end{array}$ & $\begin{array}{l}37 \\
33\end{array}$ & $\begin{array}{r}175 \\
5\end{array}$ \\
\hline $\begin{array}{l}\text { Medium carbon steel } \\
(0.25 \mathrm{C} .) \cdot(a) \\
(a)\end{array}$ & $\begin{array}{l}36 \cdot 5 \\
36 \cdot 5\end{array}$ & $\begin{array}{l}35 \\
35\end{array}$ & $\begin{array}{r}5 \\
27\end{array}$ \\
\hline $\begin{array}{c}\text { Mild cast steel }(0 \cdot 35 \text { C. }\}(a) \\
\text { about). } . \cdot \cdot, \cdot\}(b)\end{array}$ & $\begin{array}{l}29 \cdot 18 \\
28 \cdot 25\end{array}$ & $\begin{array}{l}22 \cdot 7 \\
31\end{array}$ & $\begin{array}{l}1 \\
1\end{array}$ \\
\hline
\end{tabular}

Although there is no relation between the tensile-stress test and the alternating-stress test, or between the tensile test and the shock test, the authors are not prepared to say that there is no relation between the alternating-stress test and the shock test. They will indeed be glad to learn that there is a close relation, since then the controversial ground as to the nature of the forces, "alternating " or " shock," would be at once eliminated. They think it possible that a relation does exist, because, although there are differences in the disturbance of the metal in the vicinity of the fracture, the radical phenomena ("dislocation" and "cleavage") are the same. A short consideration of these phenomena is given in Part 2 (page 1148).

It has been said previously that the maximum shock strength for the particular grade of steel containing 0.25 per cent. of carbon is about thirty blows, as gauged by the authors' machine. Although thirty may be a fair figure, such steel cannot be relied upon to give this always. More than thirty blows is rarely reached with this steel in its normal condition, while it is a very common occurrence for the number to be considerably below this. Similar remarks apply to steels of other grades. With the usual factors of safety which are considered by authorities to be sufficient, they find that there is a grave risk of those parts subjected to more or less shock breaking under the modern conditions of high speeds. The authors have no hesitation in venturing the opinion, that the comparative immunity 
from failure which does exist in machinery is due to the liberal data on which the designer usually bases his calculations, and to the "extra allowance for practical purposes" that creeps into all designs, thus bringing up the real factors of safety to a figure considerably higher than that primarily intended to be used. If, however, the increasing desire to keep scantlings down to a minimum is to be realized, security can only be obtained by ensuring that the steel used shall have the maximum shock strength for its grade.

Further, the majority of steel users require that they shall be able to use an ordinary steel as supplied to them, and without annealing, tempering, hardening, or other heat treatment. The authors therefore urge that the engineer should demand of the steel maker a greater endeavour to produce and supply the ordinary grades of steel with a more uniform "shock" quality.

\section{PART 2.}

The Nature and Peculiarities of the Fracture of Mild Steel by Shock.-It has been seen, from various Papers read during the last few years, that with good steel-steel with a practical minimum of the recognised injurious elements-maximum toughness is obtained in connection with a finely crystalline structure, that is, one with grains of a minimum size. The following remarks apply to mild steels in the pearlitic condition; and this condition may be roughly defined as follows:-Normal "mild steel" is a mixture of crystalline ferrite, or nearly pure iron grains, and pearlite grains more or less of a crudely crystalline furm. This pearlite, which is the entectic or mother liquor and separates out last, may be considered to partake of a crystalline nature when, as is generally the case, the alternate lajers of ferrite and composite carbide lie parallel to one another in definite patches.

The photographs on Plate 136 will help to illustrate this point. They show sections of an almost "saturated" steel, the only free ferrite being the thick cellular envelopes (white), while the remainder (dark) is pearlite. It will be noticed in them that the nucleus of each cell is not always of the same orientation, some cells being 
divided into lumps of different orientations. For the purpose of definition, ench of these lumps will be considered to be a pearlite crystalline grain or "pearlite erystal."

"Sorbitic" steels, which are produced by a much more rapid cooling than is necessary to produce the "pearlitic" steels, do not, as far as can be ascertained, generally have their eutectic resolved into anything in the nature of the above crystalline form. As far as can be detected, it is non-crystalline in the sense just enunciated. There are also other differences, but these need not be entered into here, as the foregoing remarks are passed only to make it clear that the subject of the investigations is "pearlitic" steels, that is, steels in the condition the steel bars and forgings of commerce are in, and particularly so after annealing.

The carbides of iron and manganese that are found in "normal" steels are known, and admitted to be very hard and extremely glassbrittle substances. Although it is generally recognised in practice that, for tools having to stand heavy blows, saturation steel, that is, steel which is wholly pearlite in its soft natural condition, is the toughest; yet this steel is an exceedingly brittle substance, when compared with a low carbon or nearly all ferrite steel. Since lowcarbon steel or nearly pure ferrite is, when not tampered with (and it very often is tampered with in that singularly variable process called annealing), a very ductile and tough, leathery substance, the natural conclusion arrived at is that the increase in minimum brittleness, as the carbon scale is ascended, is due to the presence of pearlite. Although the average size of granule for the different grades of steel experimented upon has not been measured, the authors have obtained by selection and heat treatment where unavoidable (still retaining the "pearlitic" condition), a number of pearlitic steels, in which the grains are approximately a minimum for the particular scantlings involved. It is, of course, to be expected that brittleness in steel increases with the carbon content, but the authors are convinced that the falling off in this respect is far more rapid than the majority of engineers aro aware. And further, they believe that this has been in a great measure unobserved, owing to the prevalence of the tensile as the only test. They are led to this by 
the fact that the very toughest "fancy" steels (as distinguished from the natural or normal pearlitic steels) are often produced from what is more or less equivalent to high-carbon steels, such, for example, as the nickel alloys, where the ferrite is almost wholly displaced by a composite mixture.

The authors have come to the conclusion that, given a certain percentage of carbon in steel :-

(1) It is impossible in any given mass to produce a grain below a certain size, and still preserve the eutectic as pearlite.

FIG. 7.-Curve of Maximum Shock Strength

of Commercial "Pearlitic" Steels. (Forged or Rolled Quality.)

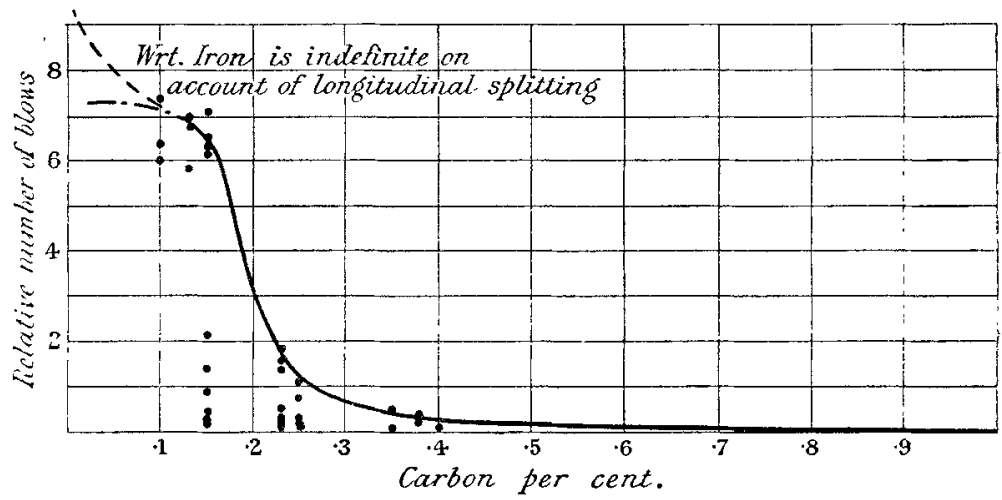

(2) There is a minimum brittleness, upon which it is impossible to improve while still retaining the pearlite eutectic.

(3) This brittleness increases very rapidly with the increase of carbon, especially at or about the " mild" region.

From the results of numerous experiments, they arrived at the results shown on diagram, Fig. 7, which gives approximately relative values of minimum brittleness or maximum toughness under shock. For instance, it may be expected that with articles of approximately the same scantlings and in their pearlitic condition, those having 0.2 per cent. carbon will be at least five times tougher: to resist shock than those having 0.3 per cent. This diagram is intended to apply to forged or rolled steel and not steel castings, at any rate, 
not such as are usually supplied. Photographs of somo sections from steel castings will be referred to with the object of assisting in illustrating phenomena common to both. Since in a "saturated" steel the line of fracture is necessarily through pearlite-an exceedingly brittle substance compared with ferrite-the next natural conclusion is that the line of fracture will be in all cases through as much pearlite as possible. There also still appears to be yet a prevalent idea that fracture of any kind takes place more or less along the crystalline grain junctions.

Attention will be now drawn to the series of photographs, Plates 137 to 145 inclusive, which should be examined in conjunction with the short description given on pages 1157-1163. Bearing particularly on what has just been said, the photographs show :-

Firstly, that, in any grade of steel of the range under consideration, the line of fracture does not go through as much pearlite as possible, but that it distinctly avoids doing so, and really goes through as much ferrite as possible.

Secondly, that fracture is extremely rare through the ferrite crystalline junctions, and really is practically always through cleavage planes.

The authors have also observed that the fracture through pearlite is not junctional, that is, between the lumps; noither is it as a rule parallel to the laminations, but appears to follow an erratic course both in saturated and undersaturated steels. In the latter the controlling agent is evidently the ferrite, but in the former the reason is obscure. This, however, is outside the limits of the Paper in view of the above two statements, but it adds weight to the appreciation of the obstinate action of pearlite.

It will thus be seen, by the first statement above, that there is a contradiction of the second natural conclusion arrived at (above), that fracture would of necessity take place through a maximum of pearlite.

There is also an apparent contradiction of the first natural conclusion, that increased brittleness is the outcome of an increase in the quantity of pearlite. Of this latter it is obvious, of course, that there is no real contradiction, seeing that carbon is the only variant. 
Suppose, for instance, that steel were compared with a mixture of soft putty and glass, fracture by a steadily applied load would surely be expected to go through the putty. But would it do so, if broken without appreciable deformation and by a repeated or single pounding sort of action? Moreover, it must be borne in mind that pearlite itself consists of alternate layers of cementite and ferrite, or more putty and glass; so that, supposing cohesion between the putty and glass to be perfect, the authors are inclined to expect the fracture to go through the putty of one of the "sandwiches," and not through the putty mass, when subjected to shock; this, howerer, is precisely what does not happen in steel. Further, there is the phenomenon of erystallization which is not present in the putty. The analogy would, however, serve fairly well for failure by tension, which is all the more reason why it must be viewed with suspicion here, since the authors have found that there is absolutely no connection between tensile strength and shock strength.

A few of the differences observable in specimens of steel fracture by tension, shock, and alternating stress respectively, will now be pointed out. The feature, that distinguishes the fracture under tension from the fracture under shock, is that in the latter case there is an almost total absence of "slipping" right up to the actual fracture itself. As Professor Ewing and $\mathbf{M}_{r}$. Rosenhain have shown, ${ }^{*}$ strain beyond the elastic limit is associated with an internal slipping within the crystals themselves; and they have also shown that this is the phenomenon which accompanies the fracture of a testbar, submitted to an alternating stress (rotating method) below the elastic limit for a considerable space in the vicinity of the fracture. The microscopic observations here, as far as the authors are aware, were only made on the surface of the test-bars, but, as the stress diminished gradually from the outside to the centre, there is no reason to suppose that the slipping is not present within the bar, although of a proportionately decreasing magnitude.

The photo-micrographs on Plate 143 are sections through, or near to, the tension fracture, as produced in the tensile-testing machine. It

* Proceedings 1901, Part 1, page 249. 
will be observed that the crystalline grains are very much drawn out, as, of course, they are expected to be, and the slip-bands are revealed throughout the entire fields shown. Visual examination of the specimens shows that they are present to the very edges of the specimens (about $\frac{3}{8}$ inch square), and therefore probably to the full extent of the drawn-down parts of the test-bars. Professor Fwing's slip-bands are a great deal more clearly revealed than those shown here, because his are recorded from the outside surface of the metal, and therefore require no after-etching for them to be seen, the edges of the slips being perfectly clear, "like the edges of a pack of cards," to use the Professor's own simile.

The slip-bands in the interior can only be revealed by etching, since the specimen is cut out of the middle of the bar after testing. And further, they can only be etched out when the disturbance of the metal (grinding or stretching) has been drastic enough.

It has been suggested to the anthors that the slip-bands seen in the tension fractures are in reality fissures, and not mere slipping. This may be so, but the fact remains that they are quite invisible before etching. In any case, it shows that the disintegration of the grains, by whatever name it is called, is of a compound and not of a simple character, and that etching can reveal it, although it is to be expected that that process will give a more blunt and confused appearance than is obtained on the undisturbed surface of the bar. There may be in places a similarity to the orientated etched figures in the crystalline grains, but there is in general a vastly greater coarseness about them, and the ease with which they are etched out leares no doubt as to their nature.

The distinction between fracture by true alternating stress and by shock is not quite so clear in sections taken from the interior of the article. Since there is little or no drawing out of the crystalline grains, it follows that separation by consecutive or progressive alipping will not be nearly so drastic as in the case of the tension specimen. It should therefore be much more difficult to obtain a slip-band appearance by etching a specimen broken by an alternating stress considerably below the elastic limit. Nevertheless, on comparing the two specimens, it appears that the fracture by 
alternating stress is accompanied by small cracks and fissures in its immediate vicinity to a much greater extent than in the case of fracture by shock. Further, slip-bands (or minute parallel fissures) are often visible close to the edge of an alternating fracture, but they have never been discovered near a shock fracture. It has not been possible to secure a piece of machinery that is known for a certainty to have broken from pure alternating stress, although it is considered highly probable that the fractures shown on Figs. 37 and 39, Plates 144 and 145, are due mainly to this cause.

In general, therefore, the remarks in this connection apply to test specimens. The authors have, as has been shown, plenty of articles which have been broken by what they believe to be shock, and there appears to be a perfect identity between the microscopic appearance of the fracture of these articles and the test-bars broken by shock.

The results are summarized as follows :-

(1) Impact test-bar fracture is through ferrite, and has no slipbands.

(2) Fractured bolts, \&c., show no drawing out or slip-bands.

(3) Alternating stress (rotating) test-bar fracture is through ferrite, with external slip-bands in profusion, and internal slip-bands sometimes visible; but there is no drawing out of crystals.

(4) Tension test-bar fracture is accompanied by slip-bands in profusion, and with the crystals very drawn out.

(5) (From Part 1.) Fracture by direct intermittent stress is highly improbable.

The only conclusion that seems possible from the above is that the fracture and method of producing the fracture is of a similar nature in the articles which break mysteriously and in the impact testbars which break by a number of blows, that is, by a spreading crack.

Reverting to the consideration of the path of the fracture under shock, for the explanation of the phenomena observed, the authors do not think a more obscure reason than the simple one of the mechanical effect of contraction when cooling need be sought, and they will briefly set forth their reason for arriving at that conclusion. 
It will be found in tables of coefficients of expansion, that steel (the carbon content of which is not stated) has a different coefficient from wrought-iron (the quality of which is also not stated). They surmise that, as " tempered" steel is referred to as well as " softened" steel, the experiments were made on a hardenable grade. Assuming this, the comparative result for iron containing a large amount of combined carbon and iron probably containing a large amount of mixed slag is therefore obtained. Steel is there stated to have a lower coefficient of expansion than wrought-iron. As "steel" covers a very wide range, and as "wrought-iron" may be merchant-bar or "Best-Best," and as silica has a considerably lower coefficient than either steel or wrought-iron, there is a very large element of vagueness in those coefficients as given. The authors have therefore made a number of experiments on a mass of saturated steel, that is, steel consisting exclusively of pearlite, and on a mass of very low carbon steel (having less than 0.1 per cent. C.), which to all intents and purposes is wronght-iron or ferrite without any slag. The experiments, which were conducted in a precisely similar manner, showed the coefficient of expansion of pearlite to be higher than that of very low carbon steel or ferrite. The results which are shown in Fig. 8 (page 1156) embrace a range of about $343^{\circ} \mathrm{C} .\left(650^{\circ} \mathrm{F}.\right)$. The authors believe these results to be correct relatively if not absolutely.

It is a well known fact that all irons and steels expand from the molten to the plastic state, and then contract from the plastic state to solid and until cold. It is unnecessary to take refuge in either of the disputed theories of the formation of steel for an explanation. The partisans of each school unquestionably admit the existence of the critical temperatures $\mathrm{Ar}_{1}, \mathrm{Ar}_{2}, \mathrm{Ar}_{3}$, and $\mathrm{Ac}_{1}, \mathrm{Ac}_{2}, \mathrm{Ac}_{3}$, so that in any case three principal periods will be observed during the cooling:-

(1) From the molten state to $\mathrm{Ar}_{3}$.

(2) From $\mathrm{Ar}_{3}$ to $\mathrm{Ar}_{1}$.

(3) From $A r_{1}$ to cold.

Above $\mathrm{Ar}_{3}$, it is self-evident by any theory that there can be no mechanical action which can have any bearing on the present question, 
for neither of the characteristic cold components of the steels under discussion can have yet taken final form. Cooling between $\mathrm{Ar}_{3}$ and $A r_{1}$ does not suggest an explanation which is supported by evidence.

Taking the second period, $A r_{3}$ to $A r_{1}$, it is highly probable that there are changes of volume of the components which take place simultaneously with the chemical or allotropic changes, whichever may occur; but the range of temperature is small and the volumetric changes of the components will be sudden, so that either there will be approximate mutual action or else gaps will be formed. The former seems to be the more probable, as there is no evidence of any

FIG. 8.-Expansion (Linear) of Pearlite and Ferrite.

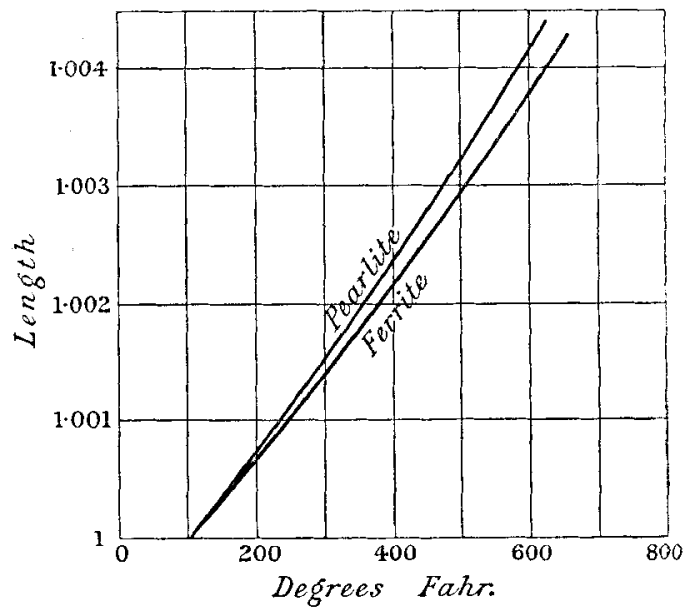

gaps under the microscope, and their existence is not confirmed by any of the peculiar ways steel fractures under various forces. Further, the phenomenon of expansion during plasticization at the higher temperatures (much above $\mathrm{Ar}_{3}$ ) may be present in the carbon-laden components at their lower plasticization temperatures which occur in the region between $\mathrm{Ar}_{3}$ and $\mathrm{Ar}_{1}$. But between $\mathrm{Ar}_{1}$ and cold there is a very long period, when the pearlite is constantly contracting at a different rate from the ferrite.

Supposing that the authors' relative coefficients of expansion be correct, then, since the pearlite is contracting at a greater rate than 
the ferrite, it shows that it is acting as a sort of hydraulic expander to the ferrite instead of a hydraulic press, and this effect will increase with the increase of carbon. There would therefore be an increasing tendency to hollowness in each individual ferrite grain, in much the same way as a piece of lead, for example, sinks down when cooling; and with this tendency they think it quite reasonable to suppose that there is a corresponding tendency to easy separation through the grains, either individually or in series. And in the case of the higher carbon steels where the quantity of ferrite is small, there would alternatively be an increasing tendency to separation between the ferrite and pearlite.

The following deductions are arrived at, which harmonize the apparently anomalous facts that the line of fracture avoids going through pearlite; that the line of fracture avoids going through the junctions; that brittleness increases with the carbon content; and further, that the larger the crystalline grains the greater the weakness, which is not only confirmed by the numerous test-bars examined, but by the intensely brittle results which are produced by long annealing. Supposing that the coefficient of expansion of ferrite be greater than that of pearlite, there would still be the tendency to openness in the ferrite, but it would be a decreasing tendency with the increase of carbon. On the whole, therefore, the authors think their experiments and observations are confirmatory.

\section{FRACTURE PHOTOGRAPHS.}

Attention is first called to the fracture photographs of cast steel, because, these being somewhat of an "exaggerated" character, the eye will then be better prepared for the subsequent finer structures.

The "normal "photo-micrographs are from the metal as received from the makers.

The " heat treatment" consisted of-

(1) Heating to about $800^{\circ} \mathrm{C} .\left(1,472^{\circ} \mathrm{F}\right.$.) quickly.

(2) Quenching in oil.

(3) Reheating to about $700^{\circ}$ C. $\left(1,292^{\circ}\right.$ F.) quickly.

(4) Cooling naturally (about half-an-hour). 
Figs. 14 and 15, late 137, show photo-micrographs of sections of a piece of good cast-steel that has been "heat-treated," this process being conducted subsequently to the usual annealing at the maker's works. The structure has developed curiously (compare with Fig. 13, Plate 137, and Figs. 16 and 17, Plate 138, which are normal) and instructively, for it illustrates three points. The dark masses are fine-grained steel with about 50 per cent. each of the ferrite and pearlite. The dark line running through the field is the actual line of fracture under shock. The bright areas are comparatively grossly crystalline ferrite. It will be seen here :-

(1.) That the line of fracture does not go through the finegrained steel, which indicates that fineness of grain is necessary for toughness.

(2.) That it goes almost exclusively through the ferrite.

(3.) That it does not go through the crystalline grain junctions but through cleavage planes.

Another point might be added, that the shape of the fracture is not apparently a measure of the size of the individual grains, as is the common idea, but rather of groups of them.

Attention is also called to the outlined duplicate of these and other photographs. These have been prepared with the specimens under immediate observation, and with the object of enabling the eye to grasp more easily the points at issue. They are frequently not so clear on a monochrome print as they are visually, owing to the great difficulty in photographing even with chromatic approximation. It is further unfortunate that half-tone reproductions confuse and render only faintly many of the critical markings. In all cases the dark areas are pearlite and the white areas ferrite. Impurities, such as sulphide blobs and slight flaws, are not specially noted.

Fig. 13, Plate 137, and Figs. 16 and 17, Plate 138.-These are from the same piece of steel as the last, but they have not been "heattreated," and aro just as cut from the casting, which was one weighing about $\frac{1}{4}$ ton. The structure here is what may be termed " inclusively homogeneous," and is of the same character as that of the forged steels under consideration, except that in this case it is very much more 
gross. It will be seen that, although with a stoel containing this fairly large quantity of eutectic there are necessarily portions of the pearlite areas fractured through, yet there is on the whole a general and distinct avoidance of the pearlite. There are indeed many places where the fracture runs along the junction of the pearlite and the ferrite, but this still more emphasizes the avoidance of the pearlite.

The mottled appearance of the ferrite in the vicinity of the fissure in some of the photo-micrographs (Figs. 16 and 17, Plate 138, particularly) is due to an unaroidable "sweating" of the fissures after drying, and is simply the raried coloration arising from the thin film of the "sweat" which is distributed around.

The following photographs of forged steels are not necessarily from steels of a maximum shock strength for the grade, the more direct object being to produce comprehensive fields and to include a variety of makes.

The average analyses for the grades are as follows:-

\begin{tabular}{|c|c|c|c|c|c|c|c|}
\hline & Figs.* & . & $19,20,20 \mathrm{~A}$ & 18 & 21 to $25 \mathrm{~A}$. & 26 to 28 . \\
\hline Carbon . & . . & per & ent. & $0 \cdot 38$ & $0 \cdot 3$ & $0 \cdot 25$ & 0.15 \\
\hline Manganese & . & . & 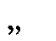 & $0 \cdot 6$ & $0 \cdot 8$ & 0.76 & 0.64 \\
\hline I'bosphorus & s. & · & , & $0 \cdot 05$ & 0.052 & $0 \cdot 058$ & 0.03 \\
\hline Sulphur. & . & • " " & , & 0.05 & 0.05 & $0 \cdot 036$ & 0.04 \\
\hline Silicon . & . . & • , , & , & $0 \cdot 10$ & $?$ & 0.05 & 0.051 \\
\hline
\end{tabular}

* Separate numbers are for different steels by different makers.

Figs. $18,18 \mathrm{~A}$, and $18 \mathrm{~B}$, Plate 139 . These are photo-micrographs of sections of a crank-shaft forging, the structure being large in consequence. The complete length of fracture in this specimen has been examined and computed; and it is found that of the total fracture-

64 per cent. of the length is through ferrite.

19 per cent. of the length through the ferrite and pearlite junctions.

17 per cent. of the length through the pearlite. 
Thus, although the pearlite area is very nearly equal to the ferrite area, the ferrite fracture preponderates to an overwhelming extent.

Figs. 19, 19A and 19в, Plate 139, and Figs. 20 and 20A, Plate 140, are from a moderately high-carbon steel (C. about 0.38 per cent.). Of course, as the pearlite increases, the ferrite becomes more and more surrounded with pearlite, until a sort of reversed picture of a low-carbon steel is obtained. Consequently the fracture has to go through a certain amount of pearlite. But the authors think it will be recognised that even then there is the same tendency to avoid the pearlite.

With the increase of pearlite, there appears to be a greater tendency for the fracture to run along the junctions of the pearlite and the ferrite. This indeed is to be expected if the fracture avoids entering the pearlite areas, and the ferrite areas are comparatively small. But this must not be confused with the fracture along interferrite granular junctions, and which, as will be seen, is extremely rare in all grades.

Figs. 21 to 23, Plate 140, and Figs. 24 to $25 \mathrm{~A}$, Plate 141, inclusive. From medium carbon steel of Admiralty quality.-Some of these exhibit very clearly the preference of cleavage to junctional ferrite frracture.

The slightly mottled appearance in places in the vicinity of the fissure (Figs. 21 and 21 $\mathrm{A}$, Plate 140, particularly) is due to the fissure "sweating" after drying, and arises from the variously coloured film of the sweated matter deposited around. The generally mottled appearance of Figs. 25 and $25 \mathrm{~A}$ is due to a thin film of wax on the surface.

Plate 142. From low-carbon steels (C. about 0.15 per cent.).Fracture las, of course, to be mainly ferritic, but a pearlitic fracture is extremely rare, if not entirely absent. (Pearlite-ferrite junctional fracture is fairly common.)

Plate 143 shows illustrations from sections of bars broken in the tensile testing machine, and are, therefore, of a different character to those just described. 
Figs. 29 to 31, Plate 143.-The test-bar was taken from the same mass of cast steel as the impact test piece, of which Figs. 14 and 15, Plate 137 , show sections. The fields were both taken at about $\frac{1}{8}$-inch from the actual fractured edge.

Figs. 32 to 34, Plate 143. Medium-carbon steel Admiralty quality, corresponding to Figs. 21 to 23, Plate 140, and Figs. 21 to $25 \mathrm{~A}$, Plate 141.-The test was stopped just as the bar was on the point of giving way, and the fissure was made by the indenting on one side and pulling over by hand. This appeared the only possible way of obtaining a tension specimen with the fracture running partially through the section. To break the bar completely in the testing machine perhaps makes a looser looking edge than that obtained in the above manner, but such an edge is almost hopeless to polish owing to the dragging away of the considerably loosened particles, as mentioned in the description of methods of preparing the specimens, Appendix II. (page 1167).

Fig. 35 is a sketch showing the position in which the specimens on Plates 144 and $14 j$ were taken, that is, at right angles to the surface.

Frg. 35.

Showing Field of View on Fractured Surface.

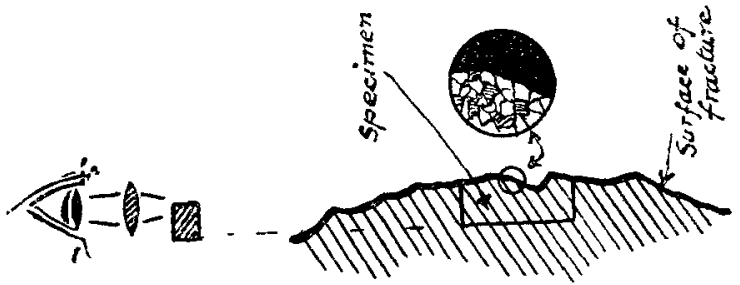

Figs. 36, 36A, 36s, Plate 144, show typical sections thruugh the fractured surface (right angles to the surface) of studs broken while at work. The slight fuzziness at the edge is due to the unaroidable rounding off of the edge of the specimen during polishing, and to the consequent inaccuracy in focussing. The 
photographs generally illustrate the clear-cut process of fracturing, and show that appreciable strain is absont.

Fig. 36B is a common example of how such a fracturo pursues its course, undisturbed by small internal flaws that happen to be in the vicinity of the path of its progress.

Figs. 37, 37A, 37ฌ, Plate 144, are illustrations of sections through the fracture of a $6 \frac{1}{2}$-inch crank-shaft that, in the author's opinion, was the result of an excessive resonant effect. The stress induced thereby would be alternating torsion mainly. One specimen only was taken at random from the interior, so that the sections may be fairly representative. The structure is generally comparatively gross on account of the size of the forging.

Fig. 37 shows one of a number of fissures near to the fracture surface, and which bear a general resemblance to those in Fig. 38, Plate 145 .

Fig. 37A, Plate 144, will on close examination reveal a considerable amount of general disintegration of the "slip-band" order.

Fig. 37s shows a crystalline grain near to the fracture, which appears to have undergone a marked amount of internal slipping. 'The adjoining grains are quite smooth.

Fig. 38, Plate 145, shows a typical section from the interior of a test-bar broken in the alternating-stress testing machine. The figure illustrates the local breaking-up or fissuring that accompanies the actual fracture itself. Refer also to Fig. 13, Plate 137, and Plate 138, for appearance of the body structure after etching. This steel was selected for the purpose of illustration on account of its structural grossness, but the appearance given by finer structures appears to be similar although on a smaller scale.

Fig. 39, Plate 145, shows a section from a smaller crank-shaft, almost undoubtedly broken by excessive alternating stress producel by the failure of a bearing. The stresses set up would be of tho bending-moment kind, and similar to those produced in the rotating alternating-stress testing machine.

The field shown is representative of a considerable extent of the local breaking up near to the fracture. Some of the mottling is due 
to the coloured "sweat," previously referred to, but there are a large number of minute fissures in and about this mottling.

Fig. 40, Plate 145, shows a typical example of progressive fracture of a large bolt broken in service, in which the strain in all directions appears to be nil.

The Paper is illustrated by Plates 136 to 145 and 9 Figs. in the letterpress, and is accompanied by two Appendices.

\section{APPENDIX I.}

In the foregoing, the subject matter has been strictly confined to the strength, etc. of steel in its natural condition, or that condition produced by the comparatively slow cooling process of ordinary manufacture. The shock strength of "treated" steels, however, is a matter of equal, if not of greater importance. "Treated" means any process whereby the steel is left in a more or less artificial condition, as distinguished from the natural condition just discussed; such as oil-hardening, water-hardening, tempering, and allied processes. The authors have not had the time nor facilities for conducting a complete series of experiments with these steels, but they have done quite sufficient to be assured of the fact that the shock strength of oil-quenched mild steels particularly is not increased a mere matter of 20 per cent. $\left(720^{\circ} \mathrm{C}\right.$. in oil, $0.25 \mathrm{C}$. $)$ to 130 per cent. $\left(1,200^{\circ} \mathrm{C}\right.$. in water), as is the case with the tensile strength, but on an average 500 to 600 per cent. more than the shock strength of the natural steel in its best condition. Moreover, oil-quenching appears to possess the highly important property of "levelling up" the shock strength of steel to a fairly constant value.

Thus there may be two similar articles made of the same grade of steel, the one coarse and brittle and the other fine and tough, and possessing a maximum shock strength. Oil-quenching will increase the strength of both to a common value, the increase in the one case being perhaps several thousands per cent., and in the other the 500 or 600 per cent. above referred to. 
TABLE 1 (continued on opposite page).

Abstracted Test Results of Various Steels.

\begin{tabular}{|c|c|c|c|c|c|}
\hline \multirow[b]{2}{*}{ Description. } & \multicolumn{4}{|c|}{ Normal Condition. } & \multirow[b]{2}{*}{$\begin{array}{l}\text { Analysis. } \\
\text { Average } \\
\text { per tent. }\end{array}$} \\
\hline & 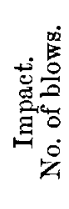 & 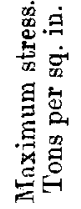 & 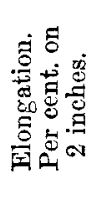 & 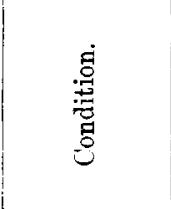 & \\
\hline \multirow{4}{*}{$\begin{array}{c}\text { Low } \\
\text { carbon } \\
\text { steel. } \\
\text { Acid. }\end{array}$} & 7 & $\ldots$ & $\ldots$ & - & C. 0.15 to 0.15 \\
\hline & 5 & $26 \cdot 9$ & $29 \cdot 8$ & as received & $\left\{\begin{array}{l}\text { S. } 0.032 \text { to } 0.050 \\
\text { P } 0.032 \text { to } 0.0 \% 3\end{array}\right\}$ \\
\hline & 165 & $\ldots$ & - & - & Mn. 0.63 to 0.75 \\
\hline & 163 & - & -- & - & $\mathrm{Si} .0 \cdot 065$ to 0.057 \\
\hline \multirow{3}{*}{ 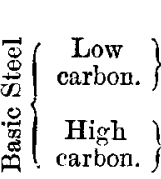 } & 293 & $23 \cdot 2$ & 46 & 一 & $\left\{\begin{array}{c}\text { C. } 0 \cdot 11, \text { S. } 0 \cdot 051 \\
\text { nn. } 0 \cdot 45, \text { P. } 0.044\end{array}\right\}$ \\
\hline & 217 & $26 \cdot 3$ & $40 \cdot 5$ & as received & $\left\{\begin{array}{l}\text { C. } 0 \cdot 17, \text { S. } 0.050 \\
\text { p }\end{array}\right.$ \\
\hline & 1 & $55 \cdot 7$ & 12 & - & $\left\{\begin{array}{c}\text { C. } 0 \cdot 73, \text { S. } 0 \cdot 056 \\
\text { Mn. } 0 \cdot 6, \text { P. } 0 \cdot 053\end{array}\right\}$ \\
\hline \multirow{2}{*}{$\begin{array}{c}\text { Medium } \\
\text { carbon } \\
\text { steel. }\end{array}$} & 23 & $32 \cdot 5$ & 35 & as recejycd & - \\
\hline & 35 & - & - & $\left\{\begin{array}{c}\text { annealed } \\
\text { in lime }\end{array}\right\}$ & C. $0 \cdot 23$ \\
\hline \multirow[t]{2}{*}{ Admiralty. } & 35 & - & - & $\left\{\begin{array}{c}\text { annealed in } \\
\text { coke dust }\end{array}\right\}$ & S. $0 \cdot 086$ \\
\hline & 5 & - & - & as received & P. 0.058 \\
\hline \multirow{2}{*}{$\begin{array}{l}\text { Ordinary } \\
\text { grade. }\end{array}$} & 47 & - & - & $\left\{\begin{array}{c}\text { annealed } \\
\text { in lime }\end{array}\right\}$ & $\operatorname{Mn} .0 \cdot 76$ \\
\hline & 5 & - & - & $\left\{\begin{array}{c}\text { annealed in } \\
\text { coke dust }\end{array}\right\}$ & Si. 0.05 \\
\hline \multirow{4}{*}{$\begin{array}{l}\text { Bright } \\
\text { rolled bar. }\end{array}$} & 3 & - & $\ldots$ & - & $\ldots$ \\
\hline & 3 & $35 \cdot 4$ & $25 \cdot 2$ & - & C. $0 \cdot 11$ to $0 \cdot 1 \mathrm{j}$ \\
\hline & $\begin{array}{l}1 \\
3\end{array}$ & - & - & - & - \\
\hline & 183 & $31 \cdot 9$ & $24 \cdot 5$ & - & - \\
\hline
\end{tabular}


(concluded from opposite page) TABLE 1. Abstracted Test Results of Various Steels.

\begin{tabular}{|c|c|c|c|}
\hline \multicolumn{3}{|c|}{ Oil-Quenched. } & \multirow[b]{2}{*}{ General Remarks. } \\
\hline 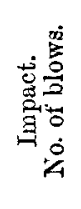 & 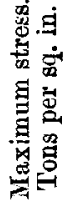 & 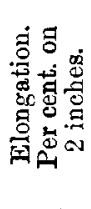 & \\
\hline 165 & - & - & \\
\hline 159 & $25 \cdot 7$ & 31 & Original bars 2 inches diameter. \\
\hline $\begin{array}{l}177 \\
181\end{array}$ & 二 & - & Impact test-bars $\frac{5}{8}$ inch diameter. \\
\hline 301 & $27 \cdot 8$ & $3 j$ & \\
\hline $\begin{array}{r}280 \\
5\end{array}$ & $\begin{array}{l}31 \cdot 5 \\
74 \cdot 4\end{array}$ & $\begin{array}{r}38 \\
\mathbf{3}\end{array}$ & $\begin{array}{l}\text { Original bars } \frac{3}{3} \text { inch diameter. } \\
\text { Oil-quenched in test-bar form. } \\
\text { Impact test-bars } 5 \text { inch diameter. }\end{array}$ \\
\hline 105 & $37 \cdot 8$ & $31 \cdot 4$ & \\
\hline - & 一 & 一 & \\
\hline 111 & - & - & $\begin{array}{l}\text { Original bars } 2 \text { inches diameter. } \\
\text { Oil-quenched in test-bar form. } \\
\text { Impact test-bars } \frac{7}{5} \text { inch square. }\end{array}$ \\
\hline - & - & - & \\
\hline 一 & - & - & \\
\hline $\begin{array}{l}\text { (a) } 73 \\
\text { (b) } 73 \\
\text { (c) } 95\end{array}$ & $\overline{-}$ & 二 & $\left\{\begin{array}{l}\text { (a) } \frac{5}{8} \text { inch square test-bars cut from core of } \\
3 \text {-inch bar previously oil-quenched. Micro- } \\
\text { structural appearance same in core as in outer } \\
\text { zone, showing that toughening extends to the } \\
\text { core. (b) (c) Similar bars cut from the outer } \\
\text { zone. }\end{array}\right.$ \\
\hline $\begin{array}{l}107 \\
109\end{array}$ & $\begin{array}{c}32 \cdot 5 \\
-\end{array}$ & $\begin{array}{c}34 \cdot 5 \\
-\end{array}$ & $\begin{array}{l}\text { Test-bars from } 2 \frac{3}{4} \text { inch oil-hardened bolts as } \\
\text { received from makers. }\end{array}$ \\
\hline 19 & - & 一 & Test-bars cut from $\frac{5}{8}$-inch to $1 \frac{1}{2}$-inch bars. \\
\hline 21 & $29 \cdot 1$ & 39 & Impact test-bars $\frac{5}{8}$ inch diameter. \\
\hline 25 & 一 & - & \\
\hline $\begin{array}{r}31 \\
207\end{array}$ & - & 二 & 5 inch diameter bar. \\
\hline
\end{tabular}


They think that practice with such things as gun-barrels shows this also very clearly, and they have no hesitation in saying that, whereas the tensile-testing machines practically make no distinction between the steel that is utterly unfit and that which is eminently fit for the parts of a machine subject to shock or vibratory stresses, the drop-testing apparatus does most certainly, and without fail, make the discrimination; and further, that wherever the drop-testing machine shows a steel to be good, the tensile-testing machine corroborates it. Therefore, it may be concluded that while the drop-testing machine is a certain and reliable guide to the maker of such structures, it is equally the friend of the construction of other structures, subject only to tension or compression steadily or constantly applied.

Table 1 (pages 1164-5) gives the results of a number of pairs of tests of normal and oil-quenched steels as determined by the authors. The temperature of heating was about $800^{\circ} \mathrm{C}$. $\left(1,472^{\circ} \mathrm{F}\right.$.), as far as could be judged without a pyrometer. The steel was heated and quenched when in the form of test-bars, except where otherwise stated. The treatment was in fact a fair sample of the way it would be done in the average works, and not with that refinement that would be obtained in the laboratory. But although their shop tests, as they may be termed, show roughly how matters lie, the moro refined methods of the laboratory, which are not at their disposal, are necessary for a complete serial investigation, as in the recent Alloys Researches.

Attention is particularly drawn to the shock strength of bright rolled bar. It is a remarkable fact that, until quite recently, all the bright bar on the market, with the exception of about two British makes, appeared to be quite rotten under shock, snapping off in all cases with only two or three blows, and not improving very much by oil-quenching. The authors have nat had occasion to obtain analyses of the numerous samples of bright bar they have tested, but in the majority of cases the carbon content was stated to be from $0 \cdot 11$ to $0 \cdot 15$ per cent.

In those samples which met in other respects the Admiralty specification, the shock strength was worse than that of lower grades. The reason for the generally inferior results may be due to the 
drastic rolling process, but the fact remains that good bars can be produced with certainty by a few makers. The authors are, however, glad to observe that other makers are rising to the occasion, and that improvement is rapidly being effected and without the accompaniment of a prohibitive price. They would, nevertheless, recommend due caution on the part of those using the larger sizes of bright bar for important parts of machinery. The number of blows that good bright bar will stand appears to be about the same as for ordinary bar of the same grade.

Their experiments are not extensive enough to determine the average ratio of benefit due to oil-quenching, but the general observation appears to be that the benefit decreases as the carbon content approaches zero (except in the highly important function of "levelling up" above referred to), the best normal condition to be the basis of computation. This indeed is to be expected, since the quantity of hardenable element decreases.

Since writing the above, the remarks of Captain H. Riall Sankey on the Sixth Report to the Alloys Research Committee have been published.* An examination of the results of the impact tests given therein appears to confirm the authors' observations generally, and it will be particularly observed that the shock strength of any grade: steel may vary between enormous limits according to treatment.

\section{APPENDIX II.}

\section{Method of Preparing the Specimens.}

To obtain a view of the course of the fracture through the metal, the bars devoted to microscopic investigation were removed from the testing machine after the erack had gone about half-way through. The specimens were cut out as indicated by the dotted lines in Fig. 3 (page 1136).

The most satisfactory method of polishing is found to be as follows:-After smooth-filing down perfectly level, the surface is rubbed down on quick-cutting oil-stone moistened with only a drop 
or two of petroleum. The last few rubs should always be made in the thick resultant mud. A finer cut may then be made on a piece of harder stone such as real Turkey or Arkansas, according to the hardness of the steel. Polishing proper is then made on a rotating block covered with smooth pig-skin or calf-leather, the harder the better, and well saturated with petroleum, and smeared with the finest rouge. It does not take very long to polish the specimen, if the initial grinding on the oil-stones has been carefully done. The surface thus obtained is perfectly free from rouge, and (in the authors' experience) petroleum is much more easy to work with than any water preparation. The speed of the block over the specimen surface is about 500 feet per minute. There is no heating, and a little higher speed might safely be adopted. A speed of three to four times as much, however, has been found to be too high, the polishing not being so rapid, and the heating excessive. For finegrained steels, the polishing may be contained on a kid leather block similarly prepared. It must be pointed out, however, that the above procedure does not suit every kind of iron or steel, but it is more particularly applicable to the softer than to the harder varieties, the soft metals being the more difficult to polish.

Etching was mostly done with dilute nitric acid, and taken all round, it is the most generally satisfactory. The chief disadrantage is the tendency for the fracture to be "smudgy," as will be seen in some of the photographs, but the great advantage is that the crystalline junctions of the ferrite can be more readily revealed than by any other process. Other methods (liquorice, picric acid, or ammonium nitrate) show the fracture up "clean," but bring out the ferrite junctions badly for photographing clearly, and there is a certain element of luck in obtaining a good result. Before etching, the specimens are thoroughly washed in benzine, and are given a gentle dry rub on a chamois-leather bob. After etching in acid, the specimen is well soaked, and washed in lime water or alkaline solution to kill any adhering acid thoroughly, then washed in water and dried as usual. 
Discussion on Friday, 18th November 1904.

Mr. Seaton said he would like to say at the outset that the Paper was really the result of some investigations made by $\mathbf{M r}$. Jude and himself five years ago, after a serious accident had occurred. That led them to further investigations of a far more searching nature than the ones with which they commenced. Since then they had pursued the subject systematically; and he was sure the members would agree with him that the pains taken by his friend and former pupil, Mr. Jude, and the patience and care in arriving at these results he had shown were deserving of their warmest praise. He (Mr. Seaton) took the opportunity of thanking Mr. Jude for what he had done both for him and on his own initiative during the last five years while prosecuting these investigations. He was quite convinced some years ago, from some rough tests made, that engineers were not in a very satisfactory position to judge the material they used; they could not discriminate between one steel and another as to its ability to resist the shocks that came on certain parts of engines. They found, as he had already said, that on investigating the cause of a serious accident that they were quite at sea in the matter. He hoped the reading of the Paper, and the diseussion that would follow it, would lead engineers generally into seriously considering the subject further, with a view to the adoption of some different tests for material that was subject to shock, as so many parts of fast-running machines were.

$\mathrm{H}_{\theta}$ did not know that at this stage he could with advantage do more than emphasize the fact that they held very strongly that their machine, rough as it was, was a very good discriminator of one steel from another for the purposes named. That its measurements were to be taken strictly as standard ones they did not say, that is, if it required twenty blows to break one steel and one blow to break another, they did not say that the first steel was exactly twenty times stronger then the second, but it was quite a sufficient gauge to show their widely distinctive merits. The 
(Mr. Seaton.)

President might, perhaps, use his great mechanical knowledge, especially in the direction of the testing of materials, in devising a better machine than theirs, but, crude as it was, it had given them a considerable insight into the different qualities of the steel they purchased. Samples of special steel were sent to them sometimes, but they had for the purposes of this Paper adhered strictly to the ordinary everyday mercantile steel. Mr. Jude and himself were only engineers; they did not pose as metallurgists or men of science; they were simply engineers who wished to approach the subject from the engineering standpoint, and they had kept to that very closely. He was sorry that his friend Mr. John Spencer, Member of Council, was not present, for that gentleman had given very great attention to the question of heat treatment of steel, for the purpose of making it fit to withstand vibratory stress. He believed he was one of the first, if not the first, to observe the fact that very fine grain fracture was coincident with toughness, and that the coarse grain was coincident with brittleness; he reasoned, therefore, that if he could find some way of producing fineness of grain he would find the way to produce tough steel. Mr. Spencer then commenced that well-known investigation of the heat treatment which so many others had successfully taken up since, and which the author's machine confirmed as being correct. He did not think he need say more, as the time of the members would be better occupied in hearing the explanations of the micro-sections which Mr. Jude would show than anything he could add to the Paper.

Mr. JUDE then described, with the aid of lantern slides, certain sections of steel used to illustrate the Paper.

The Prestdent said he was sure the members wished to convey their thanks to Mr. Seaton and Mr. Jude for their extremely interesting Paper, which was the result of so much careful research. He did not think anyone had ever seen before such beautiful analyses of cracks as just exhibited; certainly he never had. The whole scheme of breaking the pieces lent itself to the examination of a crack, and the way in which the specimens were extracted from 
the piece in order to be able to see the crack, held together by the unsevered portions, was lucidly described. He had great pleasure, on behalf of the members, in thanking the authors for a Paper which was very much valued.

Professor J. O. Arnold, in opening the discussion, said it was in no conventional sense he stated that he had read the Paper with great interest. He had to thank the authors for a most valuable Paper at a most opportune moment. With the majority of the statements made in it, he was quite in accord. There seemed to him, however, to be one or two points open to argument, and there were one or two points upon which, with his present knowledge at any rate, he could not agree. He was sure the authors would be very glad to have his reasons stated, because the object of everybody was to arrive at the truth of the matter which was so vital to engineers. He first of all wished to express his hearty agreement with the statement (page 1136) concerning researches made from steel prepared in laboratory melting-pots. It had long been his view that such results had really no bearing whatever on practical engineering, and only tended to confuse students. He had gone into the matter carefully, and at the Sheffield College they found it necessary, in order to get practical results, to make the steel in masses of about 2 tons, and to work the tests from 10-inch square ingots, before results could be obtained which would really be of value to engineers. He was, therefore, very glad that the authors had called attention to that point. There was another little matter in connection with that statement in which he was not quite so much in accord with the authors. They, he would not say in a scornful manner but in a slighting manner, referred to "fancy" steels. With all respect, he submitted that of all steels which had to stand shock, armour and armour-piercing projectiles had the worst task in the steel world, and those were extremely "fancy" steels. He hoped the authors would reconsider that sentence, because he was working on the matter now, and he was perfectly convinced that, if the metallurgist was to give the engineer a reliable steel so that he could put in a lighter scantling, it must be by means of "fancy" steel.

$4 \times 2$ 
(Professor J, O. Arnold.)

$\mathrm{He}$ also cordially endorsed the statement (page 1137) that high limit and stress did not ensure high resistance to alternating shocks. He thought that had been proved over and over again, but at the same time it did not do in such matters to lose one's sense of proportion, and they must remember that, although cases of failure were sufficiently numerous and sufficiently disagreeable, nevertheless they formed only a very: small proportion of the whole mass of structures made of steel. But, however small a proportion it was, the metallurgist and the engineer should try and reduce that proportion to zero. He was particularly interested in what was to him an extremely useful Table (page 1139), giving the distribution of stress in the steam-engine. It was a thing for which he had been wishing for a long time, and he should study it very closely. The same remark might also be made concerning Professor J. H. Smith's Table of the modified Wöhler test (page 1141), which was an extremely instructive Table.

Mr. Seaton had remarked that fine-grain steel was reliable. There was no doubt that as a broad statement that was so-that a fine-grain steel was more reliable than one with coarse grains, but it was not wise to take that as absolute, because he had known steel with a very fine and micrographically satisfactory grain to be intensely brittle under shock. He had studied the authors' machine very closely, and he felt sure that it might form a most useful adjunct to a laboratory, but there was one respect in which he should like to point out that he thought it would require altering, namely, that it was deficient in ensuring absolutely equal time-intervals between the blows. He ventured to Iay before the Institution the importance of that question. At the Cambridge Meeting of the British Association in 1904, he published a preliminary Paper on a testing machine that ho had been working at for about two years, which he would just roughly describe, Fig. 41 (page 1171). He would assume that AA was the test bar, say $\frac{?}{5}$ inch square, firmly gripped between two dies BB; CC was a horizontal arm capable of moving up to a rate of 800 alternations per minute, which he thought Mr. Seaton would say was the top speed of a destroyer's engines. DD was a gap in the bar. The stress was applied alternately first in the direction of the 
arrow $\mathrm{X}$, and then in the direction of the arrow $\mathrm{Y}$, the result being that along $\mathrm{EE}$, the line of the die, the material was placed, at a given speed of alternation, first in tension and then in compression. The die line was the line of maximum stress, and the fracture always took place in its vicinity. It was found that the number of alternations with which the steel would break raried closely with the rate of alternation. Running the horizontal arm at 168 alternations per minute, a good mild steel endured 1,400 alternations before fracture; but, increasing the rate of alternations to 268 , the alternations it endured fell to 900 . It was impossible to say what the exact curve would be until more information was obtained upon it, but still, that was an extremely important feature. It meant that, small as the interval of rest was, due to the difference between the rates of alternation, yet it was sufficient so to allow the steel to recover itself as to make the remarkable difference in the number of alternations at which it broke. He therefore suggested that, if the authors in their machine could get some appliance to ensure absolutely equal intervals between the shocks, it would bring the data a little nearer the standard. In his own test the fracture began at $\mathrm{EE}$, therefore it was essentially a skin test on each side, dying away to zero in the centre. He had found his test in many cases give a piece of information which he thought no other system of testing gave, namely, as to the homogeneity of the material.

Supposing they had a practically homogeneous bar, with its constituents evenly distributed all through (Fig. 42, page 1174, was an enlarged section of the bar), it would be found that the fracture commenced on the skin $\mathrm{E}$, at the same moment as it did on the skin $\mathrm{E}^{\prime}$, and it would progress equally until the lines of fracture were brought together in the centre. They knew that by rather an interesting fact, that the fracture along the line LL was quite a different fracture from that of the two areas $a a$, the first-named having cvidently broken in tension under the last thrust of the test. In other steels which were not homogeneous, it was sometimes found that the line exhibiting a tension fracture was obtained as far away from the centre as was indicated in Fig. 43 ; so that he thought it was a very valuable thing to ascertain in testing steel. Of course, 
(Professor J. 0. Ainold.)

it was altogether too early to make any definite announcement as to the capabilities of the machine, because he had found out already that it would require most careful standardizing. He had had a special machine built, but the preliminary operation of standardizing involved the preparation of 300 test-pieces from a standard Admiralty forging, so it would occupy a considerable time.

He now came to one or two points which were perhaps a little more in his sphere than in that of the authors, and when they had heard his arguments he hoped they would be inclined to modify certain expressions of opinion in the Paper. The authors said that

Shock-Bending Test.

Fig. 41.-Diagram of Test slightly beyond the Elastic Limit at $\mathbf{\mathrm { NE }}$.

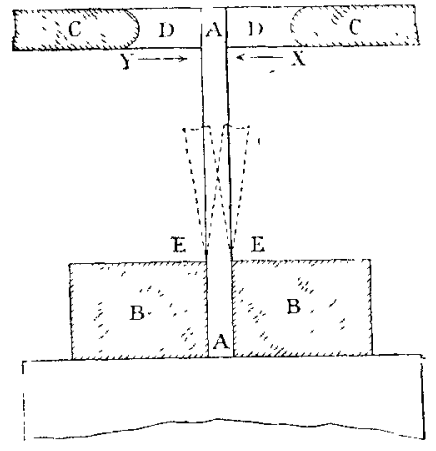

FIG. 42.-Area of Fracture.

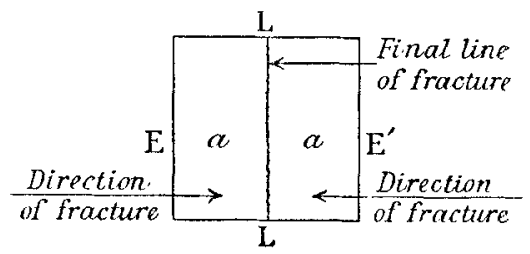

Fig. 43.- Area of Fracture.

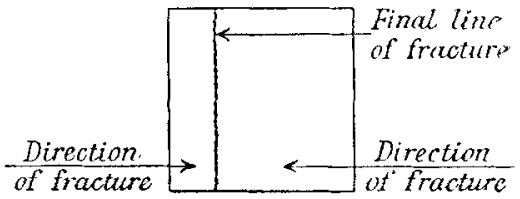

the fractures they had exhibited were due to cleavage. One of the specimens illustrated, Fig. 27, Plate 142, was something like Fig. 44 (page 1175). There was a series of ferrite grains, with here and there a little pearlite. He adopted the term used by the authors-" grains"but he called them "crystals." As Mr. Jude pointed out in that case, remembering that it was magnified 300 diameters, the fracture was practically a straight line right through. Mr. Jude explained that, by saying that he supposed the straight fracture was due to the fact that the orientation in all the crystals was identical. He respectfully submitted to Mr. Jude that, had the orientation in those grains been identical, there could have been no junctions, because crystalline grains 
Course of Shock-Fracture.

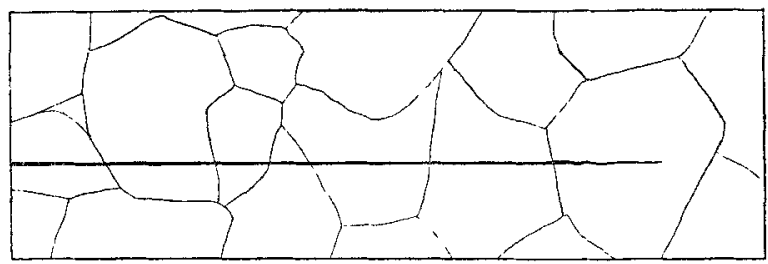

FIG. 44.

Fracture through Ferrite and Pearlite Crystals as exhibited by authors.

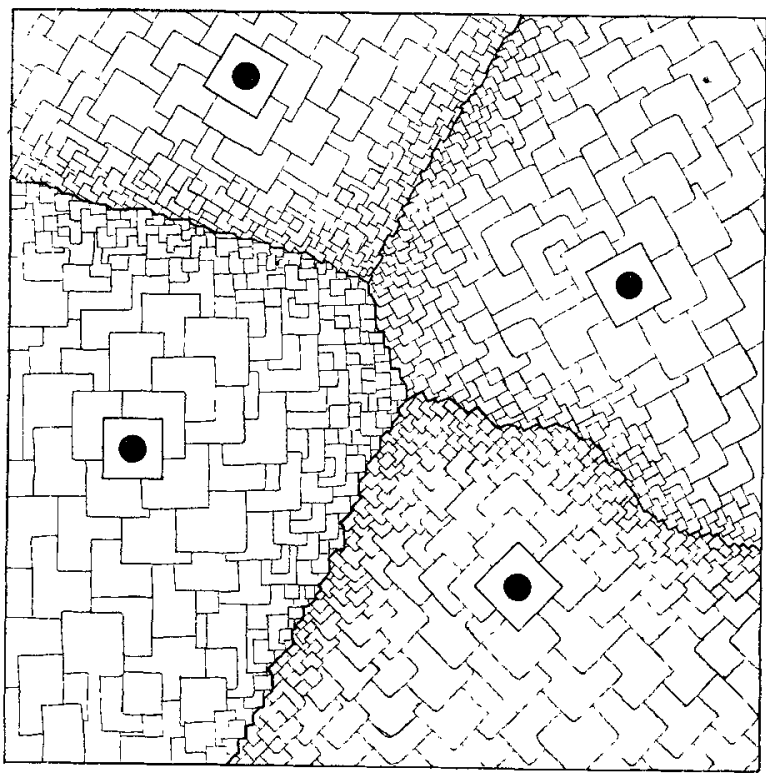

FIG. 45.

Crystals uith varyin. angular orientations.

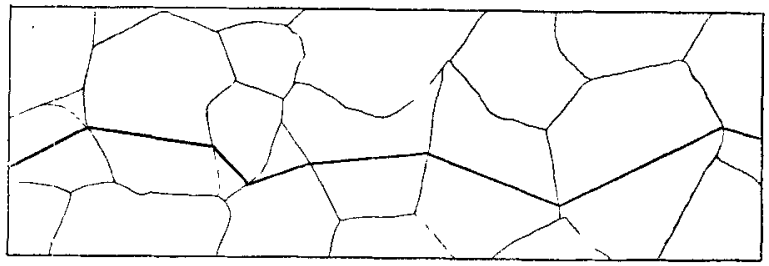

FIG. 46.

Real Cleavage

Fracture. 
(Professor J. O. Arnold.)

(allotrimorphic crystals) were essentially due to the fact that, as shown in Fig. 45 (page 1175), adjacent crystals started their growth from centres at different orientations, and hence collided along interference lines. The right-angled etching figures in the centre of the crystals in Fig. 45 have been made diagrammatically large, so as to illustrate better their varying angular orientations. Had the fractured crystals in Fig. 27, Plate 142, had one orientation, there would have been no junctions at all; it would have been one crystal identical in orientation. He thought there was no doubt about that. That being so, it followed that in real cleavage the fracture would be something like that shown in Fig. 46-not in a straight line but in a zigzag-due to the axes of each crystal differing in direction from those of its neighbour, and hence having a different cleavage with reference to the plane of section. He should be very much obliged if the authors would reconsider their views on the matter, because it was extremely important for students. He thought they could not attach too much importance to the undoubted fact shown, that the fracture ran mainly through ferrite. It must, in the nature of things, do so, because in every case they had two-thirds of ferrite to one-third of pearlite present, so that naturally it would go 2 to 1 through the ferrite, because of the proportions of the constituents present.

Sir Wilriam H. White asked Professor Arnold if he would give his view as to why that particular fracture was of that nature, and so similar to all others. Could he offer any explanation of the fact?

Professor Annoud said he could not; it had gone straight through everything. He could not explain it at all.

Mr. Seaton said it had gone as it ought not to have done.

Professor Arnold agreed. He noticed on page 1148 the reappearance of the ghost of a metallurgical myth which he really thought had been finally laid, but, as ghosts must in accordance with precedent be laid by grotesque incantations, he was afraid he must 
try their patience for a minute or two in that direction. The authors spoke of the constituent pearlite as a eutectic which was the last to solidify. He wanted to clear the matter up. The history was as follows:-In 1895 he laid before the Institution of Civil Engineers," in a Paper on "The Influence of Carbon on Iron," the determination of the quantitative composition of Dr. Sorby's pearlite constituent, and secondly the discovery of the saturation point of steel. He showed that if they took pure iron and added successive quantities of carbon, when they reached 0.9 per cent. the ferrite had disappeared, and the whole mass consisted of pearlite. He showed that when carbon was below 0.9 it consisted of a mixture of ferrite and pearlite, and when it was above 0.9 per cent., of a mixture of pearlite and carbide of iron (cementite). To those substances he gave respectively the names-saturated, unsaturated, and supersaturated steels. Those terms were rejected-he would not say why-by another school of thought, who substituted for them the terms eutectic, hypo-eutectic, and hyper-eutectic. From the very nature of things those terms were absurd. Eutectic meant, literally translated, the constituent which was lask fluid $\lambda$ Pearlite could not exist much above $700^{\circ} \mathrm{C} .\left(1,292^{\circ} \mathrm{F}\right.$.), and was never fluid. That error went on for some years, until a well-known American Professor wrote a letter to the American " Engineering and Mining Journal " to say that he found it very difficult to make his students understand how a constituent that was never fluid could be the last fluid, and he said he thought it was necessary to have a change of name. The first amendment which seems to have been suggested was eumetallactic, hypo-eumetallactic, and hyper-eumetallactic. Those terms were rejected on the ground that the "metall "therein referred to was not "metal," and students might think it was. The next trio were eumetamorphic, hypo-eumetamorphic and hyper-eumetamorphic. Those phrases were rejected on the ground that people would consider them "shocking jargon," which was right. The next series proposed were benmutic, hypo-benmutic and hyper-benmutic. That triplet died an untimely death, being ruthlessly strangled by

* Proceeding, The Institution of Civil Engineers, 1895, vol. cxxiii, page 127.

+ Eutectic = exsily melted; therefore the tast to remain iquid in the cooking of the mixtrure for confunend-

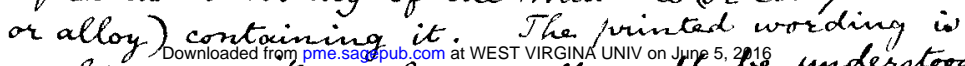
ambignows; it might equally well the underatood ambignows; "t might equally well is is haating." 
(Professor Arnold.)

Mr. Bennett H. Brough, Secretary of the Iron and Steel Institute, on the ground that their philology was execrable. The next three were xolic, hypo-æolic and hyper-æolic. Those did not last very long, ho did not know why, but there was evidently something wrong with them. The next terms suggested were eutectoid, hypo-eutectoid, and hyper-eutectoid, three terms which seemed to him to be just as objectionable as eutectic, of which they were a modification. He could only say that, so far as he was concerned, the old termssaturated, unsaturated, and super-saturated-would serve him quite satisfactorily; they expressed the facts without involving any theory, and the only objection he had heard made to them was that pig-iron was saturated at 4.3 per cent. of carbon. His term had reference not to the saturation-point of pig-iron, but to the pearlite saturationpoint of steel. In conclusion he again thanked the authors very sincerely for their Paper, and the Council for its kindness in enabling him to be present to discuss it.

Mr. C. E. Stromeyer said that, as Professor Arnold had mentioned, the Paper was one of extreme interest, but he had a few objections to make to it. To begin with, he thought the title did not give a full explanation of what was in the Paper. The title referred to " impact tests," whereas much had been heard about the microscopic composition of the metals. On the other hand, the impact tests, which he hoped would have been thoroughly gone into, and perhaps firmly established, had not been dealt with as largely as one could have wished; in fact, judging by the figures and the diagrams in the Paper, he would say that the impact test was one which should not be employed, because it was not as reliable as other tests. It would be noticed on Fig. 7 (page 1150) that the spots (which he believed indicated experiments) for $0 \cdot 15$ per cent. of carbon, showed a number of blows from practically nothing up to $6 \frac{1}{2}$; and again at 0.23 per cent. carbon the number of blows which should break a specimen were not definite for that particular composition of material; they seemed to range from practically nothing to very high numbers. Turning to Table 1 (page 1164), and looking at the actual figures to which he believed the Fig. 7 referred, it would be seen that the top 
specimens, two samples of low-carbon steel, seemed to have broken with seven and five blows respectively, and two of the samples seemed to have broken with 165 and 163 blows. So far as he could see, there was no remark to show why that should have happened, and he did not think it was fair to accept a new method of testing based simply on these few tests. He remembered that, when mild steel was being introduced, the Admiralty and Lloyd's carried out very careful investigations, and the tests which were settled then were settled not because one expected the material would do what the tests said, but practice had already shown that certain materials were good for structural purposes, that they did not fail as some had failed, and that they were strong enough, and that the tests selected identified this material. He was afraid that point was very often lost sight of when endeavours were made to introduce now tests. For special purposes, such as armour-piercing projectiles and armour plate, and many other materials, it was necessary to devise tests which would show what the substance was, but the ultimate test was, of course, the practical test. For instance, with armour-piercing shells and armour itself, the practical test was to expose a certain percentage of armourplates and projectiles to actual impacts. Any chemical tests or microscopic tests which might be devised in the laboratory might. help the manufacturers in producing the material, but the experimental tests had to be in harmony with what the material actually was.

The authors mentioned (page 1140) that very few pieces had broken through fatigue in actual practice. He believed the tail-shafts of the ss. "City of Paris" were said to have been broken from that cause. As far as he remembered, the surface of the steel was intact near the couplings, but below the surface there were very fine cracks. Some of the material was trepanned out of the shaft and tested by Professor Unwin, who showed that the material at that point had entirely lost its good quality.

Mr. J. T. Mrtron said that he quite appreciated what the authors had stated as to the necessity of some other test being looked upon as a standard test for some of the steels that were to be used in 
(Mr. J. T. Milton.)

construction. He would like to refer to what was mentioned at the meeting held at the Institution which discussed the Sixth Report of the Alloys Research Committee, that it was not only steel subject to shock which had given trouble at times, but Professor Arnold * and others had been trying to investigate cases of mysterious fracture in steel subject to steady stress, with no shock whatever, but which had proved exceedingly brittle, while the test pieces for the ordinary tensile test were perfect, as far as the mechanical results were concerned. Professor Arnold's testing machine for dealing with such matters was based on a very different principle from that of the authors. Professor Arnold's gave the test-piece a definite strain; the authors' was a question of energy absorbed by the test-piece. Wöhler's test, again, was one where there was a definite stress applied. He was inclined to think that not one of them met all the requirements that engineers wanted. The one giving millions of reversals took far and away too long to deal with. He did not, however, think a machine giving only a few blows, such as $\mathbf{M r}$. Seaton's, met the requirements of practice, because it did not reproduce anything even nearly like the conditions of actual work. Mr. Seaton stated very clearly that a few days' work on a machine would mean some millions of repetition of stress. If that was so, where the maximum which could be obtrined by a test was thirty, it appeared to him to show that the test which had been applied had been far and away too severe; they ought to have something more nearly approaching the actual stress that the material was going to endure, such a stress that would not produce a permanent deformation, but still something that would not take millions of repetitions before giving the record. That something was wanted he quite agreed; what it should actually be, he could not say.

He would like to refer to Professor Arnold's explanation of why the fracture that the authors described went in a straight line. Professor Arnold said (page 1174) that the fracture of the contiguous crystals, as he called them, or grains, as the authors called them, was not due to cleavage. In his (Mr. Milton's) opinion it might

* Proceedings 1904, Part 1, page 116. 
possibly be due to cleavage. He had been working on another metal lately, namely brass, and in annealed brass one obtained a very large number of what he thought some people called "twin crystals." He did not think "twin crystals" was the right name, but certainly contiguous crystals could be obtained with absolutely parallel planes of cleavage, and yet the ordinary orientation of the crystals themselves might be different. For instance, if one supposed the planes of cleavage of crystals to be three planes mutually at right angles, it was easy to see that one of the cleavage planes of each of a few contiguous crystals might be parallel, whilst the other two cleavage planes of each crystal might be oriented in any possible way.

The Presidencs said he quite understood that in one plane their faces were parallel.

Mr. Milton agreed, and said that in the other two cleavage planes they were not parallel to one another, so that they might have a perfectly straight fracture going through several contiguous crystals. With regard to the fracture going through the ferrite, as Professor Arnold had said, it was to be expected it would do so because of there being far more ferrite in the structure of mild steel than pearlite. He had examined microscopically some broken steel-shafts made of ordinary mild steel, and $\mathrm{h} \Theta$ found the minute cracks that had branched off from the actual fractures had almost invariably followed the ferrite, exactly as the authors said. They had largely avoided the pearlite, and had very rarely gone across the pearlite grains.

Sir William H. White, K.C.B., Past-President, said he had read the interesting Paper with great care, and the discussion so far had gone on lines which were likely to add to its value. But he would like to come back to the point of view which the users of the steel should take. The analyses and suggestions in the Paper were no doubt of great importance to the steel maker. It was a singular fact that two gentlemen representing users of steel should have produced a Paper, the greatest value of which would probably be to the steel maker. The authors aaid in the Paper (page 1148) "The majority of 
(Sir William H. White, K.C.B.)

steel users require that they shall be able to use an ordinary steel as supplied to them." It appeared to him, however, that as the steel supplied must clearly have very different qualities for different purposes, it followed that no universal test put upon the steel by a user could possibly fulfil all conditions. He recalled a circumstance, of which he thought more would be heard in the discussion, which occurred many years ago. Mr. Yarrow had had some difficultiesfortunately they had not resulted in accidents-in regard to certain portions of quick-running engines, in the manufacture of which he was so distinguished, and he went to work to try and discover what sort of material would be best adapted to bear the particular stresses and shocks which had produced difficulty. He did not find it quito an easy matter, but he had recourse in that case to the system of "nicking," and to impact tests. Mr. Harold Yarrow was present, and had with him some illustrations of the method which Mr. Yarrow then adopted, and which he supposed Mr. Yarrow still continued to use. There was an example of a user establishing a system of tests that gave him the information he wanted; he did not want to go on continually repeating those tests, but he decided in his own mind what was the quality of steel that he would use for the future for those parts of his engines, and he obtained his information by having supplemental nick tests. Speaking broadly, he should say that if any part of an engine, or any other structure, must have nicks, or what were equivalent to nicks, cut in it, it was very desirable that there should be frequent tests of nicked specimens, but he was not prepared to say for a moment that impact tests on notched bars should be regarded as the best of all tests: really it was one of many modes of testing, necessary with certain portions of structures, and of machinery in particular. He did not think, in regard to ship structures, subject to alternating loads-those that were put in class (d) on page 1139-that tests of nicked specimens were ever likely to become common, or likely to become necessary. His experience led him to believe that the tests established-particularly the tests of working qualities involved in the. forge, and bending tests-which they had now been working upon for thirty years, met all practical conditions; but he quite agreed that there were certain fittings in 
ships on which (from their form and the work that had to be done upon them in order to make attachments) they might occasionally and usefully make tests of nicked specimens; or do as Mr. Yarrow did, decide what was the quality of the steel, when nicked and subject to impact tests, which would give them greatest endurance, and then take care they obtained that quality.

He had listened with very great interest to Professor Arnold's remarks; his history of the progress of the terminology of the microscopic work in steel was most instructive, for this reason; again speaking as a user, he had learned several times over the terminology of various periods, but life was too short to overtake the changes in terminology which accompanied these discussions, and they came back in the end to the facts. He believed that now gentlemen like Mr. Milton, Mr. Seaton and his colleague, and others who were users of steel, were taking up the position of the microstructure of steel, some simpler and perhaps general terminology might be arrived at which would be more adapted to ordinary minds. There could be no question whatever that good had come out of the Alloys Research, conducted under the auspices of the Institution, and by individual workers like Professor Arnold and Mr. Seaton, quite apart from differences in the terms which might be best employed to describo phenomena. They had been enabled to look more into the heart of things; they could now associate phenomena which had been obscure with conditions of structure of which formerly they were ignorant; and, although it was perfectly true that the bottom of the mysteries had not yet been reached, he thought no one could look back at the work done by the Alloys Research Committee over a long term of jears without feeling that many of the mysteries had disappeared, and those who came after would probably solve the others.

Mr. Harold Y Yarrow stated that some experiments on nicked specimens were carried out by Messrs. Yarrow, the results of which had been published,* and some specimens showing the actual results

* "Engineering," 18 April 1902, page 513. 
(Mr. Harold Yarrow.)

FIG. 47.

Apparatus for Testing Nicked Specimens (Yarrow).
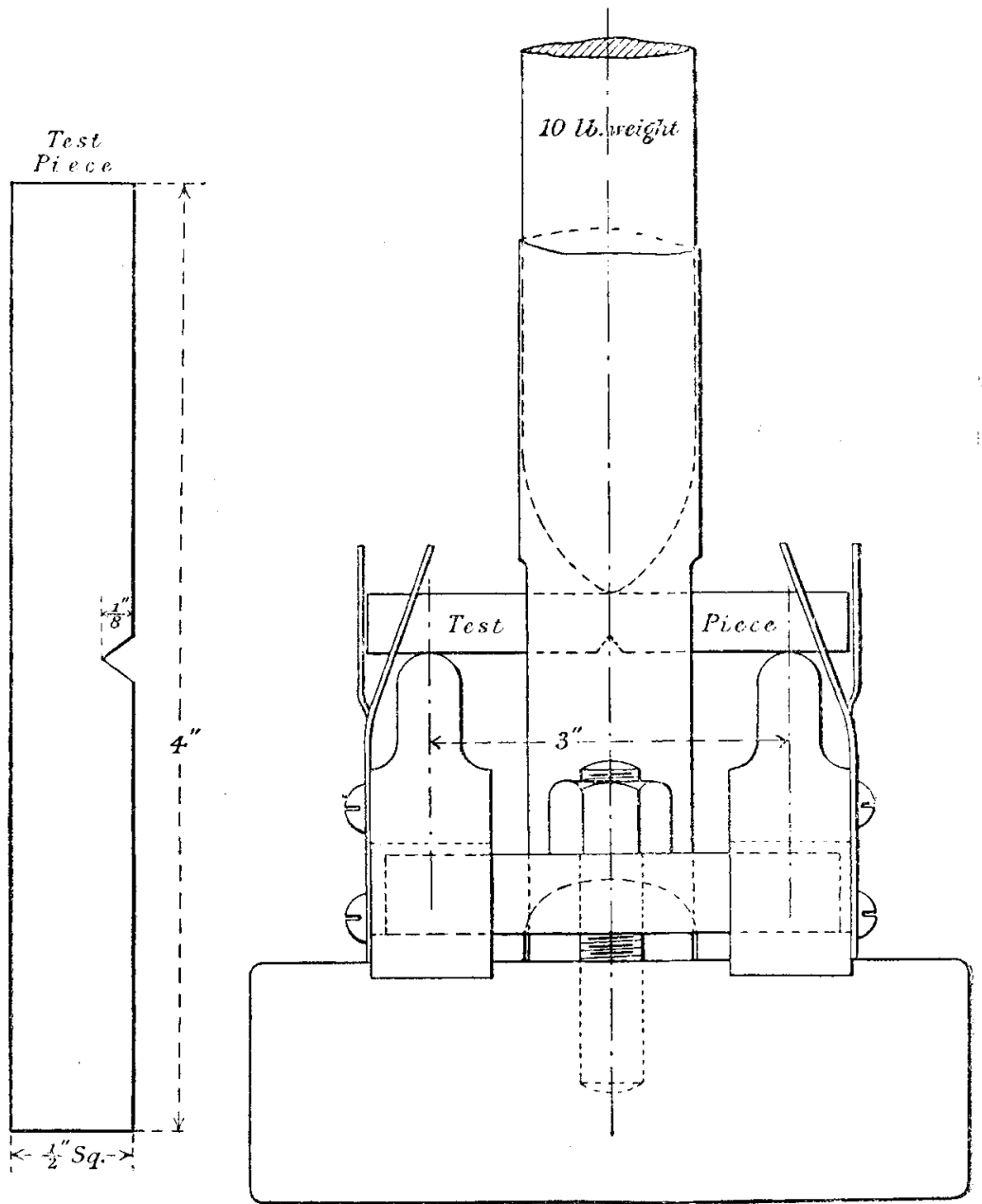
of the test were exhibited on the table. [He then demonstrated the working of the apparatus, which was shown in Fig. 47 (page 1184).] It took a specimen 4 inches long, $\frac{1}{2}$ inch square, and 3 inches between the supports and a weight of $10 \mathrm{lbs}$. was allowed to drop 18 inches.

Dr. T. E. Stanton thought there was some reason to doubt whether the result of impact testing to destruction did, after all furnish the best measure of the resistance of the material to withstand shock. He presumed that what engineers required to know was the proof resilience of the material they were going to use, that is, the maximum amount of work which might be put upon it without impairing its strength. The question then arose: Was the proof resilience always the same proportion of the total resilience in all materials, and if so, what proportion? It must be borne in mind in that connection that the proof resilience of the material could be determined in a testing machine with the aid of a good extensometer. If they took a piece of steel and carefully determined $f$ its elastic limit in lbs. per square inch, and also $E$ the value of Young's modulus for it, then the proof resilience in tension of the material was $\frac{1}{2} \frac{f^{2}}{E^{2}}$. This expression represented the maximum amount of work which could be put on the material in inch-lbs. per cubic inch. For mild steel the value of this would be approximately 50 . If reference was made to a very interesting Paper* by Professor W. K. Hatt, of Purdue University, a description would be found of a very elaborate impact-testing machine, and a Table was also published giving the total resilience in tension of various samples of mild steel. The figures for the total resilience, that is, the total work done in breaking the steel, varied from 9,000 to 17,000 inch-lbs. per eubie inch, so that the quantity which an engineer required was something like $\frac{1}{2}$ of 1 per cent. of the total given in those experiments. Yet he thought-and $h_{\theta}$ believed all engineers who had studied the question would agree -that this quantity did represent the maximum amount of work which that material would stand, so that he ventured to suggest

* " Engineering," 4 July 1902, page 28. 
(Dr. T. E. Stanton.)

that it would have been more valuable to engineers to determine if possible the proof resilience of the material, instead of the enormously greater quantity obtained from the impact test to destruction.

It was an interesting and disputed question as to whether the result obtained from the statical test, such as he had described, would agree with the result of an impact test. A few experiments had been made at the National Physical Laboratory lately, to see if there was such an agreement. A piece of steel of fairly high quality was used, that is, one in which the elastic limit had a perfectly definite value-78,000 lbs. per square inch, and in that sample of steel the value of the proof resilience was 104 inch-1bs. per cubic inch. Taking the same bar, and putting it into an impact-testing machine which had just been erected, and subjecting it to loads of gradually increasing magnitude, it was found that with a blow of approximately 210 inch-1bs. per cubic inch, there was a distinct set on the specimen. He had no doubt that, with more refined methods in mensuring the deformation, the agreement would be still nearer, that is, it would be found that there was a permanent set under a blow considerably below that in amount, but of course the experiments were not conclusive so far.

Mr. Seaton enquired whether it was a notched bar.

Dr. Stanton replied in the affirmative, saying that the bar was screw-cut all the way along, which he took to be a very notched bar. He thought it was interesting to point out that, if there was that agreement, then possibly the theory of which so much was heard nowadays, that there was a strength property of materials, which could only be discovered by impact tests, might possibly have to be modified; but if it had to be modified, or given up, that would not detract from the value of impact testing, and he thought the authors should be congratulated on having bronght the subject forward.

Professor Thomas Torner said he agreed with what had fallen from some of the previous speakers as to the value of the kind of 
test which had been employed by the authors of the Paper, and he thought the members owed them a debt of gratitude for directing attention once again to the importance of shock tests. There was, of course, no one test which would answer for all sizes and for all metals. There might be a difference of opinion as to the suitability of a test of such a kind for some particular purposes, but if they wished to get information as to the general physical properties of the metul, there could be no doubt as to the value of a shock test; and it was a great advantage to have a simple form of apparatus, so that it was not necessary to have large specimens or expensive equipment. A number of other forms of apparatus had been introduced which were intended to accomplish the same thing. Many of the members were familiar with the work of M. Pierre Breuil, prablished by the Iron and Steel Institute, and issued in a separate report in connection with the last volume.* Breuil introduced a machine for impact-tests, very similar in principle but somewhat larger than the one the authors had employed, and Breuil was of the opinion that, on the whole, nicking the bars was not necessary. $\mathrm{H}_{\theta}$ (the speaker) was inclined to think that, if a rapid result could be obtained with a small machine, nicks should either be avoided, or should be of a definite standard size and pattern. In connection with cast-iron, a very useful form of apparatus for impact tests had been introduced by Mr. W. J. Keep, of Detroit, and had been largely used in America; there were several in use in this country too. In that machine there was a swinging weight, practically a hammer swinging from a given height, and giving a definite blow, the work corresponding to which was, of course, well known.

He had been very much interested in two of the points referred to by the authors and the previous speakers. The first was as to the question of the direction of the fracture, and its selecting the ferrite in preference to the pearlite. He remembered some years ago having in his hall a tesselated pavement, which was unfortunately subjected to considerable shocks. Pavements were intended merely to be walked upon, but at times furniture was moved about upon

* Journal, Ifon and Steel Institute, Supplement, rol. 65, page 76. 
(Professor Thomas Turner.)

them, and all kinds of things happened, which produced considerable shocks. The pavement was made up chiefly of two kinds of bricks, one of which was darker in colour and harder than the other, as shown in Fig. 48 (page 1189). The soft bricks always cracked first, and the cracks in the case of a hard blow tended to go along through several of the soft bricks, as shown at $a$. In reference to the statement by the authors that fracture frequently passed through the centre of the ferrite areas, and nearly in a straight line, it might be pointed out that Osmond had made some interesting observations with high magnifications of grains of ferrite. He remembered that in one of Osmond's illustrations, with deeply etched ferrite and a magnification of a thousand diameters, there was a definite cubical structure within the grain. There could be no doubt as to the correctness of Osmond's observation on this point, as it had been confirmed by others, and they had obtained the same structure at the University of Birmingham. He saw no reason why fracture should not pass through the junctions of the cubes in what was to all intents and purposes a straight line, through the centre of the grain, or in any other direction, as determined by the hardness of the pearlite round it, as illustrated in the diagram, Fig. 49.

The authors had referred to what they called a well-known fact that iron and steel-and he believed they said other metalsexpanded at the moment of solidification. He knew that was generally stated, but he was not prepared to accept it as a wellknown fact. There was no doubt that different metals behaved in different ways while they were cooling from the casting temperature to the ordinary temperature of the air. The usual case cited was that of cast-iron, which was said to expand at the moment of solidification, but, as Mr. Keep had proved, with grey iron an expansion took place after it was solid. If the iron was very grey, there were three definite expansions, and these expansions were not within the range of $\mathrm{Ar}_{1}, \mathrm{Ar}_{2}$, or $\mathrm{Ar}_{3}$, but were higher, the temperature having been determined by Mr. Hudson, his assistant, in a certain case, as being $1,115^{\circ}, 953^{\circ}$, and $860^{\circ}$ C. $\left(2,039^{\circ}, 1,747^{\circ}\right.$, and $1,580^{\circ}$ F.). $\mathrm{He}$ believed Dr. Moldenke had also made observations in the same direction, the temperature at which the expansions-took place being 
well over $1,000^{\circ} \mathrm{C}$., when the metal was allowed to cool slowly He only mentioned that as showing that cast-iron and steel behaved in a different way.

The authors had given a very interesting diagram on page 1156 showing that the pearlite, or pearlite steel, expanded and contracted more than the ferrite. There was practically a straight line in the diagram. [Mr. Seaton said it was slightly curved.] He was going

F1G. 49.-Diagrammatic representation of a Ferrite grain with fracture passing through the centre.

Fig. 48.

Tesselated Pavement.


to draw attention to the fact that though, through a short distance of $300^{\circ}$ or $400^{\circ}$, the lines were practically straight, when higher temperatures were reached, the curve became much more sharp.* The authors were dealing with the lower part of the curve, which was very nearly straight. Had they continued further they would have found the curve bent more, and it would have supported their argument that the difference in expansion and contraction would be more at the high temperature than at the low temperature, with

\footnotetext{
*For diagrams, see "Lectures on Ironfounding," page 118.
} 
(Professor Thomas Turner.)

which they had to deal; but at the same time he was not quite convinced that they had given the true explanation.

He would like to say a word or two about other metals that were used by engineers, and their expansion and contraction with heat. The point he wished to emphasize was that a thick piece of iron or steel or other metal, as the case might be, when passing from the fluid state to the ordinary temperature, did not contract to the same extent, or in the same way, as a thin piece. If two bars, say 1 foot or 2 feet long, were cast side-by-side, and one was 1 inch square and the other $\frac{1}{8}$-inch square, and they were allowed to cool, it was found in most metals that there was a fairly uniform curvo of contraction like that to which he had previously referred. In other metals, such as steel or cast-iron, there were curves showing intermediate expansions while contraction was going on. In the case of east-iron, it would be found that the small bar would ultimately contract more than the thick bar. In the case of steel it would be found that they contracted more nearly alike, but that the thin bar usually contracted more than the thick bar. In the case of copper, tin, aluminium and a number of other metals, it would be found that the thick bar contracted more than the thin bar in passing from the fluid state to the ordinary temperature. With most metals, the contraction, or "shrinking," of the thick bar was the greater, while the thin bar contracted least, which was the opposite in iron and steel. In alloys, if one took the case of brasses, when one added zinc to copper and obtained an alloy, it was found that the contraction (or "shrinkage" as he preferred to call it) was reduced by alloying, and that was no doubt one reason why alloys were found so advantageous for many purposes when a sharp impression was desired. A familiar example of that was the case of type metal. In antimony there was a fairly large shrinkage; in lead there was rather a low shrinkage, but when a relatively small quantity of antimony was alloyed with lead, it not only reduced the total shrinkage, but at the same time it was found that the thick bar and the thin bar had, as nearly as possible, the same shrinkage, and there was no doubt that was one reason why typemetal was found so suitable for the purpose for which it was employed. 
There were a number of interesting questions in this connection upon which further information was required, and these were at present receiving attention.

The President said he would now adjourn the discussion to the next Meeting on Friday, 16th December, when he hoped the authors would be able to be present and reply to the whole discussion. $\mathrm{He}$ hoped they would not find it inconvonient to be present, because on that occasion the evening would be devoted to a kindred subject, so that all those gentlemen who were particularly interested in the completion of the discussion would be able either to join in the discussion or to listen to further revelations concerning the microscopic structure of steel, and its behaviour under impact and other tests. The Paper which would then be read would harmoniso with the one read that evening, so that it would be no hardship to the authors of the Paper, nor to the gentlemen who were interested in the subject, to cut the discussion into two. He had been very anxious to make a few remarks himself, because he took some views in direct opposition to those set forth in the Paper as to the best way in which metals should be tested. He would abstain from going into the question that evening, but he would express his opinions on impact tests as compared with statical tests after they had heard the Paper by Messrs. Sankey and Kent Smith.

Discussion on Friday, 16th December 1904.

Mr. Sidney A. Houghton thought the fact that the results as to quality given by the impact tests very frequently varied from those given by tensile tests had created a great deal of doubt in some minds as to the real value of the former. But if the matter was looked at from a broad point of view and the ideal way of testing a piece of metal considered, it would be found that this was to break the test-piece by the same stresses as those to which the material it belonged was subject in 
(Mr. Sidney A. Houghton.)

practice. Considering first tensile tests and judging them by that standard, it would be seen that the authors had estimated that only about 4 per cent. of the parts in an ordinary engine were subject to pure tensile stresses; but he thought the best proof was to examine the fractures in breakdowns of machinery, when it would be found there was practically never any reduction of area nor any elongation. That showed, he believed, conclusively that the strains that produced fracture in machinery were very seldom those that occurred in the tensile testing machines. It might be argued that the ductility as shown by the tensile testing machine was a sufficient guide as to the suitability of the material, but what was the object of the upper limit in most specifications for steel? He thought that limit was placed there as the result of the experience engineers had had, which showed that the ductility as represented by the tensile test was not by itself a sufficient guide in most cases.

Turning to the notched-bar test, there were many examples in which the stresses in actual work were the same. He would take as an example a part of machinery which probably broke more than any other part, namely, propeller shafts. These shafts had liners on them, the effect of which was to produce a discontinuity of strength very similar to a notch, and when in a heary sea-way, or when the ship was in ballast, the shaft was exposed to very severe blows, and the same effects were obtained as were produced in the notched-bar test. He had no hesitation in saying that a very large proportion of the fractures of propeller shafts were due to these causes, and not to anything similar to tensile test stresses. It was a rather curious fact with regard to propeller shafts that several engineers specified iron shafts instead of steel. Now, even good iron was inferior under the tensile test to mild steel, but under the impact test it was superior. It therefore secmed as if by groping through experience they had got to the same conclusion as was now given by the impact tests. The authors stated that these tests were not applicable to boiler plates, and looking at it from the theoretical point of view they certainly were not, but ho could give a very remarkable case showing that even in the case of boiler-plates they were of some use. 
Some little time ago, when a new large boiler was being tested by hydraulic pressure, the shell-plate split right across. It was scarcely necessary for him to say that that was a very serious occurrence indeed, and a very unusual one. Tensile tests and chemical analyses were made in order to ascertain what was wrong with the plate, but all the results obtained were quite normal, and there was nothing to show that the material was not good. He had had the opportunity of examining some of the plate under the microscope, and although there were some peculiarities in the structure, he was quite certain that no one would have objected to the plate on account of its structure, especially taking into account the other satisfactory tests. It occurred to him that perbaps the impact test might show something, and through the courtesy of Mr. Yarrow, Mr. Marriner very kindly made four impact tests from the plate. Two were taken from the outer half of the plate with the notch on the outside, and two from the inner half with the notch on the inside, that is, about the middle part of the plate as rolled. One of each of those was tested in the normal condition, and one of each was heated to a bright red in a non-oxidising flame and allowed to cool slowly. The dimensions of the test pieces were those of Messrs. Yarrow's standard size, and the machine was the one they usually employed, so that the results were quite comparable with the other tests made by them. With that quality of steel about thirty blows, he was told, was considered a fairly good result to obtain, and the number that should be expected from average specimens. Of the pieces that were tested in the normal condition, the outer piece broke with three blows and the inner piece with five blows; indeed, both began to break almost at the first blow. Of the two that were annealcd the outer broke with twenty-six blows and the inner one with eighteen blows. The impact test therefore showed that the plate was brittle, although the tensile test and chemical analysis gave no indication whatever of it. $\mathrm{He}$ thought, if there were no other results beyond that, the impact test was one which must be taken into account in finding out brittle material.

With regard to the microscopical portion of the Paper, everyone ought to feel grateful for the careful way in which the authors had traced the manner in which a fracture passed through mild steel; 
(Mr. Sidney A. Houghton.)

but they seemed to treat it too much from the point of view of a crystalline break. If it was regarded as a rapid tear instead of a break, the explanation was much more simple, as the fracture would naturally pass in the way they described without requiring any elaborate theories to explain its course. With regard to mild cast steel, examples of which were given in Plates 136 and 137, the most essential point was that it should be properly annealed. This was unfortunately very frequently not the case, and in nine cases out of ten where bad results were obtained from mild cast steel, it would be found that the annealing had not been sufficient, generally owing to the temperature not having been high enough. The examples given by the authors were very clear cases of this defect; the steel had not been properly annealed, and that should be borne in mind when looking at the results.

There was another point with regard to the impact tests with respect to mild steel, namely, that frequently there were small segregations which contained a great deal of sulphur and phosphorus, and which were very brittle. With the tensile test the remainder of the steel marked the defective parts to a great extent, but with the impact test if the bottom of the notch happened to come on the brittle parts, a very inferior result would be obtained. This might or might not be an advantage, depending on the purpose for which the steel was required, but it should be borne in mind when a very bad result was obtained from the impact test that it was well to examine for this cause. Impact tests of mild steel were very valuable, as showing brittleness due to very large crystals arising from overheating. He did not say that all steel with large crystals was brittle, but the tensile test was a very poor judge of bad steel in that respect, and the impact test was much better. Lastly, although he was a firm believer in the latter tests, before anything could be done to get their importance recognised they must be standardized. It was possible to compare tensile test pieces, although they might be of different sizes, and get a very fair idea of one result with another, but with the impact test unless the pieces were the same size and the notch the same and everything else was similar, no comparison whatever could be formed. 
Mr. Michael Longridar, Member of Council, said he agreed with the last speaker in his wish that the shock test should be standardized. He felt sure that everyone with much experience of breakages of steel must have seen some for which no cause could be assigned. By way of illustration he might mention some which had come under his own notice. The first was connecting-rod bolt 3 inches diameter. It broke not in the thread but about $\frac{3}{8}$ inch below it, in the cylindrical part where there was no reduction or change of diameter; the crack had started at the circumference probably at a scratch left by the turning tool and gradually extended through the bolt at right angles to the axis.

The second was a link, coupling the crosshead to the centre in the beam of a beam engine. It was machined out of a solid steel billet. It broke clean across through one side, a little below the top bend, where there was no oil-hole or change of sectional area. The load upon it was only about 4000 lbs. per square inch. The third was a boiler plate which, after working about fifteen years, cracked for a length of 24 inches near to one of the double-riveted longitudinal seams. There was no sign of heavy caulking or hammer marks to account for the fracture. Strips cut from it were tested and found satisfactory. The broken pieces were afterwards sent on to Professor Arnold for analysis and microscopical examination, who found no fault with them except that they possessed "potential brittleness."

He mentioned these, which were only examples of many other unaccountable breakages, as evidence of peculiarities in steels which neither tensile tests nor chemical analysis seemed able to detect. Whether the shock test would give all the supplementary information needed seemed very doubtful, but it was such an easy test to make, and the apparatus and preparation of specimens would cost so little, that if it were possible to standardize both test pieces and apparatus he thought the test would be widely used, and probably much useful information would be got from it. Before standardizing the apparatus, it would be necessary to consider not only the weight of the hammer but also that of the anvil, and also to decide whether the specimen should be broken at one blow and the work expended 
(Mr. Michael Longridge.)

in breaking it measured as in Captain Sankey's apparatus, or whether a smaller weight or less fall should be used and the resistance of the piece estimated by the number of blows required to break it. The size and shape of the specimen also needed careful consideration. It should be so small as to be easily cut from broken pieces of all kinds, and, on the other hand, large enough to prevent small errors in dimensions having undue effect. It should be of such a shape as to be cheaply, easily, and accurately prepared, and in these respects he thought a round bar distinctly preferable to a square one, particularly when the specimen was intended to bear several blows before final fracture. If the edges of a square bar were at all rough and sharp, an incipient fracture would be more easily started than if they were quite smooth and slightly rounded, and an incipient fracture once started the piece would give way with fewer subsequent blows than if it were quite sound. The sharpness of the notch would probably also influence the resistance of the piece. For these reasons he thought a cylindrical test piece, 4 inches long and $\frac{3}{4}$ inch diameter, with a Whitworth thread cut in the middle, would probably give more uniform results than the $\frac{1}{2}$-inch square sections with $\frac{1}{8}$-inch notches which appeared to be the present standards. He was inclined to think, however, that a shorter and smaller test-bar might be more convenient.

Mr. F. W. Harbond said the Paper on Impact Tests read on the previous occasion, and the one at the present meeting, were two of the most important read before the Institution for a long time. That tensile tests were, when taken alone, not altogether satisfactory, he thought would be admitted by everybody who had anything to do with steel. This was thoroughly recognised in many cases, and in the case of rails and axles impact tests were made on large masses by most engineers, and were considered far more satisfactory than any tensile test : but of course they were very expensive, and if as reliable results could be obtained with small bars, it would be infinitely better in every way. The real point was this : was a notch test on a small bar a reliable test which could be compared with similar tests on different steels, so that given a certain result it could be said the material was good, or the material was bad. 
Some three or fonr years ago a most elaborate series of experiments were made by Brinell and Wablberg, ${ }^{*}$ in which they took nine steels and subjected them to various heat treatments, about eighteen in all, afterwards testing them in every possible way, and amongst other ways by impact tests. The impact tests were somewhat different from those given by Mr. Seaton and Mr. Jude. Instead of a bar being supported on two bearings and the blow being struck in the centre, one end of the bar was held in a vice, a portion $2 \cdot 16$ inches long projected beyond the nick; a weight was allowed to fall on the projecting portion, the height of the drop being increased after each blow, until the bar fractured. The results were so very. erratic and so very different from those given by Mr. Seaton and Mr. Jude that he thought the meeting should have its attention called to them. In the case of a raw 0.16 carbon steel, the foot-lbs. were 470 ; in the case of 0.34 they were 195 ; that was to say, the 0.34 steel showed a resistance to shock equal to nearly half that of the 0.16 carbon steel. Mr. Seaton's results showed that a 0.2 carbon steel was five times as tough as a 0.3 carbon. The bars of Brinell, when they were annealed, showed a still less difference between the low and higher carbon steels. With $0 \cdot 16$ carbon the result was 361 foot-lbs., and with 0.34 carbon 274 foot-lbs., a difference roughly of a little over one-third. That is to say, increasing the carbon from 0.16 to 0.34 only reduced the toughness one-third, instead of something like five times, as shown by the tests of Mr. Seaton. This showed, as had been pointed out by Mr. Houghton (page 1194) the great importance, if impact tests were to be used, of standardizing the test.

Another important point brought out by Brinell was that on annealing at $750^{\circ} \mathrm{C} .\left(1,382^{\circ} \mathrm{F}.\right)$ the bars found no improvement; on annealing at $800^{\circ} \mathrm{C} .\left(1,472^{\circ} \mathrm{F}\right.$.) they found a certain improvement with their impact test. At $900^{\circ}$ C. $\left(1,652^{\circ}\right.$ F.) they

* Journal, Iron and Steel Institute, 1901, Vol. ii, page 234. The programme of heat treatment is given on page 235 , where bars are treated as rolled, annealed, hardened with water, hardened with oil, and hardened with lead, the various annealings and hardenings being done at a number of different temperatures, as recorded. After heat treatment in these various ways, the bars were subjected to all kinds of mechanical testing. 
(Mr. F. W. Harbord.)

got their best results, and at $1,200^{\circ} \mathrm{C} .\left(2,192^{\circ} \mathrm{F}\right.$.), the temperature which ruined steels, they found their impact tests were better than with the raw material. That, he thought, was confirmed somewhat by Captain Sankey's results. On turning to Plate 148, on the soaking of steel at $1,200^{\circ} \mathrm{C}$., there was found there a bar (No. 27) on which the impact test was distinctly better than in the raw steel. Before generalising as to the value of the impact tests, in view of the fact that the steel which had been ruined by heat treatment gave a better impact test than the raw material, he thought they should pause a little, because it was clear that it was only the impact test which gave better results. The Arnold test showed the steel was practically ruined, and the tensile and other tests showed that it had deteriorated in every way.

Another very important Paper bearing on the subject, referred to by Professor Turner at the previous meeting (page 1187), was a Paper by M. Breuil, read before the Iron and Steel Institute, which was a most exhanstive research on the value of notch-tests versus unnotched bars. He came to the conclusion that there was no virtue in notching the bar at all, and that it was far better to make the drop test on a plain bar. How far that was so, he, Mr. Harbord, was not prepared to say, but that was the result $\mathbf{M}$. Breuil arrived at after a very elaborate series of tests.

There was one matter brought forward by Professor Arnold he should not have referred to, had it not been so widely reported in the technical Press that he thought it was liable to give a false impression. Professor Arnold had said that he had buried the term "eutectic" long ago. If so, it had had a most wonderful resurrection, and he believed was now practically used by all scientific metallurgists. Professor Arnold spoke further of the terms-_" saturated," "super-saturated," and " unsaturated," and said that the term "saturated" was exactly the same as eutectic. It was not the same. A "saturated" steel meant a steel with 0.89 per cent. of carbon, and "over-saturated" steel was a steel with more than that percentage. The term "saturated" conveyed absolutely nothing as to the condition of the carbon. If it was said that the steel consisted entirely of the eutectic, not only did this give the 
percentage of the carbon, but it showed the condition of the carbon, and that the steel was more or less in an annealed condition, and also conveyed a conception of the whole physical structure of the steel, which the mere term saturated or unsaturated did not. This was a matter which, in his opinion, should never have been introduced into the diseussion, as it did not fairly arise out of the Paper. The string of terms Professor Arnold referred to had never been adopted at all by any school of thought; they were simply suggested by one or two very eminent metallurgists as possible alteruative terms which might be used, and with the exception of two or three had never been generally accepted or used. Professor Arnold, however, gave the impression that they were in general use by those who were unable to admit that his terms "saturated" and " unsaturated" conveyed a clear conception of the complex changes induced by variations in chemical composition and heat treatment. He thought in a society of Engineers such subjects should not be introduced in the discussion on practical Papers, but when they were, there was no alternative but to refute misleading statements.

Whether the so-called solution theory was correct or incorrect was a comparatively small matter; it had made poople think and work, and a great deal was owing to those who originated the hypothesis, and started a vast amount of research work all over the country. These attempts, in the discussion of technical Papers, to discount one's scientific opponents, especially in their absence, by means of cheap ridicule, he considered were greatly to be deprecated.

Mr. Bentram Blount could only hope to be useful in what he said by a few generalitios. It seemed to him, as one accustomed to what he might term the pathological side of steel, eminently desirable to add to the methods of testing anything which was competent to show, if in those individual specimens of steel which had been found in practice to be diseased, to what that disease was due. It was necessary, in fact, to assign a cause, and in consequence of the need of assigning a cause and giving a distinct opinion as to the disease which the specimen was suffering from, it was necessary to invoke every possible means. For years past it had 
(Mr. Bertram Blount.)

been customary to subject steel to well-devised mechanical tests, and analysis had been constantly employed, and more lately microscopical work had been done. All those were very useful. Recently shocktests had come into fairly common use. As far as his knowledge of what had been done with the use of shock tests went, the shock test would show something of value.

What he was particularly concerned with was the heterogeneity of steel. He broke a lance with Professor Unwin a year or two ago on that very point, when the Professor presented before another Institution a great number of very valuable tests of steel as examined in the ordinary testing machine. The notion in his mind was that it was wrong to regard mild ordinary structural steel, the steel engineers constantly used, as a homogeneous material. He regarded structural steel-he quoted the phrase he employed then-as a bundle of muscles and nerves. If he was forced to define his terms, he would call the muscles those molar constituents which one could almost see without the aid of magnification or under a lens, and the nerves the actual microstructure. He did not wish to push the parallel too far; he simply meant that there was a molar structure and a micro-structure, and both must be considered. He ventured to think that the microstructure, from its beauty and great significance, had perhaps carried engineers a little farther than reason dictated. The molar structure must be also considered, and, if he might conclude that very elementary sort of reasoning, he would say that he believed the use of impact tests of any kind-the form really did not matter as long as some standardization was arrived at-was to display the influence of that molar strueture.

With regard to the standardization of the impact tests, even in so simple a matter as determining the mechanical properties of steel as ordinarily done in a testing machine, where it behaved pretty well as a plastic material, there was still some little debate as to the size of the test-pieces, areas, rate of pull, \&c. ; and those things, although they were being settled, were not absolutely determined. With the much more difficult matter, the standardization of a method of testing by shock, it was not likely at present that any complete concordanco 
would be found, and a great deal more work had to be done and many more experiments made before standardization was arrived at. But that standardization had to be made and would be made, he had not the faintest doubt. When it was made in combination with a proper consideration not only of the micro but of the molar structure of the metal, he believed there would be means of determining the origin of the disease of those pathological specimens, to the examination of which he particularly referred.

Mr. Seaton said that, as time was very short and as there was really much to say, his colleague and himself would contribute a further reply in writing to most of the criticisms, and he would confine himself to making a few remarks on what had dropped from some of the speakers. In the first place, on behalf of Mr. Jude and himself, he had to thank the members for the vote of thanks they had passed. The greater portion of the Paper was due to Mr. Jude, for what Captain Sankey had said of his colleague he could also say of his, that his colleague had done the work and he had done the editing. Mr. Jude had taken a great interest in the subject from the time he was a pupil of his own, years ago, due in a great measure to what he had told Mr. Jude he had seen in Professor Arnold's laboratory. He was very pleased Professor Arnold had taken part in the discussion, for it was really from Professor Arnold that he first learnt how the structures of metals might be examined.

Like Mr. Longridge, he himself had had an unfortunate experience with steel boiler-plates. A boiler constructed of steel supplied by one of the most eminent makers in the kingdom failed under water pressure before the test point was reached. The shell split from end to end in a very curious way, and, strange to say, it did not commence at a rivet-hole. In fact, it seemed to avoid the rivetholes and go between them. These plates had been surveyed and tested by a Board of Trade Surveyor. They were analysed chemically by four or five chemists ; mechanical tests were made in the tensile testing machine by two or three independent gentlemen; and Professor Arnold examined the structure of the metal microscopically. The chemical tests showed nothing particularly 
(Mr. Seaton.)

abnormal, and the mechanical tests were satisfactory; and all that Professor Arnold could say was that there was a slight excess of sulphur, and that in places it was in a dangerous form, but not so bad as to account for the accident. That was one of several mysterious fractures of steel that had come under his notice.

Much had been said about the notched bar. Both Mr. Jude and himself were engineers, and, not having a very large amount of time at their disposal, had to content themselves with a method that appealed to them as being satisfactory for their purposes which could be compassed in the time they could give to it. At the same time, neitler Mr. Jude nor himself ran away from the belief that the notched bar was the sufficient criterion test of steel subject to shock. What they maintained was that a material which in every-day practice was subject to dynamic stress-he used the word stress for want of a better one-should be tested by a similar action. They had found in every-day practice that accident was often the result of a very large number of comparatively small shocks repeatedly applied, not of one big shock that would come on the machine, or of the one big shock that would come as in Colonel Maitland's experiments. These things he alluded to were generally broken after a number of comparatively small shocks-at all events shocks small by calculation-had been applied some hundreds of thousands of times. They believed that under those circumstances it was better to test the bars by a comparatively small shock applied a considerable number of times; hence their weight was very much less than that of Mr. Yarrow's. They also thought that their testing machine was a finer discriminator than Mr. Yarrow's, inasmuch as with his very heary weight a comparatively good steel might fracture, and he supposed did fracture-the experiments showed that on the previous occasion-with one blow. They thought that only the very worst description of steel should part at one blow, and hence they differentiated lower grades of commercial steel than could be done with Mr. Yarrow's machine. He agreed with Mr. Longridge that the round section test-bar was probably better than the square, and had in addition the adrantage of cheapness; it was easy to make, and he thought answered perfectly well the purpose for which it was wanted. 
Mr. Harbord had asked (page 1197) whether very much variation had been found. With the exception of various bright cold-drawn bars which were introduced into the engineering market some seven or eight years ago, they did not find much variation in the same bar. Their practice was to make at least two tests from a bar, one at each end of it; sometimes an additional one in the middle in a bundle of rods of the same make and quality; they had found sometimes very large variation in one rod from another, but practically none between parts of the same rod. In the case of the bright steel, they had often found great variation in the same bar. There was no doubt that what was said in the Paper further justified the use of the notched bar, for in nearly every engine member there was something analogous to the nick, although perhaps not always so sharp and pronounced as found in their test-bar.

Mr. Stromeyer had given an illustration of the breaking of the screw shaft of a ship with a casing on it; the casing ending abruptly indeed was quite analogous to the notch in the test-bar. There was bardly a part, especially in the moving parts of an engine, which was not more or less nicked, as necessitated by the design; and coming to microscopic conditions, the scratches from a file or the tool marks of a turning tool, if looked into carefully, were all notches, and sometimes notches of considerable magnitude. So that steel in general every-day use was in the notehed state.

$\mathrm{He}$ quite agreed with the speakers who had alluded to standardization. The Paper simply said that by the special machine certain steels stood a certain number of blows; it did not insist that, because one steel stood twenty-four blows and another six, that one was four times stronger than the other. But they did maintain that the one that required the larger number of blows was very superior to that which required the smaller number. Further investigation would no doubt enable some form of standardization to be observed, and some inventor-possibly the President-would introduce a machine that would be taken as a standard one for such tests. In their machine the fracture was due entirely to shock. In the case of a bar secured in a vice and sticking out 2 inches, and having a weight dropped on it, fracture would be partly due to shock and 
(Mr. Seaton.)

partly due to bending. That was to be deprecated. It was somewhat analogous to the question which had been raised on Captain Sankey's Paper, as to whether it was vanadium or chromium that had so much improved the steel-they would not know whether it was the shock or the bending that killed it. The term "fancy steel" was used, not to cast any slur or slight on many of the good steels that had been brought forward, but only to distinguish them from the every-day ordinary steel that was obtained by sending to a merchant or steel works an order for so many bars of steel. Sir William White, according to the drift of his argument, had held there was no need, having once ascertained that the steel was right, to continue the process of testing. He was afraid if Sir William was the works manager of some of the big engineering concerns he would find it necessary to keep testing, for the uniformity expected was not always obtained. He thought it was better to satisfy oneself in this simple and inexpensive way than to assume that one would get always what one ordered. The test was a very cheap one and easily made, so that there need be no difficulty on that score.

He again thanked the Institution for the manner in which they had received the Paper. He hoped that their end would be accomplished, which was primarily to bring before the Institution the subject of shock testing with a viow to discussion and further thought, rather than to pose as discoverers of something new. They certainly knew in a vague way of Mr. Yarrow's experiments, but not the results. They thought in giving not only the method but the results of their tests, it would open the subject for further consideration, and that object he thought had been accomplished.

\section{Communications.}

M. Pierre Bredil, Head of the Metallurgical Department of the Conservatoire National des Arts et Métiers, wrote that, in his opinion, Messrs. Seaton and Jude had given too much importance to the method of making shock tests on notched bars on two supports. 
$\mathrm{H}_{\mathrm{e}}$ had recently shown * that to make the same notch in identical bars of various metals did not place them at all in the same condition for experiment, seeing that when a notehed bar was broken its shape was not altered in the plane of the notch but outside of this notch, and in proportions which varied according to the nature of the metal and the shape and depth of the notch.

In order that the notched bars might be of use in comparing metals, it was necessary at once to know the laws which governed the reunion of the geometrical shapes of the notch and of the nature of the metal. This would compel one to make an elaborate research in each case, analogous, for example, to that which has brought about, in tensile tests, the foundation of the law of similarity. This law of similarity could be stated as follows: equal stresses brought about equal deformations in test-pieces geometrically similar in the same metal, as in the example of compression and bending of smooth bars; and it was on this that one relied for accepting and for judging metals, whatever the dimensions might be. It was hardly ever contradicted, that is to say, one always met with it in metals previously studied; it led to numerical coefficients constant enough even with dimensions varying to an important degree; it was, therefore, a clear test (he did not say unique) of valuation of metals, and it was necessary to find a similar one for notched bars before admitting them into the tests of metals.

He had been able to show elsewhere that considerable variations in the proved results between two metals very similar in appearance, by this method of notched bars, could be explained by several reasons. Firstly, because one was wrong, in his opinion, to measure in a shock the work performed, apparent or real, without knowing how the work was distributed in the piece tested; all depended on that. To be able to establish a comparison between two different qualities, it was evidently necessary to reduce them to unity. This was everywhere done in science. For example, one would not pay the same price for a 300-ton Buckton testing machine as for a 10-ton machine, simply because they were of the same type. It was, however, what one did with the notched-bar tests.

* Journal, Iron and Steel Institute, 1904, No. I, page 416. 
(M. Pierre Breuil.)

Putting these considerations out of the question, as the writer believed them and as be had endeavoured to prove them, if the notched-bar test did not yield other information than ordinary bars it did not remain less true that the Paper was interesting, especially concerning the method in which the authors made known the distribution of the various stresses in parts of machines. He would not take exception to this, after they had so clearly apportioned the stresses; he would take only one exception to their views, that was, that having clearly defined the various kinds of stresses, they should have decided upon impact tests alone for the study of metals.

If, for example, they had carried out tensile tests at the same time as these shock tests, giving complete diagrams, they would have been able, perhaps, to explain why the tests showed such large deviations in the numbers of blows required to break their bars of similar steels. The writer would draw attention on this point to the fact that no two metals of the same elasticity, of the same maximum load, of the same elongation, were able to give very different diagrams. Before condemning tensile tests it would be better, in the writer's opinion, if a deep study of the subject were made, to see, for example, how elongation in tensile tests of various metals was distributed up to and beyond the maximum load; there were some metals which showed a very long falling curve after the maximum load. Others gave a short and rapid one. How would these metals appear in the shock test? 'This test should be made.

The writer had once made some tests on Bessemer and Martin steel of the maximum load and elongation, and he had proved that the test-pieces did not stretch at all in the same way in all directions on the fracture. For instance, copper, which was a very ductile metal, hardly fragile, showed a very rapid falling curve immediately; ductile aluminium bronzes, which stretched 50 per cent., also had an equally rapid fall. This point had, in the opinion of the writer, been somewhat overlooked.

Notched-bar tests exaggerated small differences between metals and without a fixed law, and this fact militated against deductions of true value being obtained; it was much better to work on unnotched bars, but, as in the experiments with ductile metals the bending 
tests were slow, it was preferable, in his opinion, to make shock tests by tension on smooth bars. Would anything novel be found? The writer was inelined to doubt this. $H_{\Theta}$ found that the drop-weight used by the authors was rather small, and it was the reason probably why one found enormous differences in the results obtained with similar metals, seeing that only a fraction of the work performed by the falling weight was absorbed by the test-bar, the remainder being taken up by the anvil block and in other ways. It was evident that these losses, although possibly small, combined to increase the difference between the metals in consequence of their elasticity, the extent of which was not stated.

The writer thought that the method employed, namely, that of repeated blows, was not so good a method as the authors appeared to imagine, as there was a risk that the same spot would not always be hit by successive blows. Therefore irregular stresses in the metal were produced at different parts of the notch. This fact was of less importance in smooth bars. It was necessary to take great precautions in shock tests in order to be able to draw correct conclusions. A shock test on two supports had a drawback, inasmuch that the bar was struck at a point which had a tendency to break, and therefore deteriorated it. This was why it was better, in the writer's opinion, to make tensile tests by shock, which method had the advantage that each unit of metal was subjected to about equal work. The usual shock test on notched or unnotched bars was, in his opinion, a rough test which could be made without any measurements; then, however, one must look upon it only as a qualitative and not a quantitative test.

With reference to the curve in Fig. 7 (page 1150) it was of the same class as that which the writer established in his Paper to the Iron and Steel Institute (1904, Supplement, Plate 21). It showed that in steel having more than 0.35 per cent. of carbon very little work was necessary to cause rupture, and below 0.35 more and more work was required; but in the latter case far more metal was deformed than in the former case, and when all was taken into consideration the conclusion might be reversed.

Where Messrs. Seaton and Jude deserved congratulation was in their study of the spread of fracture through the metal; there were 
(M. Pierre Breuil.)

in this very interesting and, he belicved, novel indications which he hoped would bring to future experimentalists discoveries towards the progress of one's knowledge of metals.

Mr. JoHn Hardisty wrote that he was decidedly in accord with Messrrs. Seaton and Jude's desire, as expressed on page 1144, for the usual tensile and bending tests to be supplemented by shock tests for all material which would be subjected to shocks on becoming part of a machine or an engine. Since Professor Heyn read his valuable Paper before the Iron and Steel Institute on notched test-pieces, much had been done by other experimenters in this direction, but the sizes of specimens, shape and size of notches had been so variable that the results obtained by different observers were not readily comparable. What was now wanted was: (1) a standard size and shape of test-piece; (2) a standard notch; and (3) a standard drop-testing machine to be adopted both by steel makers and steel users, preferably, he thought, one with a light tup and of sufficient height to enable specimens to be broken at one blow if desired, but in which the height of the drop could be regulated at will, just as in the droptesting machines commonly used for testing rails.

The conditions of testing, namely, weight of tup, height of fall, size of test-piece, size and shape of notch, distance between supports, and shape of nose of tup, should always be the same for similar steels, so that tests made at different works, and with differently treated specimens, might be readily compared. The noteh to be of any account must be sufficiently deep and preferably sharp at the bottom. Last year the writer tested a number of $\frac{1}{2}$-inch square pieces of "Lily" brand Swedish steel having a tensile strength of 22 tons per square inch, with over 50 per cent. elongation in 2 inches. The $V$ notch was 1 millimètre deep and 1 millimètre wide, and it was clearly too small for this kind of steel, as under repeated blows of a 15-lb. tup falling 30 inches, the notch spread out, and there was practically no difference between the number of blows required to break the notched and unnotched specimens. Professor Heyn, in his Paper, pointed out the importance of the depth and shape of notch, with regard to the size of test-piece and weight of tup. 
If tests were to be broken at one blow, it was of paramount importance that the energy expended in producing fracture should be measured and recorded by some simple means, but this was just where the difficulty would come in, and where errors of observation would be made. It would be interesting to learn how the authors proposed that the energy should be measured. On account of the difficulty of measuring the energy with any degree of accuracy, he was inclined to prefer the drop test requiring several blows to produce fracture; the deflection for each blow could then be recorded, as in rail testing; or for the first blow only if the test-piece was reversed after each blow. The Table on page 1147 would appear to require some explanation as to the condition of the bars $a$ and $b$ for each of the four materials, the quality of which, as shown by the impact tests, differed enormously in the first three cases.

The last sentence in Part I (page 1148) seemed to require more from the steel maker than could reasonably be expected, or than was necessary in ordinary every-day work; but if material of the highest shock strength were required, it should be specified, and then no doubt the maker would (at a suitable price) produce it either by the Coffin or Stead-Richards process, or perhaps by careful oilhardening as suggested by the authors. The statement (page 1150) that steel "containing 0.2 per cent. carbon will be at least five times tougher to resist shock than those having 0.3 per cent. of carbon," was one which fow steel makers would be ready to accept without ample experimental evidence; and indeed, if it were true, why had steel containing 0.30 to 0.35 per cent. of carbon been used for so many years for guns, and why had there been so few accidents with the inner tubes?

The improvement by oil-quenching referred to in the Appendix had been fully recognised for many years by gun-makers and others, but had not, except in a few instances, received adequate attention from mechanical engineers. The writer particularly drew attention to this point in a Paper on "Steel for Guns" which he contributed to "Industries" in 1886, where the following passage occurred :- "The increased strength of steel obtained by proper oil-tempering should be more generally taken advantage of by mechanical engineers, such 
(Mr. John Hardisty.)

things as shafts, spindles, connecting-rods, piston-rods, crosshead and crank pins might, with advantage, be oil-tempered."

The following experiments which he made in June 1903 confirmed the authors' experience as to the value of oil-quenching when applying the shock test on notched specimens:-

\section{TABLE 2.}

\begin{tabular}{|c|c|c|c|c|c|}
\hline $\begin{array}{l}\dot{\tilde{g}} \\
\stackrel{\Xi}{\Xi} \\
\dot{z}\end{array}$ & 范 & 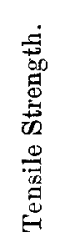 & 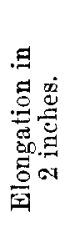 & 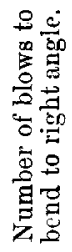 & Remarks. \\
\hline 1 & As rolled & -- & $\begin{array}{l}\text { Per } \\
\text { cent. }\end{array}$ & 19 & Broke easily while straightening. \\
\hline 2 & Annealed & $27 \cdot 9$ & $34 \cdot 6$ & 14 & $\left\{\begin{array}{c}\text { Broke while straightening, but not } \\
\text { quite so easily. }\end{array}\right.$ \\
\hline 3 & $\left\{\begin{array}{c}\text { Water- } \\
\text { quenched }\end{array}\right\}$ & $32 \cdot 6$ & $28 \cdot 2$ & 22 & $\left\{\begin{array}{l}\text { Required four blows with hand- } \\
\text { hammer to straighten, and broke at } \\
\text { first drop blow. }\end{array}\right.$ \\
\hline 4 & $\left\{\begin{array}{c}\text { Oil } \\
\text { quenched }\end{array}\right\}$ & $31 \cdot 9$ & $31 \cdot 2$ & 20 & $\left\{\begin{array}{l}\text { Required six blows with hand-hammer } \\
\text { to straighten, and then stood eight } \\
\text { drop blows to bend it again to a } \\
\text { riglit angle, when it broke. }\end{array}\right.$ \\
\hline
\end{tabular}

'The test-piece, notch, and drop-testing machine were as already described.

The toughening effect of water-quenching ordinary bridge steel had for years been observed by steel inspectors. When the soft bend test was good the water-quenched one was almost invariably so, and very frequently when the soft bend test had fractured, the waterquenched one was satisfactory.

Bright " rolled" bars were referred to (page 1166). These bars were however not "rolled" bright. They were produced from ordinary hot-rolled rounds which were pickled, cold-drawn, and then cold-reeled, to make them round, smooth and straight. They were sold in this condition, and were largely used for stud-making, \&c., in automatic machines. All the three above-named processes, even 
when the greatest care was exercised, increased the hardness and brittleness of all kinds of steel more or less ; and excessive pickling would make any steel rotten. The brittleness produced by all three processes could, however, be completely removed by annealing, but as this would destroy the bright surface, it was not done, and it was therefore not surprising that bright bars were found to be more or less rotten and never so tough as ordinary hot-rolled bars.

Effects of Pickling.*-The following tests which the writer made in 1896 and subsequently, fully exhibited tho changes due to pickling and cold-drawing :-

Tensile Elongation Strength. in 8 inches.

5 Samples of British basic open-hearth steel

"annealed" averaged . . . . . . . $\quad 24.42027 .06$

The same bars "pickled" averaged . . . . . 24.94 12.08

They all broke in the grips, and were therefore again

put in the testing machine to try and break them

between the dots with the following result . . $25 \cdot 4 \quad 13 \cdot 58$

Four of them broke on dot and the other in grips, showing that pickling had slightly raised the tensile strength (4 per cent.), and reduced the elongation by one-half, and the samples were so brittle that even the very small centre dot was sufficient to start fracture.

* The pickling of bars and tubes as usually carried on was a very crude operation, performed by labourers having no knowledge of chemistry or metals; a wooden bosh was used, and contained at the outset about 1 part strong sulphuric acid to ahout 12 parts water (by volume); the bath was then heated by steam to hasten the action. The bars or tubes were then put in until the bosh was full, and remained there until the scale was removed. If the pickler considered the operation was taking too long, he added more acid and used more steam for hcating. The defects of this system were that:-

I. The temperature was variable.

II. The strength of solution was veriable.

III. The time of immersion-and this had a most important bearing on the brittleness produced--was variable; the last bars to go in were the first to come out, and the thicker thie scale the longer it took to remove. The time also depended on the nature of the scale.

There were therefore three variables, any one of which might affect the material. It was no wonder that some of the bars were more brittle than others. After removal from the pickle bath, the bars were washed, dried, oiled, and then cold-drawn and reeled. 
(Mr. John Hardisty.)

The following tests were made to try the effect of re-annealing after pickling :- -

Tensile Elongation Strength. in 8 inclies.

3 Samples of same material as above "annealed" Per sq. in. Per cent.

averaged . . . . . . . . . $\quad 22 \cdot 1 \quad 30 \cdot 27$

The same bars "pickled" averaged . . . . . . $22 \cdot 6 \quad 15 \cdot 3$

(Two broke on the dot and one between the dots.)

The same bars "re-annealed" averaged . - . $21 \cdot 6 \quad 28.6$

Showing that re-anncaling restored the steel to its normal condition.

Effects of Pickling and Cold-Draxing.--The following tests were made on Swedish open-hearth acid steel, "Lily" brand :-

$$
\text { * Containing }\left\{\begin{array}{lll}
\mathrm{C} & 0.12 & \text { per cent. } \\
\mathrm{Si} & 0.003 & " \\
\mathrm{~S} & 0.01 & " \\
\mathrm{P} & 0.025 & , \\
\mathrm{As} & 0.026 & , \\
\mathrm{Mn} & 0.38 & ,
\end{array}\right.
$$

An annealed test from the billet showed

Tensile Elongation Streurth. in 2 inches. Per sq. in. Per cent.

4 Pieces, after being worked up and "annealed,"

$$
28 \cdot 0 \quad 48
$$
averaged .

$21 \cdot 23 \quad 58 \cdot 3$

12 Tests from the same bars, after pickling and colddrawing, averaged . . . . . .

\section{(All broke in grips)}

To avoid breaking in grips the pieces were reduced for

a length of 2 inches and re-tested, when they averaged . . . . . . .

The same bars re-annealed averaged . . . . . $21 \cdot 25 \quad 53 \cdot 1$

These tests were almost identical with those made before pickling and cold-drawing, and showed conclusively that the brittleness produced by those two operations was completely removed by re-annealing. Bright bars should never be used for parts subjected to "shock" unless previously annealed, or trouble would almost inevitably follow.

* For this analysis the writer was indebted to Mr. J. E. Stead, F.R S. 
Mr. JAMLS HoLDEN wrote that he regretted he had not been able to complete some tests he had been making in connection with the subject of Impact Tosts. The impact machine shown in Fig. 1 (page 1136) was, to his mind, of so crude and elementary a type as not to permit of any delicacy of result, as the damage which would be done to the structure by a series of blows from a machine of the kind would go far in his opinion to interfere with the accuracy of the result. Professor Unwin, in speaking at the Institution at the discussion subsequent to the Sixth Report of the Alloys Research Committee on the Heat Treatment of Steel, mentioned that if one notched a bar and broke it in the ordinary way in a tensile machine, the results were wholly of the same kind as if one notched a bar and broke it by impact.* Professor Unwin did not, however, state that, in a case where the bar was notched and subjected to tensile strains, there was a very remarkable increase in the load per square inch in the case of the bar so notched over one that had not been so notched, and tests that the writer had made in this direction did not entirely bear out Professor Unwin's experience as to the absolute absence of elongation under test.

For some years past at Stratford they had had a method of testing by alternating stresses, one ond of the test-piece being held fixed in dogs, while the other was slowly moved in such a manner that the centre was continually describing a circle of $\frac{1}{4}$ inch diameter. Professor Unwin had also very properly called attention to the fact that, in the ease of notched-bar tests, they were undoubtedly of considerable value, but they required standardizing.

Mr. E. G. IzoD wrote that the method of testing by impact was one in which he had had some experience, as he had been using a one-blow machine for some years; and the results which had been obtained in actual working tests proved that this form of test must be seriously considered with a view to its more general adoption. It could only be a question of time before it was specified as an essential test of materials. Messrs. Seaton and Jude had used a

\footnotetext{
* Proceedings 1901, Part 1, page 126.
} 
(Mr. E. G. Izod.)

repeated-blow method of testing; and it was, perhaps, rather early to make any definite comparison between this test and the test with one blow. It might be interesting to note, however, that the writer's experience with an impact machine which broke a notched bar at one blow and measured the actual amount of energy absorbed by the test-piece coincided with the experience of Mr. Fremont, who was one of the first to advocate this form of test.

A curve had been drawn (page 1150) showing the decrease of shock strength with increase of carbon content. The writer had found, however, with the single-blow machine that somewhere in the region of 0.4 per cent. carbon the shock strength increased and fell away again towards the higher carbon percentages; one example of this was shown in the Sixth Report of the Alloys Research Committee.* In order to compare the two methods of impact testing, the authors kindly sent some samples for test with the writer's machine, and the results were given in Table 3 (page 1216), while they were shown diagramatically in the curve, Fig. 50. From this it would be seen that there was a distinct relation between the two methods of test employed, though the resistance to shock was in some cases very much more marked in one machine than in the other.

The writer could cite innumerable instances where the impact testing-machine had given a ready solution to problems of apparently inexplicable fractures, but they were outside the scope of these remarks. Summarising, however, all the tests of materials which had been made on the single-blow machine, it was a noteworthy fact that in every case of investigation into a material that had broken in actual use, there had never been a test made which had shown other than a low-impact figure. A question had been raised as to the length of time taken in making repeated-blow impact tests, and it was in this particular that the single-blow machine had an advantage over other machines, as it was quite easy to test one sample a minute, even when the tests were carried out by an unskilled operator.

The writer would like to say that, though hardly agreeing with the methods of tests proposed by Messrs. Seaton and Jude, he agreed

* Proceedings 1904, Part 1, page 171. 
entirely with their endeavours to impress upon engineers the vital importance of impact testing ; when once this test became well known and properly applied, it would be found that the users of special high-class steel could obtain equally satisfactory results from a

Fig. 50.-Comparative Breaking Tests with Single-Blow Machine (Izod) and Repealel-Blow Macline (Seaton and Jude).

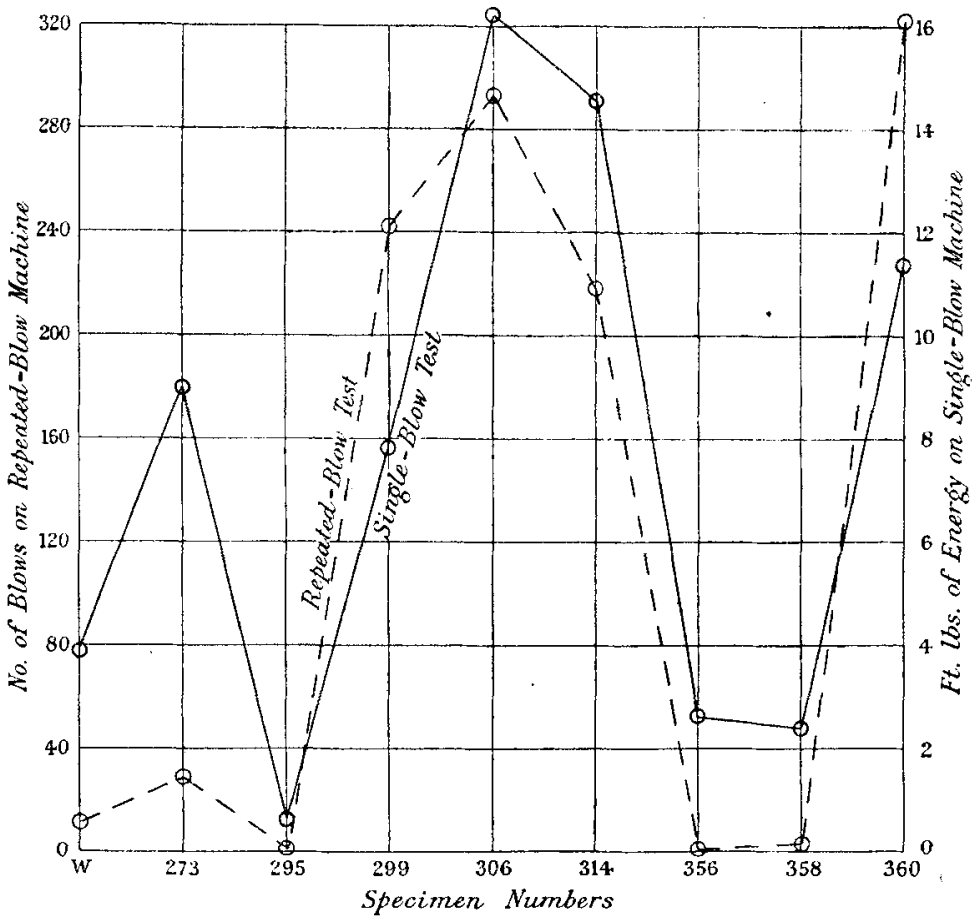

cheaper material altogether, for the very simple reason that the impact test was a quick and ready means of ascertaining which of the cheaper materials was suitable for the work the steel had to perform. If the majority of fractures were caused by shock, as the writer fully believed, it was hardly wise to test for another quality altogether and neglect the shọck strength, which was unfortunately the rule in nearly all present-day specifications. 
(Mr. E. G. Izod.)

\section{TABLE 3.}

Comparison of results obtained by Single-Blow Method (Izod)

and Repeated-Blow Method (Seaton and Jude).

\begin{tabular}{|c|c|c|}
\hline $\begin{array}{c}\text { Specimen } \\
\text { Number. }\end{array}$ & $\begin{array}{c}\text { Single-Blow } \\
\text { Machine. } \\
\text { Energy absorbed in ft.-lbs. }\end{array}$ & $\begin{array}{c}\text { Repeated-Blow } \\
\text { Machine. } \\
\text { Number of Blows. }\end{array}$ \\
\hline W & $3 \cdot 9$ & 11 \\
273 & $9 \cdot 0$ & 29 \\
295 & $0 \cdot 6$ & 1 \\
299 & $7 \cdot 8$ & 241 \\
306 & $16 \cdot 2$ & 293 \\
314 & $14 \cdot 5$ & 217 \\
356 & $2 \cdot 6$ & 1 \\
358 & $2 \cdot 4$ & 323 \\
360 & $11 \cdot 4$ & 3 \\
\hline
\end{tabular}

Professor H. Lm Chatelier wrote that he had read with much interest Messrs. Seaton and Jude's Paper, and regretted that business prevented him being in London to take part in the discussion. He believed that these researches would have a considerable influence in spreading more and more the opinion that the tensile test alone was insufficient to determine completely the quality of extra-mild steels, being unable to show definitely the amount of brittleness, according to the nature of the work to which they were put. The photo-micrographs showing how the fracture passed through the grains of ferrite were particularly instructive. This detailed study of the phenomenon, by making the structure of metals better understood, would make the authors' conclusions more acceptable, which, based on the fracture trials alone, would have been difficult to explain. 
In the discussion on the Sixth Report of the Alloys Research Committee, the writer particularly insisted upon the advantage which trials by impact on notched bars would have for completing the investigation.* It was satisfactory to see that this had already been taken up by the two authors of the present Paper.

Mr. Percr Longmutr wrote that the impact test adrocated in Messrs. Seaton and Jude's Paper did undoubtedly act as a "selector" by picking out good from bad material, as "the results most fully showed. The variations in shock strength obtained from steels of similar tensile properties met with ready confirmation, but the authors gave no clue as to the source of this variation. Thus the experimental work of the Paper showed that impact fracture followed a particular route, but this feature did not explain why identical. steels, as judged by analysis and tensile results, varied in their shockresisting properties.

A statement at the foot of page 1155 read :- "Above $\mathrm{Ar}_{3}$ it is selfevident by any theory that there can be no mechanical action which can have any bearing on the present question, for neither of the characteristic cold components of the steels under discussion can have yet taken final form." To the writer there appeared various possible influences operating at temperatures above $\mathrm{Ar}_{3}$, which left a distinct impress on the cold metal. Burnt steel formed one example. One distinctly important source of variation was found in the temperature of casting. Commencing with an exceptionally high casting temperature, results something like those given in Table 4 (page 1218) were obtained.

The extensibility of these steels was worth examination. The analyses of the four were identical ; they were poured from one large ladle at intervals of a few minutes, commencing with an exceptionally bigh and finishing with the lowest safe casting temperature. In any case where the casting temperature was excessive, similar results were obtained, but mild steel was in practice seldom cast at too high a temperature. The obvious danger was in casting at too low a

* Procecdings 1904, Part 1, page 94. 
(Mr. Percy Longmuir.)

\section{TABLE 4.}

\begin{tabular}{|c|c|c|c|c|}
\hline $\begin{array}{c}* \\
\text { Analysis. }\end{array}$ & $\begin{array}{c}\text { Yield point. } \\
\text { Tons per } \\
\text { square inch. }\end{array}$ & $\begin{array}{c}\text { Maximum } \\
\text { Stress. } \\
\text { Tons per } \\
\text { square inch. }\end{array}$ & $\begin{array}{c}\text { Elongation. } \\
\text { Percentage on } \\
\text { 2 inches. }\end{array}$ & $\begin{array}{c}\text { Reduction } \\
\text { of area } \\
\text { per cent. }\end{array}$ \\
\hline C 0.29 & 12.5 & 24.2 & 9.5 & $18 \cdot 0$ \\
Si 0.07 & 13.5 & $27 \cdot 2$ & $24 \cdot 0$ & $32 \cdot 3$ \\
Mn 0.16 & 13.3 & 27.0 & 12.5 & 17.5 \\
S 0.07 & 13.2 & 25.5 & 8.0 & 12.0 \\
P 0.06 & & & & \\
\hline
\end{tabular}

* Journal of the Iron and Steel Institute, 1904, No. I, page 420.

temperature, a feature intensified by the fact that tensile tests apparently did not discriminate when the molten steel had not been overheated. The following results, Table 5 (page 1219), obtained from a steel in three conditions were given as an illustration.

It would be noted that tensile properties throughout were fairly similar, but the results obtained by Professor Arnold's alternatingstress test showed decisive brittleness in the steel cast at a low heat. The time interval between Nos. 97 and 98 was only two minutes, that is to say, No. 97 was cast, the crucible stood on the floor for two minutes, and No. 98 cast from the same crucible. Annealing and forging conditions were absolutely comparative, and the only variant was that of casting temperature.

The writer offered these remarks not in comment on the Paper but solely to call attention to one possible source of disease, and he ventured to think that the authors' impact test offered one medium whereby this type of disease might be detected.

Messrs. Seaton and Jude wrote, in further reply to the discussion and communications, that the impact test itself having been the chief topic of diseussion, their remarks would be mainly directed to this point. Professor Arnold (page 1173) drew attention to the necessity of keeping the rate of repetition of the blows or the alternations of stress uniform; with this they fully agreed, especially for high 
TABLE 5.



* Journal of the Iron and Steel Institute, 1904, No. I, page 428. 
(Messrs. Seaton and Jude.)

rates of repetition. This idea had been followed in all their impact tests, and by practice and the help of an assistant to reverse the specimen after each blow, the rate of repetition departed very little from uniformity. That rate has been about thirty blows per minute. In the Paper referred to by Professor Arnold, they understood him to say that his preliminary experiments pointed to the conclusion that the resistance to rupture under his particular kind of alternating stress appeared to be inversely proportional to the rate of alternation. From the many miscellaneous experiments made by the authors, and from service observations, they were led to think that the progression was geometrical and not arithmetical. The common ratio remained to be found for standard conditions, and they hoped that Professor Arnold would be able to determine it from the further experiments he was carrying out.

It was obvious that the slower the rate of repetition, the greater was the permissible time variation from absolute uniformity, so that with a slow-blow machine such as theirs, any little variation from a uniform rate was quite negligible. In fact tests had been made with a number of bars from adjoining metal at different rates. The difference in the number of blows registered was so very small as to appear to be independent of the rate. In other words, the necessary time of "recovery" was apparently much less than one or two seconds. What the average recovery-period was they could not say with certainty, but they were of opinion that under ordinary circumstances its influence was not great under 200 or 300 repetitions per minute, so far as it concerned tests of the kind under discussion.

A misconception appeared to have arisen as to the crudeness of their impact machine. It was certrinly crude in the sense that it yet remained to be determined whether it was the best arrangement or not to compare different grades of steel; and also in the sense that it was not encumbered with elaborate mechanism of more or less utility; and further that it was not polished up and made to look pretty. But for comparing similar grades of steel, crudeness was not present to any important degree; and it was the comparison of the impact strengths of different samples of the same grade to which they had endeavoured to draw attention quite as much as of different grades. 
Professor Turner (page 1187) supported them in observing that the average user did not want an expensive and delicate machine, if a cheap one would tell him what he wanted to know. Whether he required a knowledge of the brittleness of the steel depended upon what he used it for, and was a matter for his personal judgment; but they had given a few reasons and suggestions that a knowledge of the brittleness was really more often required than not, especially in some branches of engineering. Now their machine actually did possess the essentials of obtaining reliable comparative results. The most important part-- the anvil--was a comparatively heary mass of steel (about $36 \mathrm{lbs}$.) and stood on the cast-iron beds of the test house; these beds were themselves supported on a 3 or 4-foot concrete bed. Thus in their case a considerable amount was given to start with, although solidity to this extent was not necessary; in any cnse, a heavy anvil was desirable so that as much of the energy of the blows as possible could enter the specimen. A light anvil and a thin wood floor were therefore highly undesirable. If an impact machine of this type was ever adopted, the anvil part-the very part that ran the risk of being ignored-should be standardized.

The question of size and impulse of the machine was naturally a matter on which opinions might be very divergent; but after all, the element of convenience must enter into the problem. Everyone would probably agree with Mr. Milton and Mr. Houghton that the best test of a metal was when it was made under service conditions. The one-blow machine was as far removed from the average condition of actual service in machinery as a shock machine could be. It was this fact that such machines broke all steels with one blow, that rendered them defective as shock testers. It appeared that with really tough steels, that were also fairly soft, such as the ordinary low-carbon steels for instance, the blow might be far too much adulterated with a pure tension effect. It might be contended that the tension was a mere after-effect and that shock fracture always started first. There was, however, much reason to doubt this. The authors would call attention to the additional photographs, Figs. 51 to $51 \mathrm{D}$, Plate 146, showing the fractures of the same material by the one-blow machine and by their machine, and also as made by a 
(Messrs. Seaton and Jude.)

heavy rapid blow with a hand hammer. The steel used for this illustration was intentionally soft and tough, and happened to be the first of the three basic samples referred to on page 1164. It would be observed that, in the one-blow fractures, there was conspicuous evidence of a pure tensional strain, especially in the root of the nick, but that in the fracture caused by 293 blows, there was an entire absence of this appearance, as was also the case in actual service (see Figs. 36, 36A, 368, Plate 144). These photographs (Figs. 51 to 51D) were intentionally of low magnification, so that the lines of strain might be more clearly seen. High-power magnification confirmed the absence of drawing-out in the multiblow fracture, as would be seen by the illustrations in the Paper, many of them being taken close to the start of the fracture. They did not insist that no tension effect whatever presented itself with their machine, but it was certainly ultra-microscopic and probably quite negligible. A tensional strain always appeared to be present in any bar on the side confines, but its effect on the value of the shock strength must be very small, unless the bar be unduly narrow, which was not the case either with Mr. Izod's or their bars.

It did sometimes happen that the multiblow fracture started in a compound fashion, which ultimately became simple, but the tensional effect in the vicinity of the nick bottom was not visible. Mr. Izod's machine was not to be condemned entirely; in fact for most purposes it was a valuable indicator of the general toughness of steel, and it had done much useful service. But with its particular mass and impulse, its capacity as a true shock measurer was limited to the harder or more brittle steels. On the other hand, the authors' particular machine was not suitable for the higher grades of steel (non-structural), and a multiblow machine suitable for comparative tests with those steels would require a much less drop than 2 feet, and perhaps a less weight than 6 lbs. as well. If then the evidence above were accepted, it followed that for a one-blow machine the energy of the blow must be in excess of what might be termed the "structural inertia" of the whole section, or else a false value of the shock strength would be registered. This would largely account for the lower relative values for tough and brittle steels as registered by 
that machine, and also for the local inconsistencies. They therefore ventured to submit that if a system of shock testing were established, let it be shock alone as far as possible. One had the tension test; let it also remain unadulterated. It would appear from the above that the real shock strengths brought to bear in actual service, the blows applied being comparatively minute, would be relatively much more accentuated than even the curve (page 1141) represented it.

Suppose for example that the one-blow machine gave 10 and 2 foot-lbs. respectively, absorbed by two specimens, and that their machine gave 240 and 20 blows respectively, the real relative service values would be not less than 12 to 1 , but greater, perhaps 40 to 1 , or some other ratio.

It was quite feasible to design a machine that would give a very large number of less severe blows than did their machine-several thousands per minute-so that the test-bar might break in a reasonable time. The machine would undoubtedly be more complicated and more expensive than theirs. At present, however, a very rapid-blow machine was not what was wanted, for one could conceive it possible that the "recovery factor" might be vastly different with differently constructed steels, and consequently, the common ratio referred to at the beginning of these remarks, would have different values. A shock strength value embodying the property of recovery was no doubt of very great importance, but a very rapid impulse machine might be as far removed from the conditions of actual service as the other two types, and an embodiment of the wrong recovery-factor might lead much further astray in the other direction. On the whole, therefore, it was advisable, if possible, to keep the recovery-factor out of the test altogether, and reasons have been already given why their machine carried out this idea to all intents and purposes.

There was, however, another objection to the one-blow machine, which was that such a machine always gave practically the same blow; the important question then arose as to the selective magnitude of this blow. It was manifestly unfair to test all steels hard, soft, high and low tension, with the same blow, principally for the reason that the magnitude of the blow then bore a different ratio in each case to the structural inertia. 
(Messrs. Seaton and Jude.)

The only legitimate plan, they thought, was that suggested by M. Barba some time ago, where the height of the blow was varied to suit the steel, and, by a series of test-bars (assumed of equal strength) to take the height that just produced a short fracture (no tonsional effect) as a gauge of the toughness. But this after all was not a very practical arrangement. Therefore the magnitude of the blow should be as far removed from the critical region as possible. A blow of generally overwhelming magnitude was not a convenient thing to manage and measure, and, apart from other reasons, the best alternative seemed to bo to make the blow as small as possible, consistent with a reasonably rapid test and the avoidance of the recovery factor.

They bad beon unable to discover any radical objection to the circular test-bar. It cost about one-fourth of the square bar, and was more easily made to standard size. The only thing to be careful awout was in setting it fair for the first blow. Mr. Izod's nicks appcared to vary considerably in depth, according to the specimens exhibited. This might not matter much, but, in their opinion, the nick part should be more precisely finished, a very easy matter to do with a shaping tool.

Mr. Harbord (page 1198) had raised the question of nickod versus plain bars. The authors had not said that plain bars were not capable of giving useful results, but they did say that with such the tests were doubtful. In the first place, it bad been agreed that most details in service were usually more or less nicked;

Secondly.-A multiple-blow test on a plain bar supported at its two ends would be rendered practically valueless on account of the general hammering or "bashing-up" the surface metal would receive on both sides. With an overhung bar a similar condition would obtain, and after a time the vice would practically hammer a nick into the bar. In any case the duration of a plain bar test would be enormous, if no appreciable bending was to be iuvolved. With the notched bar, the place where fracture started and the whole of the side of the bar that really determined the shock strength was preserved intact, Fig. 51B, Plate 146; 
Thirdly.-A single-blow test of the Izod type would introduce still more of the tension element for it to be considered a true shocktest-certainly for ductile material that was really tough. It might discriminate between really good and really bad, but that was all ;

Fourthly.-With a plain bar the position of the fracture must be more or less arbitrary (as in the tension bar), an advantage perhaps from one point of view, but a disadvantage in that a correction would have to be made for the effective leverage of the blow, which was not a case of direct shear;

Fifthly.-The endurance of the plain bar would probably depend greatly on the surface condition of the metal-scratches, minute flaws, \&c. The proportionate effert of a scratch, for instance, would be very much greater with the plain bar than with a nicked bar with the scratch at the bottom of a substantially deep nick;

Sixthly.-A plain bar would of necessity be square, thus involving extra expense.

It was better, therefore, for purposes of comparison, that the general position of the fracture were predetermined as it was by a nick. In referonce to Mr. Harbord's remarks on Brinell's experiments, the authors quite appreciated the possibility of getting a superior impact strength to the ruination of the tensile properties. Heat treatment of such an unusual description was, however, not supposed to come within the range of commercial practice, and if any heat treatment were given to steel, it was presupposed that those properties, which were useful as well as shock strength, were not spoiled. Their few experiments with ruined steel, however, indicated that the impact strength was much more likely to be rnined with the tensile strength, and therefore the remarks on page 1146 still held. But it depended on the definition of " ruined."

Dr. Stanton's remarks (page 1185) were of great interest, and bore on the vital point of the whole matter. Engineers had been taught for a very long time that the proof resilience was a gauge of the impact strength of materials. But this was just where engineers had been misled; and for the following reasons among others:

(1st) They had been taught to assume, and elasticians also assumed in connection with these matters, that the substance was 
(Messrs. Seaton and jude.)

isotropic or amorphous or in some such condition, which was precisely what steel and iron were not.

(2nd) The common interpretation of "resilience" had failed in its practical application.

(3rd) Generally sperking, the test was not delicate enough, although very delicate apparatus was required.

It was quite conceivable, in fact experiment proved it, that the resilience of a volume of metal, composed of a large number of heterogeneously formed and disposed crystalline grains of a certain average size, might be the same as that of a similar volume of metal (of similar composition) where the grains were of a much smaller or larger size. As masses, both of them were isotropic. As very thin wires of equivalent section commensurate with the size of the grain, the structure was as far removed from isotropy as it was possible to be. Now, observations on the many service fractures of the type under discussion, where the strain had been zero, were confirmatory that the fracture usually started at one or more spots of an unknown area - it might be a surface flaw - and spread gradually. (Soe Fig. 40, Plate 145.) So that, when shock entered into engineering problems (to say nothing of alternating stresses, \&c.) it appeared that one had invariably to deal with local strength and not volumetric strength so much. Local strength necessarily implied micro-structural strength or even individual grain strength, and one had a parallel case to a thin wire made of very coarse material.

It was not evident how the proof resilience as at present defined could in general be a measure of tho kind of brittleness the engineer had to deal with. It seemed as if for the same grade of steel, some such expressions as the following would be a great deal nearer the mark :-

Useful toughness $=$ Proof resilience per cubic inch $\times$ number of grains per eubic inch.

or, more conveniently-

Useful toughness $=$ Proof resilience $\times$ number of grains per field of standard microscopic magnification. 
Such an expression was, however, of limited application, and not equal to the short and inexpensive eut to a tangible idea of the brittleness given by a simple form of impact machine, which was preferably a multiblow one.

In connection with the size and configuration of the grain, the anthors did not agree with Captain Sankey's statement on page 1254, line 14 et seq. The quantity of ferrite exposed in the nick bottom would, unless the length of nick were unduly small, be very approximately the same for a given grade whether the structure were coarse or fine. Probably what he meant was " the greater the bulk of ferrite in the average grain the less the impact figure." As there expressed, the statement was not in conformity with the authors' experimental results, Fig. 7 (page 1150). Neither did little variation in the total ferrite along the nick affect the shock strength generally, as was evidenced by the broken bars and microscopic observations which indicated that the question wars one mainly of size of grain in the case of pearlitic steels. Generally speaking, referring to pearlitic steels only, it appeared to be more or less agreed that brittleness was some function of the size of the grain. Dr. Stanton's preliminary experiments indicated that the proof resilience might or might not vary with the shock strength for variations of the latter in the same grade. It was rather early to arrive at conclusions as to the first observation; but it did not look very hopeful.

The President had drawn their attention to the often neglected quantity "reduction of area." * But there was no question about the matter, so far as different grades were concerned, and Fig. 7 (page 1150) confirmed the known decrease of this factor with the increase of grade. For the same grade of steel, however, and in spite of the more or less consistent relation that appeared to exist in Messrs. Sankey and Kent-Smith's tests between impact strength and reduction of area, they must differ from the President generally as to a measurable relation existing in the ductile steels of everyday use. Reduction of area was mainly a measure of ductility or plasticity, namely, the processes represented in Plate 143.

"See Discussion on "Chrome-Vanadium Steel," page 1294. 
(Mess's. Seaton and $\mathbf{J}_{\mathbf{u} d e .)}$

If it was a measure of shock as well-for the same grade-it was only a very indirect and shadowy measure. As opposed to the President's deduction from Messrs. Sankey and Kent-Smith's results, innumerable examples had been before them where the difference of shock strength had been extreme, but where the reduction of area had been practically the same. Any deduction as to the shock strength from the reduction of area was rendered still more dubious by the fact that the differences in the reduction of areas between good bars themselves-even cuts from the same bar--might and, as often as not, did exceed the differences obtainable between good and bad bars of the same composition, Fig. 52, Plate 146. By " bad" and "good," they of course referred to their shock strength.

Table 6 showed half-a-dozen examples :-

TABLE 6.

\begin{tabular}{|c|c|c|c|}
\hline \multicolumn{2}{|c|}{ Admilalty grade. } & \multicolumn{2}{c|}{ All same size test bars. } \\
\hline $\begin{array}{c}\text { Maximum } \\
\text { stress. } \\
\text { Tons per sq. inch. }\end{array}$ & $\begin{array}{c}\text { Elongation. } \\
\text { Percentage on } \\
2 \text { inches. }\end{array}$ & $\begin{array}{c}\text { Redurtion of area } \\
\text { per cent. }\end{array}$ & Blows. \\
\hline $31 \cdot 3$ & 36 & 56 & 29 \\
$30 \cdot 2$ & 33 & $54 \cdot 2$ & 3 \\
$30 \cdot 2$ & $40 \cdot 5$ & $56 \cdot 4$ & 1 \\
$31 \cdot 7$ & $38 \cdot 5$ & $55 \cdot 8$ & 25 \\
$27 \cdot 75$ & 35 & $49 \cdot 79$ & 1 \\
$31 \cdot 4$ & 35 & $51 \cdot 6$ & 23 \\
\hline
\end{tabular}

It might readily be conceded that the reduction of area might be on the whole a little less for woak material, but that was a matter of 2 or 3 per cent. in the vicinity of 50 per cent., and therefore not enough on which to form a tangible idea of the brittleness of steel, especially when dealing with different batches. Steel makers would consider themselves very harshly treated, if condemnation or 
acceptation hung on such narrow issues. The authors' impact test did not render it necessary to quibble over an odd few per cent., and, according to the grade, a considerable range in the vicinity of the maximum shock strength might be allowed with fairness and satisfaction to both parties. A uniformity of opinion as to the value of the tension test as a criterion of brittleness did not seem to exist eren among its adrocates. On the one hand was one authority favouring the theory that the shock strength was mainly some function of a happening beyond the elastic limit, while on the other hand, another authority contended on behalf of the happening below the elastic limit. Even if anything more satisfactory were evolved on the latter theory, they feared it would, by itself, involve quibbling over odd per cents.

Professor Arnold objected (page 1176) to the authors' use of the word "eutectic." This word was deliberately selected as the most convenient one for the purposes of the Paper. Steels presented the visual appearance of eutectic alloys, and as the micro observations were purely visual, the term was appropriate, although it was suggestive of the solution theory. The expressions "liquor" and "separates out last" (page 1148) were perhaps a little unfortunate in any case, although it should be obvious from the remarks on the following pages that a literal sense was not intended in the case of steel. Both these expressions and the word "platicization" must necessarily be taken in a relative sense.

With Professor Arnold's remarks on the orientation of the grains they did not concur. His criticism on this point, however, was met by noting that the photographs and sketches, Fig. 27, Plate 142, were in two dimensions, whereas the actual fracture was in three. Mr. Milton's remarks on this point were supported by Mr. Rosenhain's recently published Paper on the "Plastic Yielding of Iron and Steel" and by the ample evidence of stepped fractures, which would be noticed in many of the author's photographs. Further, it must be remembered that etching was a process that dulled sharp edges, and that although minute stepped fractures were invisible as a general rule with the comparatively low magnification of these photographs, they might none the less exist. 
(Messrs. Seaton and Jude.)

One of the conclusions then of the whole matter was that steel appeared to possess some property which was very far from uniform, while it had others which remained constant. The question was, did the non-uniformity of this property, which appeared to be revealed by some kind of impact test, tend to render engineers liable for consequences that might be serious, or did it not? In many cases they did not know and possibly might ever remain in ignorance of the true forces at work. They had, however, attempted to show by examples and deductions that there might be a relation between the cause of some service fractures and the impact machine blows. But whether or not, the first step to take, and which, by the prevalence of the tensile test, engineers thought they had taken years ago, was to try and get uniformity in the "quality" of the same grade of normal steels, if not for articles of greatly different scantlings, at least for those of similar scantlings. And by "quality" they meant similar performance under any kind of tests whatever on two or more similar samples. Possibly the impact test after all had nothing to do with many of the complicated stresses set up in service. Nevertheless the same sized articles of the same grade should give the same test results, within limits as narrow as those demanded in the tensile test. If they started with material in a known best and uniform condition, they started fairly. They therefore must invoke the aid of the metallurgist to indicate to the steel maker how to get over the difficulty of non-uniformity, which certainly existed at present, although the question' of variation for different scantlings was admittedly a big difficulty. 
Cast Steel, illustrating the Granulation or Quasi-Crystallization of Pearlite.

Fig. 9. Vertical Illum. $\times 60 \mathrm{~d}$.

Fig. Io. Oblique Illum. $\times 60 \mathrm{~d}$.
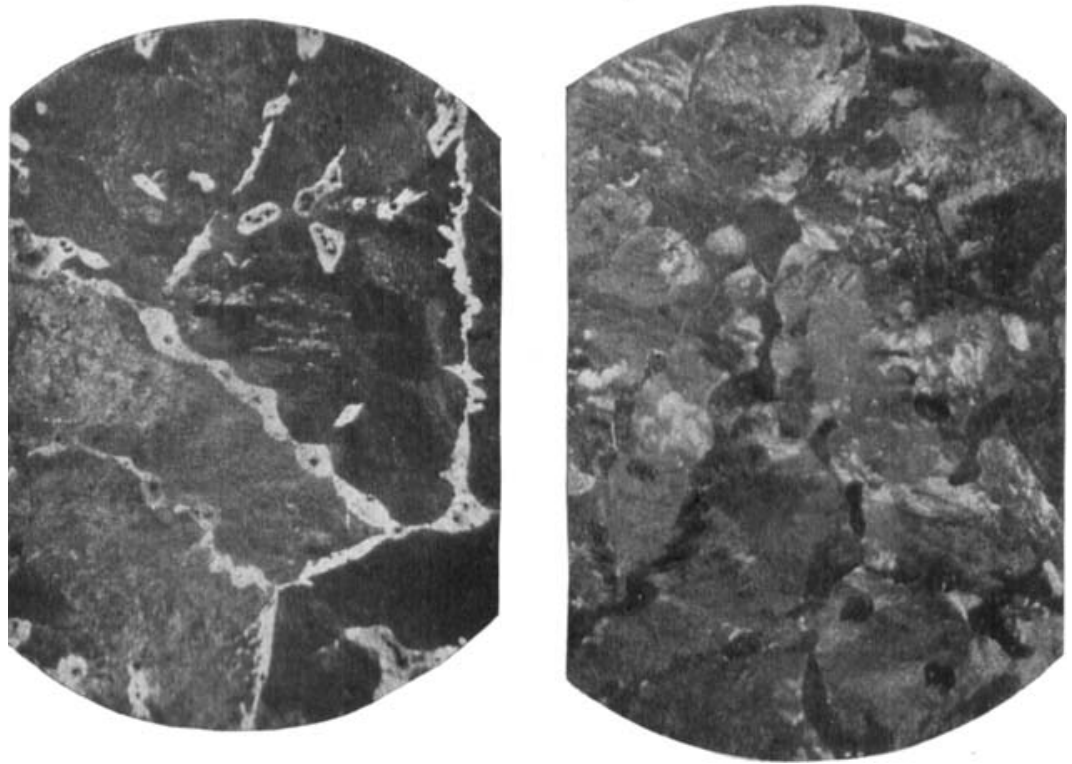

Fig. 11. Vertical Illumination. $\times 300$ diams. Fig. 12 .

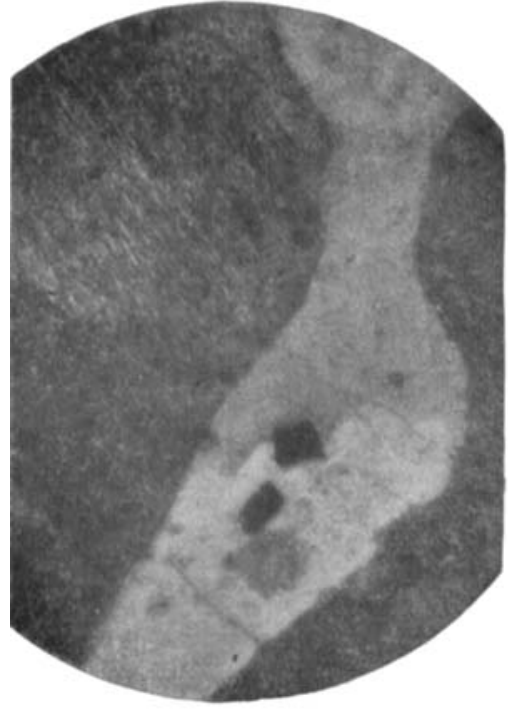

White $=$ Ferrite

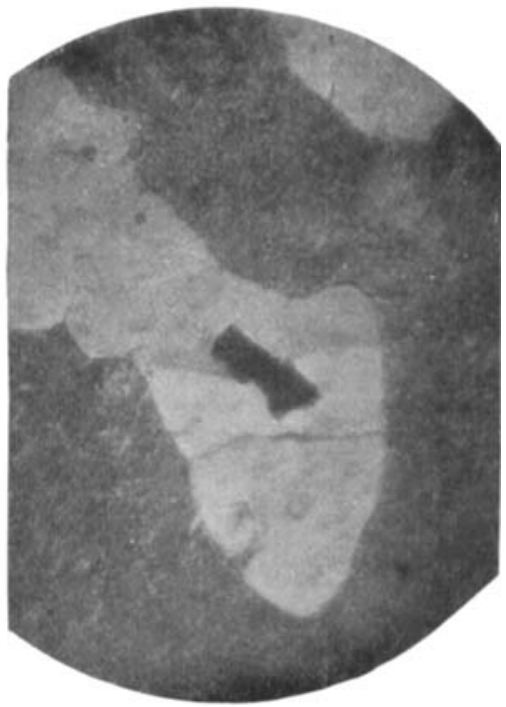

Dark $=$ Pearlile.

Downloaded from pme.sagepub. com at WEST VIRGINA UNIV on, June 5, 2016 Mechlinical Englneers 1904. 


\section{Mild Cast Steel (Pearlitic).}

Actual Line of Fracture under Shock. (All vertically illum.)

Specimens shown on this and following Plate were cut from a large casting

weighing about $\frac{1}{4}$ ton.

Fig. 13. Normal. $\times 75$ diams.



Fig. 14. Heat.Treated. $\times 75$ diams.

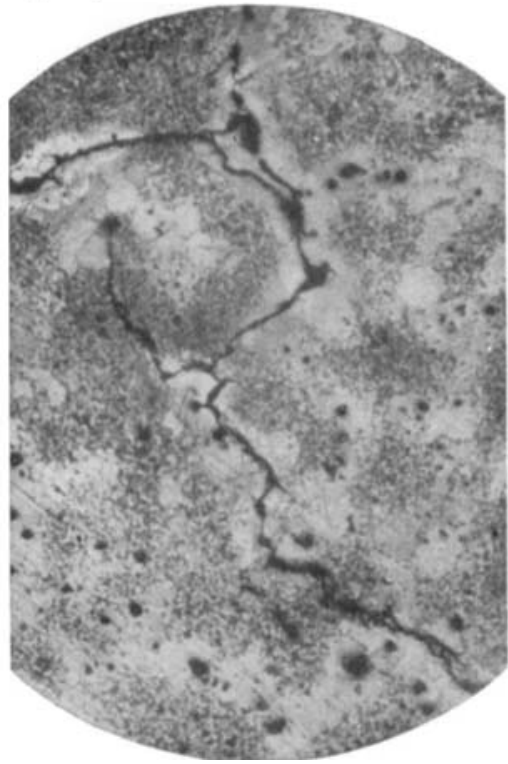

Fig. 15. Heat-Treated. $\times 300$ dians.
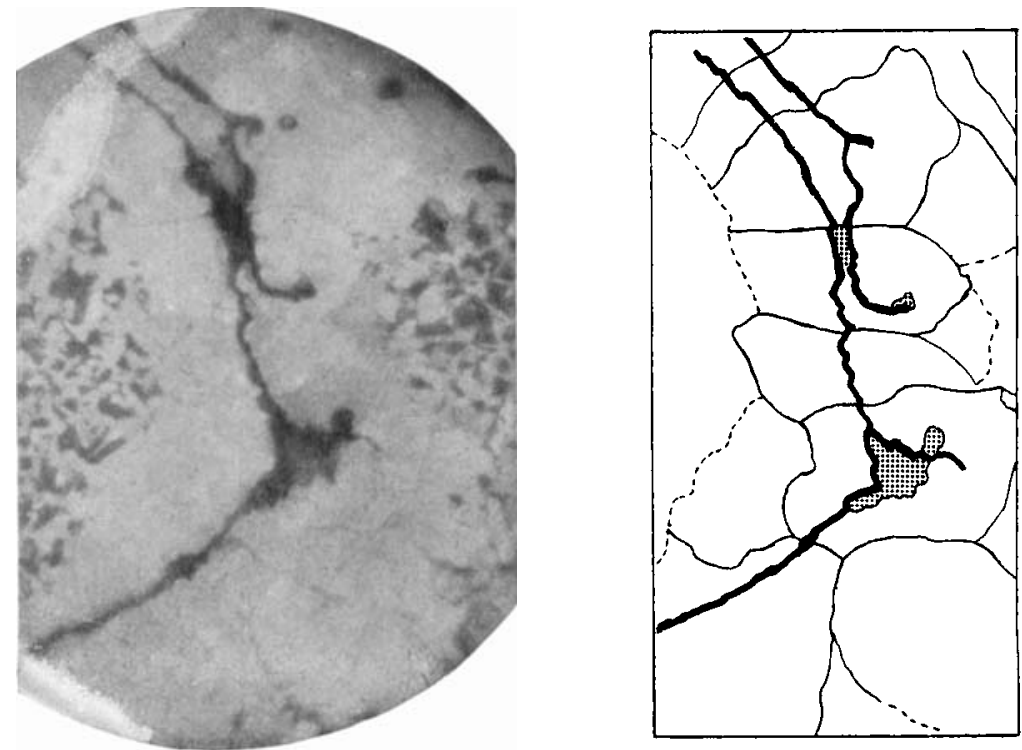

White $=$ Ierrite. Dark $=$ Pearlite

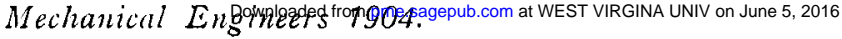


Mild Cast Steel (Pearlitic).

Actual Line of Fracture under Shock. (All vertically illum.)

Specimens shown on this and former Plate were cut from a large casting weighing about $\frac{1}{4}$ ton.

Fig. 16. Normal. $\times 300$ diams.
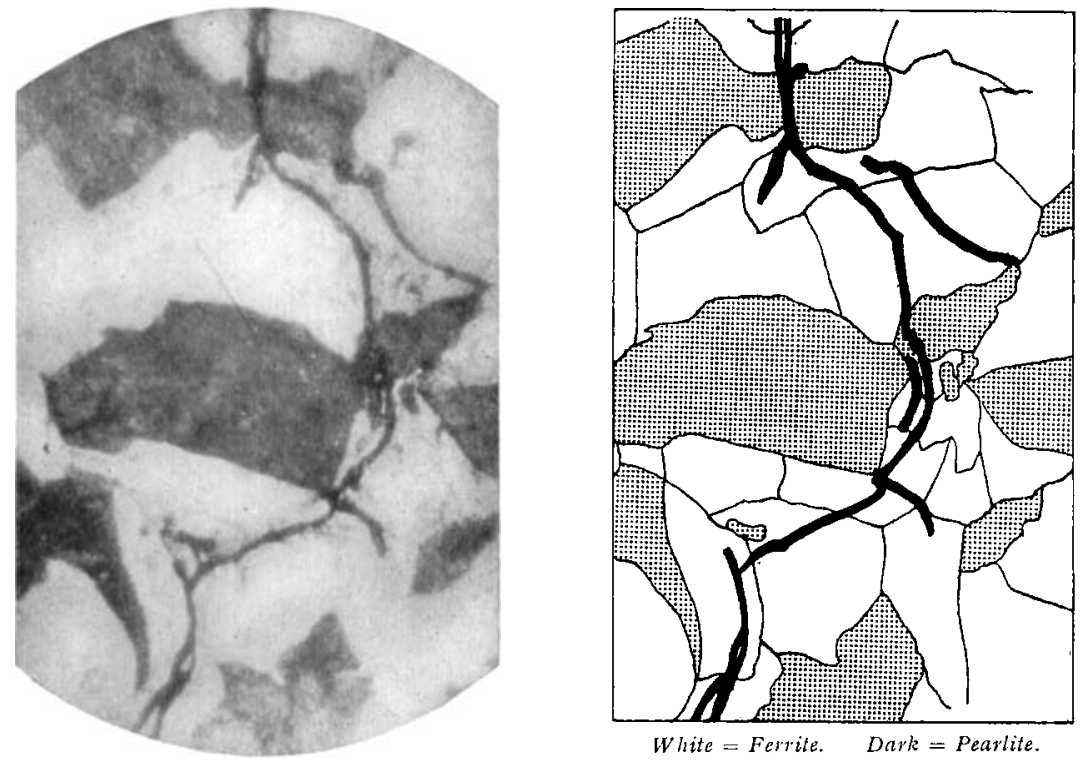

Fig. 17. Normal. $\times 300$ diams.
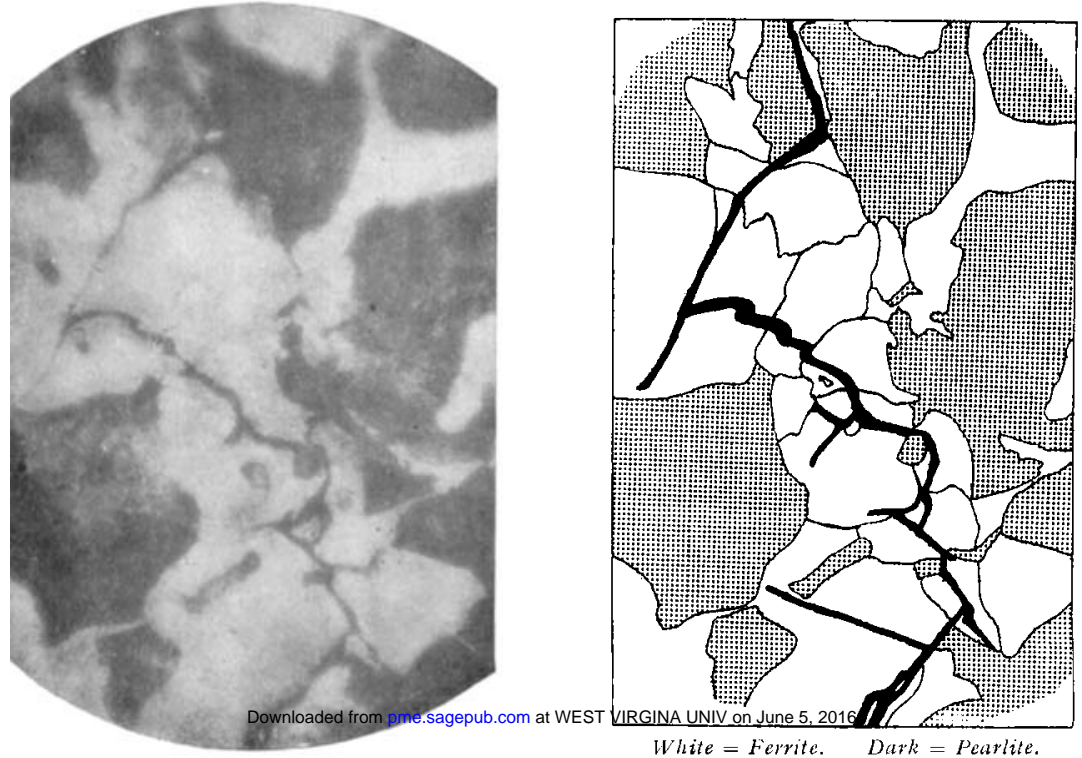
Forged Mild Steel (Pearlitic). Actual Line of Fracture under Shock. (All vertically illuminated.) Medium Carbon Steel ( $0.3 C$.). Highest Carbon Admiralty Mild Steel.

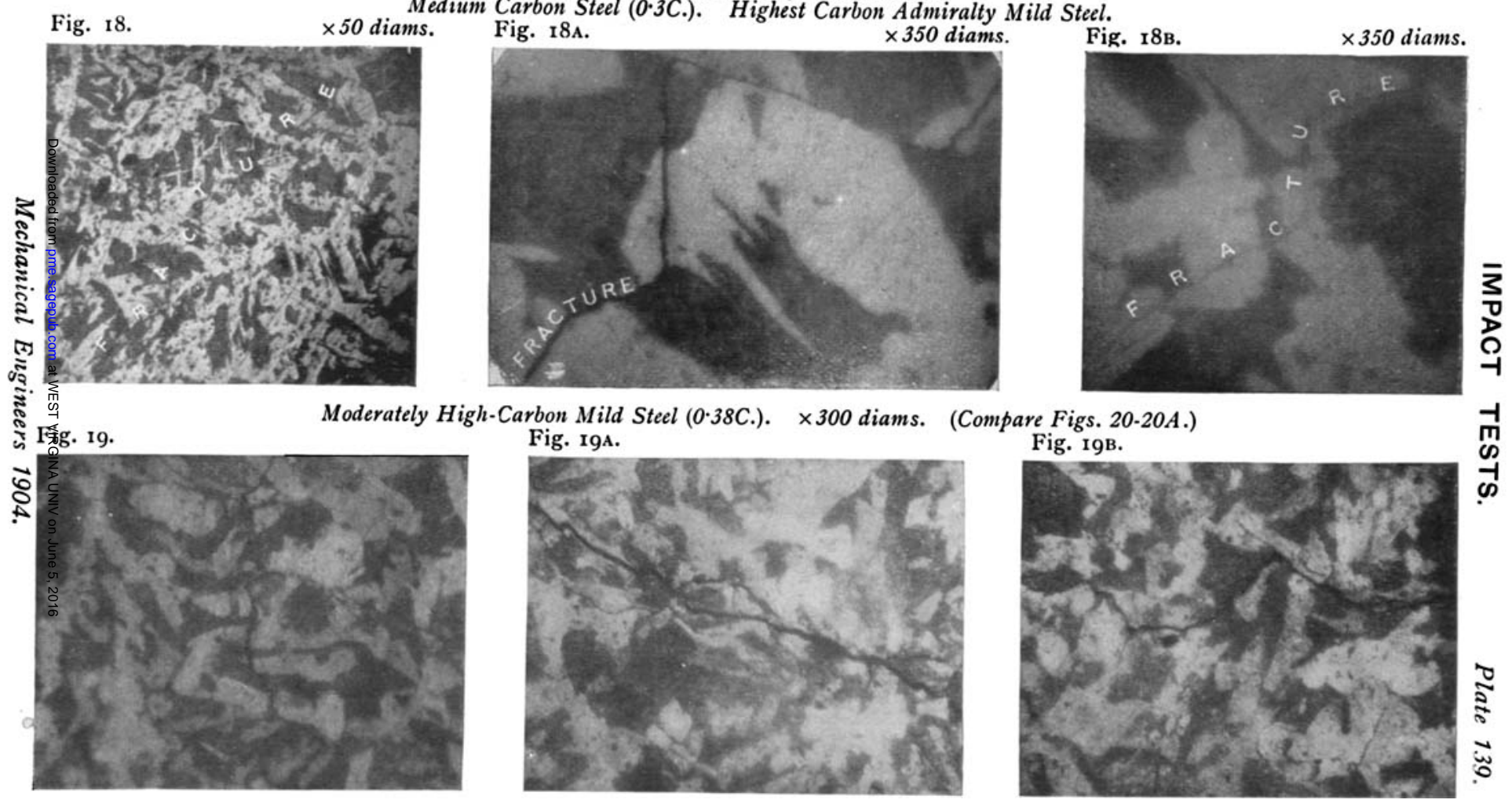




\section{Forged Mild Steel (Pearlitic).}

Actual Line of Fracture under Shock. (All vertically illum.)

Moderately Highl-Carbon Stecl $(0.38$ C. $) . \times 300$ diams.

Fig. 20. White $=$ Ferrite. $\quad$ Grey $=$ Pearlite. Fig. 20A.
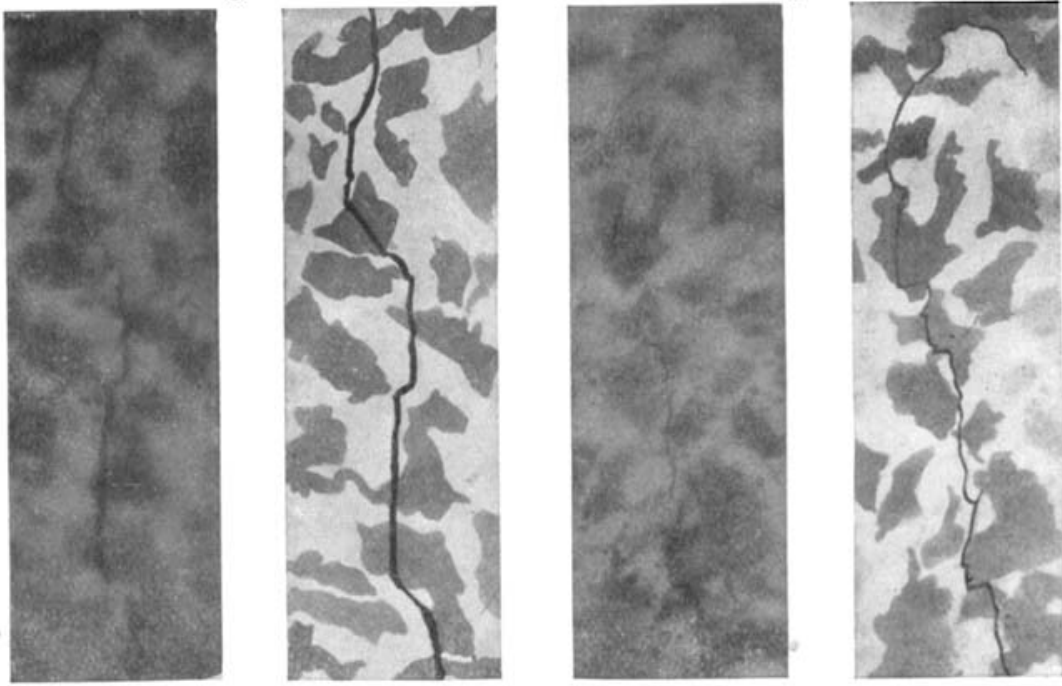

Fig. 21 .

Average Grade Admiralty Mild Steel $(0 \cdot 25 \mathrm{C}$.). $\times 350$ diams.

Fig. 21A.
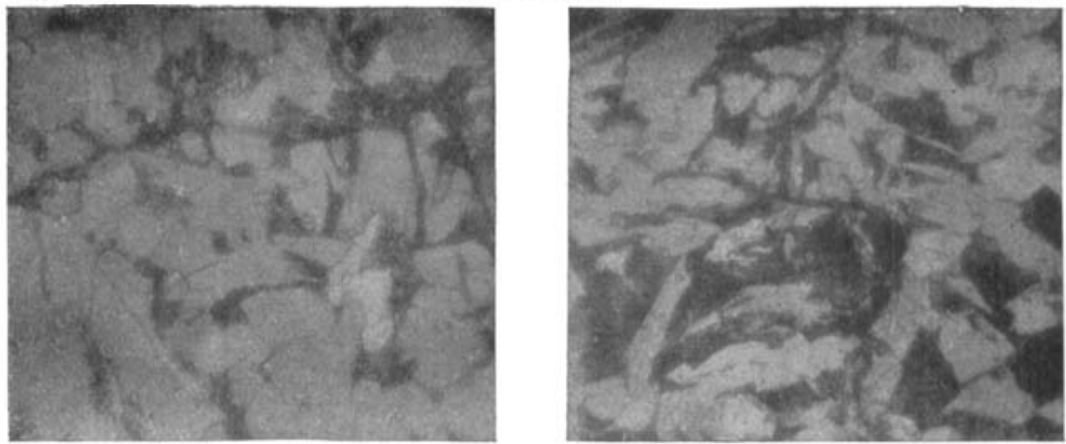

Fig. 22.

$\times 300$ diams.

Fig. 23 .

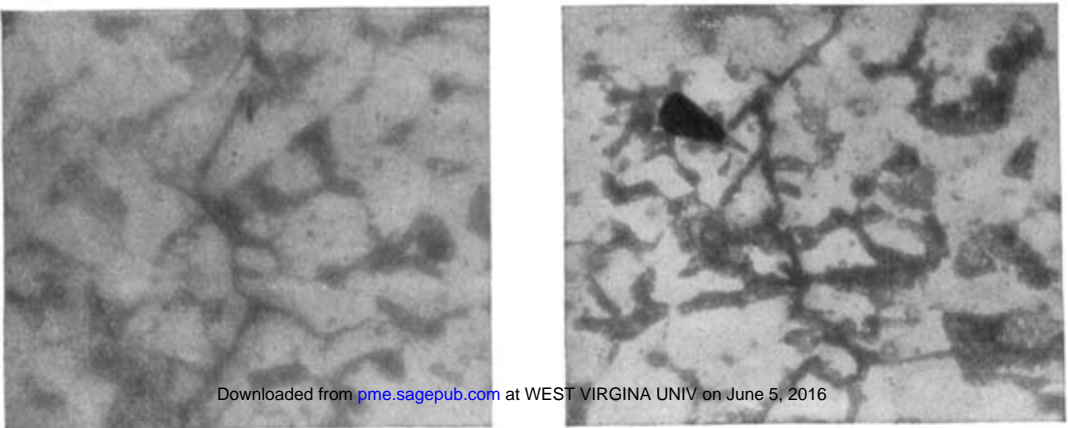


Forged Mild Steel (Pearlitic).

Actual Line of Fracture under Shock. (All vertically illum.)

Average Grade Admiralty Mild Stecl $(0.25 \mathrm{C}$.).

Fig. 24. $\times 250$ diams.

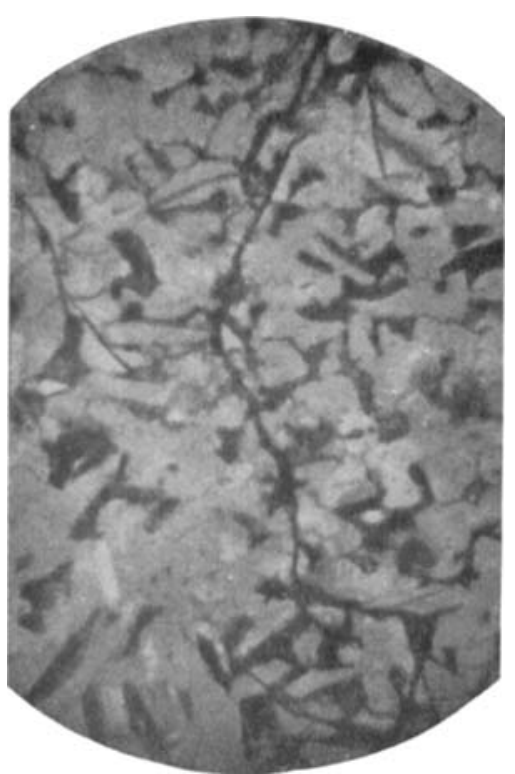

Fig. 25 .

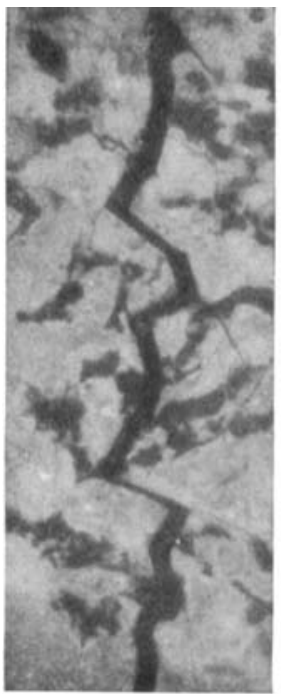

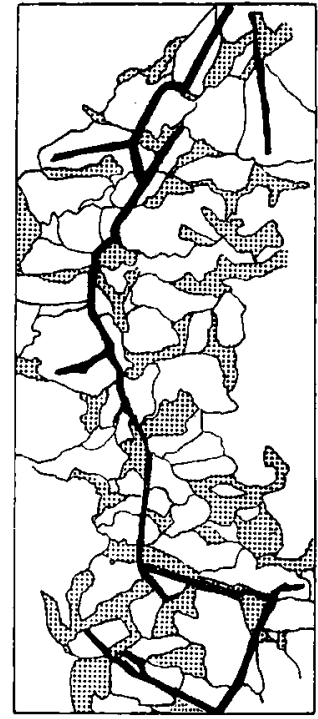

White $=$ Ferrite.$\quad$ Dark $=$ Pearlite.

Fig. $25 \AA$.

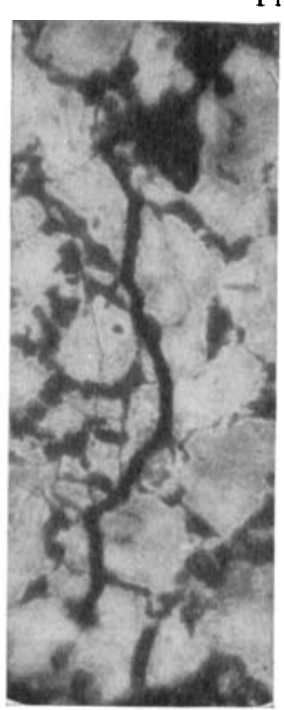

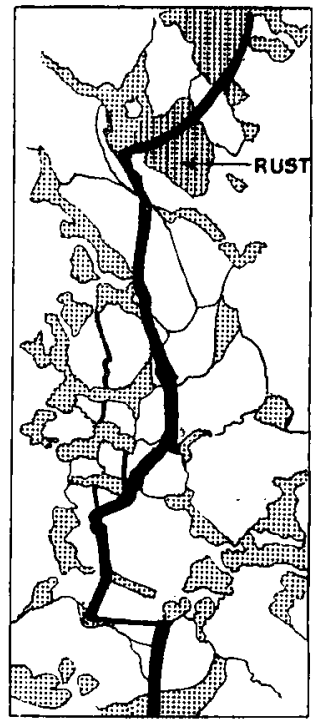

White $=$ Fertite.

Dark = Perurlite. 
Forged Mild Steel (Pearlitic).

Actual Line of Fracture under Shock. (All vertically illum.)

Low-Carbon Steel $(0 \cdot 15 \mathrm{C}$.).

Fig. $26 . \times 350$ dians.
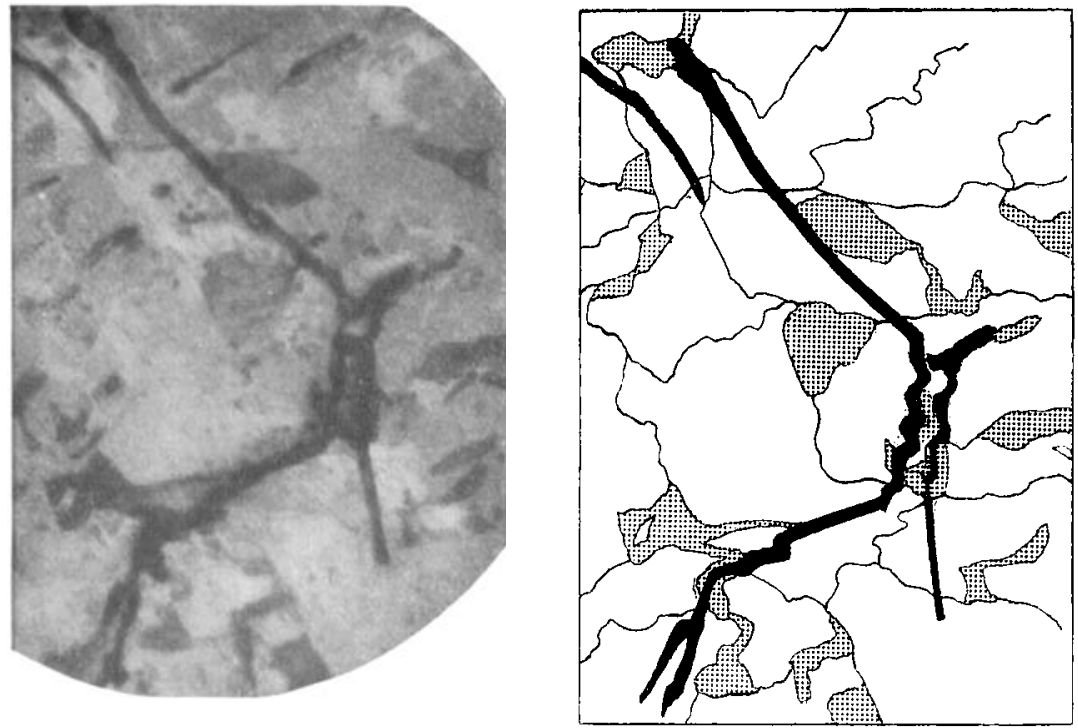

Fig. 27.

$\times 300$ diams.
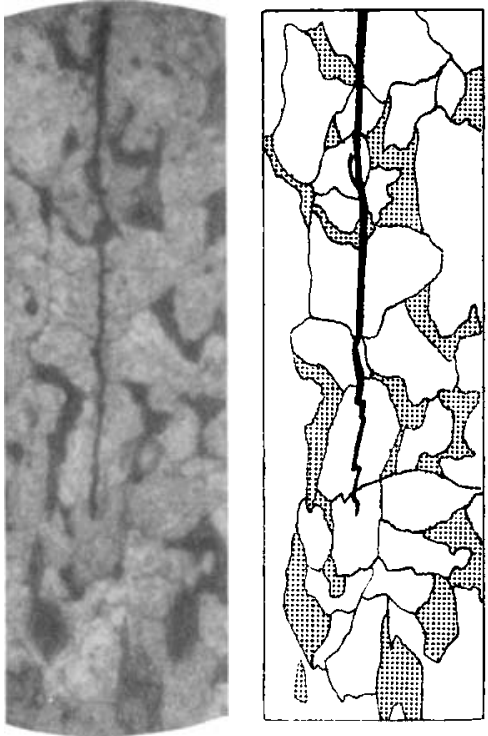

The motted appearance of $\mathrm{Fig} .27$ is the to a film of wax on the surface.

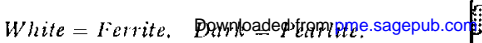
Mechanical Engineers 1904.

Fig. 28. $\times 300$ diams.
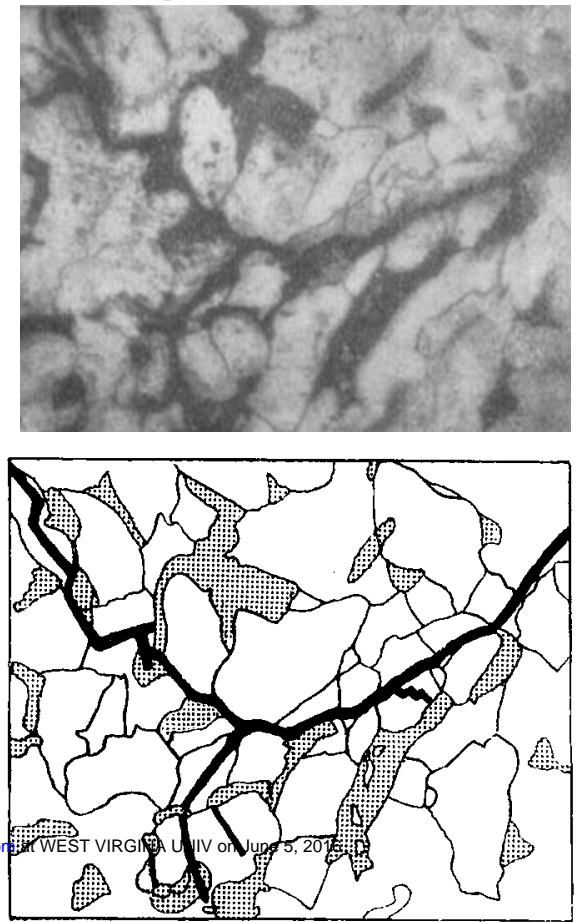
Mild Cast Steel (Pearlitic).

Vicinity of Fracture under Tension.

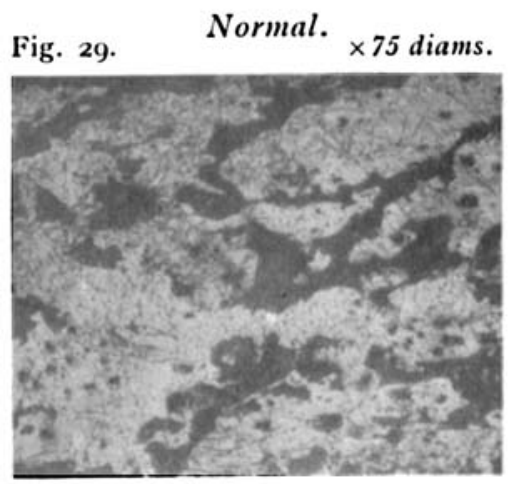

Fig. 30. $\times 300$ diams.

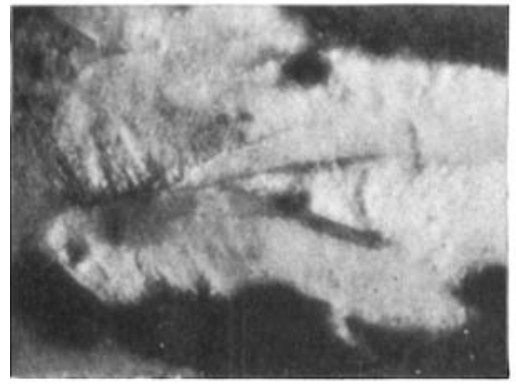

Fig. 3 I. $\times 350$ diams

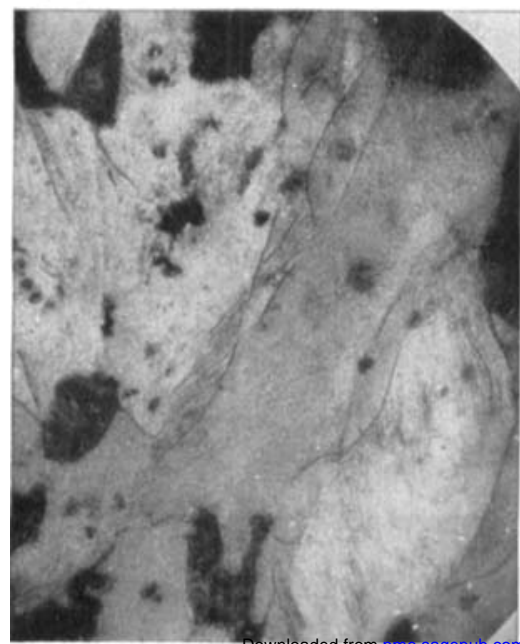

Forged Mild Steel (Pearlitic). Actual Line and Vicinity of Frachure under Tension.

Fig. 32.

$\times 75$ diams.

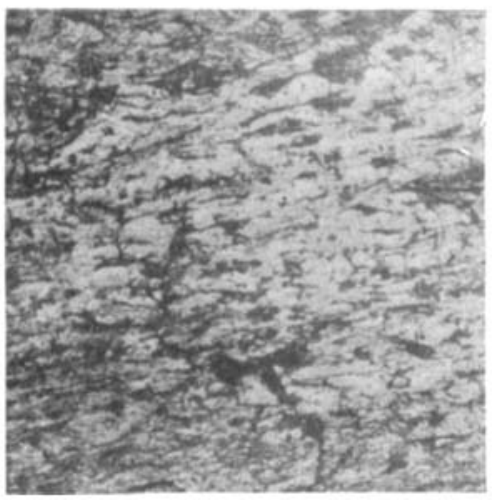

Fig. 33 .

$\times 350$ diams.

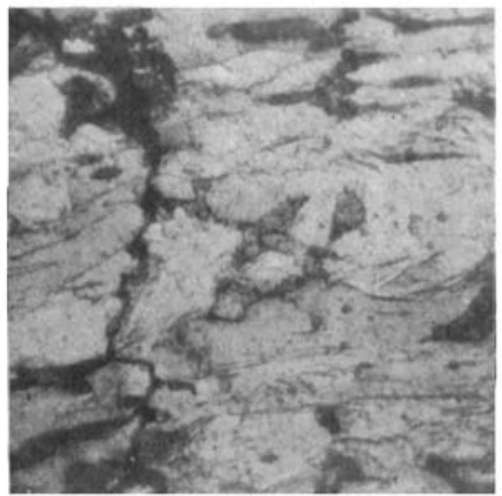

Fig. 34 . $\times 350$ diams.

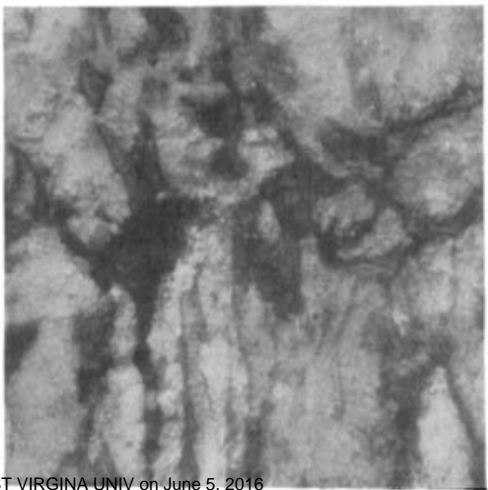


Fractures in Service (at right angles to surface). 2 "Stuls. "Admiralty" Forged Mild Steel, about 0.25 C. Considered to have been broken by Repeated Shock.

Through the Fractures, see Fig. 35 in text.

Fig. 36.

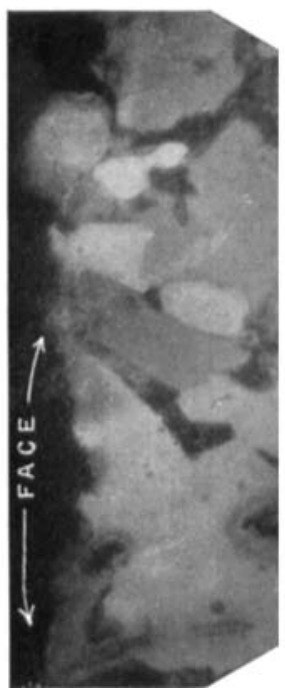

Fig. 36A.

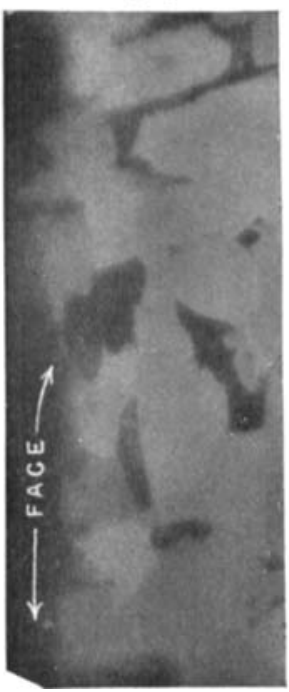

$\times 300$ diams.

Fig. 36B.

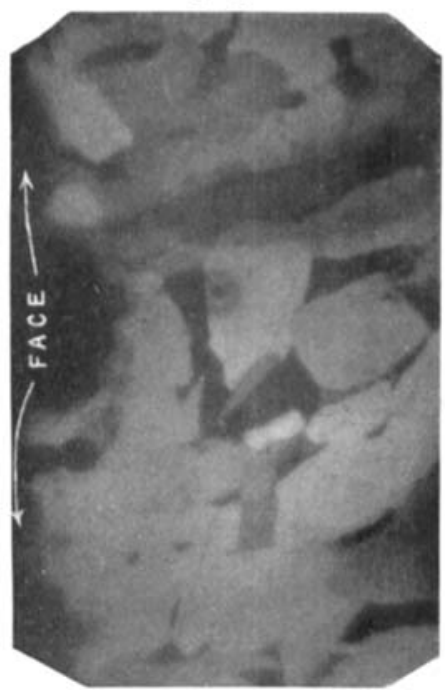

Crank-shaft. Mild Stecl, about $0 \cdot 3 \mathrm{C}$.

Considered to have been broken by Excessive Torsional Alternating Stress.

Fig. 37. $\times 250 d$. Through Fracture. Un-etched.

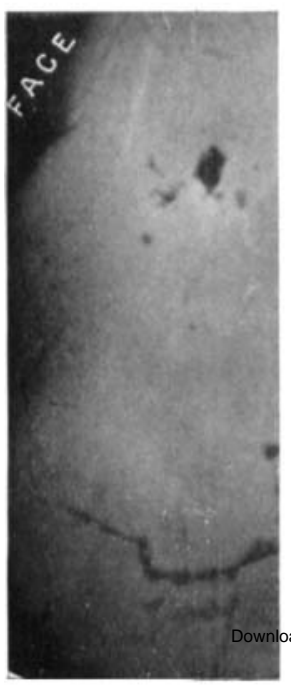

Fig. 37A. $\times 300 d$.

Through

Fracture.
Fig. 37в. $\quad \times 350 \mathrm{~d}$. Near Fracture.

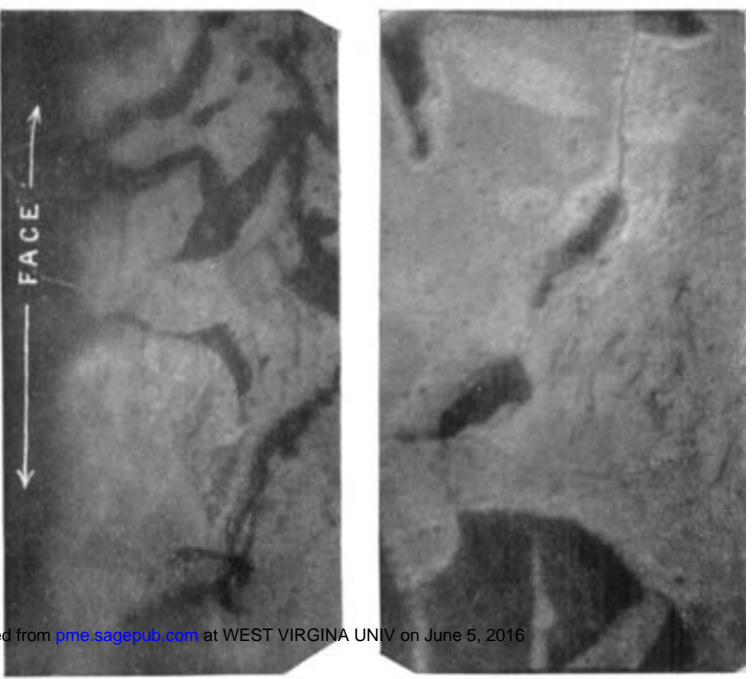

Mechanical Engineers 1904. 
Fractures (at right angles to surface) due to Alternating Stress.

Fig. 38. Cast Mild Steel Test-Liar. (The same as shown in Fig. 13, Plate 1.37; and Plate 138.)

Broken by Rotation Method, Exing's Standard.

Through Fracture. Un-etched, $\times 300$ diams.

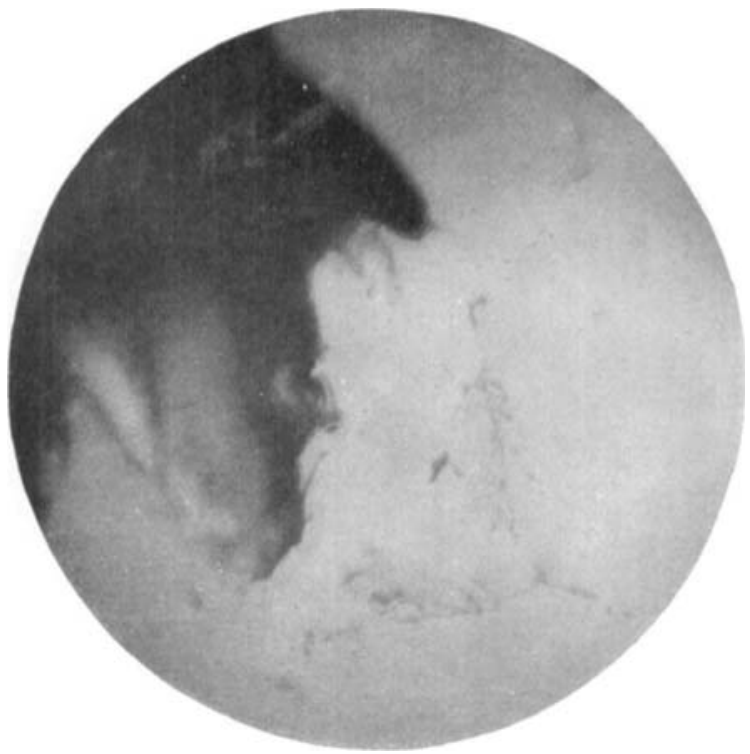

Fig. 39. Crank-shaft, section through Extensize Lissures. Probably broken by Excessive Bending Alternating Stress.

Near Fracture. $\times 260$ diams.

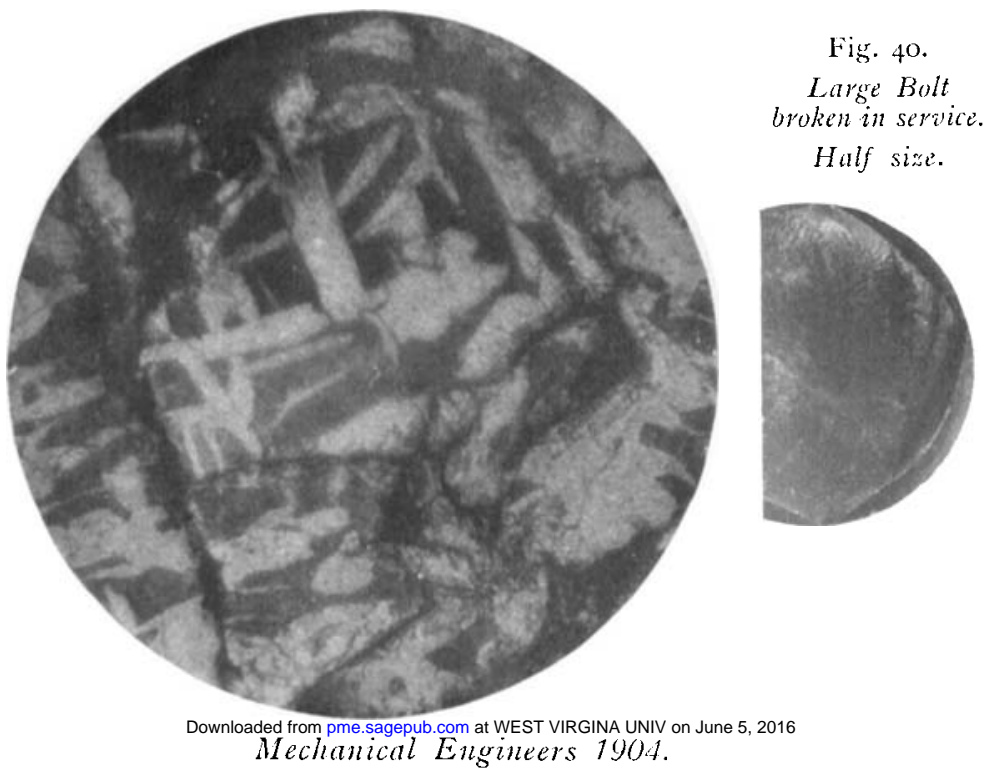


Tough Low.Carbon Basic Steel. Line 5. Table 1. Comparison of Fractures by One-blow Machine and Multiblon Machine.

Standard Tist-bar (Izod)

fractured in One-blon . Yathine.
Test-bar (Authors' Firo, 3. fractured by 293 bloz's in Machine, Fig. 1.

Fig. 51 .

$\times 20$ d. Fig. 51A.

$\times 20$ d. Fig. 5 I B. $\times 20 d$.

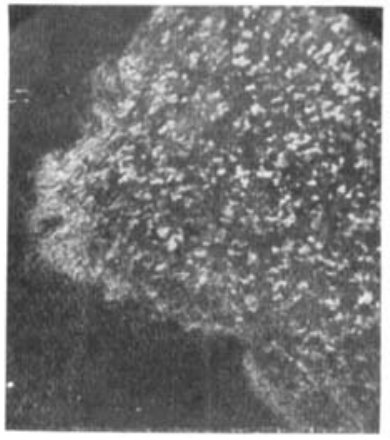

These tro sections are not quite on the sume

longitudinal plane.

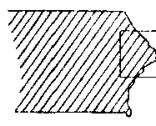

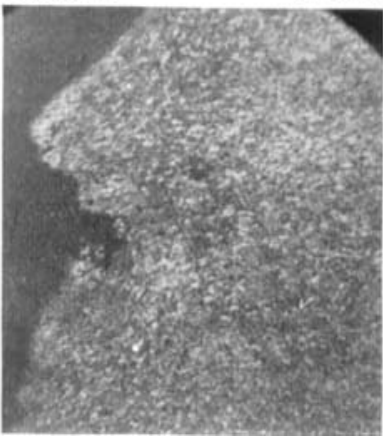



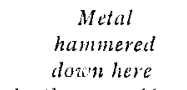
by the many blows.
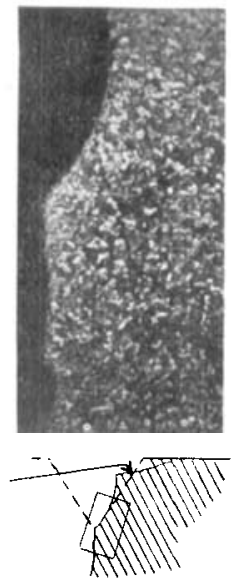

Standard Test-bar (Izod) held in vice \& fractured by 1 sharp blow reith hand hammer. Fig. 5 rc.

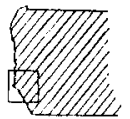

The Metal is mostly ferriteboth the black and the white grains. The iariation of dicusity is due to the yellow colouration from rather heavy etching.

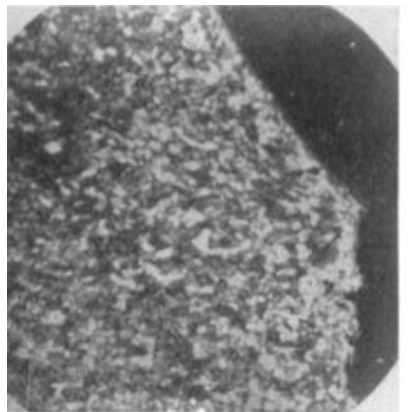
$\times 94 d$.

Fig. 52. Fractures of Impact Test-Bars (Figs. $2 \& 3$ ) in Machine, Fig. 1. Giving No. of Blore's to produce I'racture. Scale is full size.

Loa' Carbon. Medium Grade.

Mild Stecl $0.15 \mathrm{C} . \quad$ Mild Steel $0.23 \mathrm{C}$.

bal. Good. Fair. Oil Hart.

7

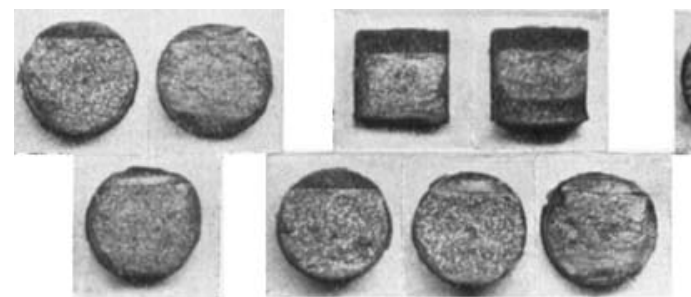

Oil Hard. 177

\begin{abstract}
Downloadøl
\end{abstract}
3

Michinicit

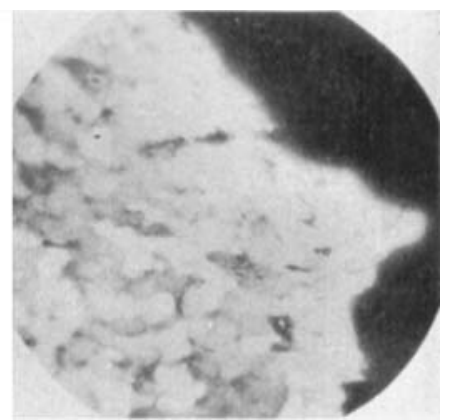

